\title{
GROUP COORDINATION DURING COLLECTIVE MOVEMENTS \\ IN GUINEA BABOONS (PAPIO PAPIO)
}

Dissertation for the award of the degree

"Doctor of Philosophy (Ph.D.)"

Division of Mathematics and Natural Sciences

at the Georg-August-Universität Göttingen

in the doctoral program Behavior and Cognition

at the Georg-August University School of Science (GAUSS)

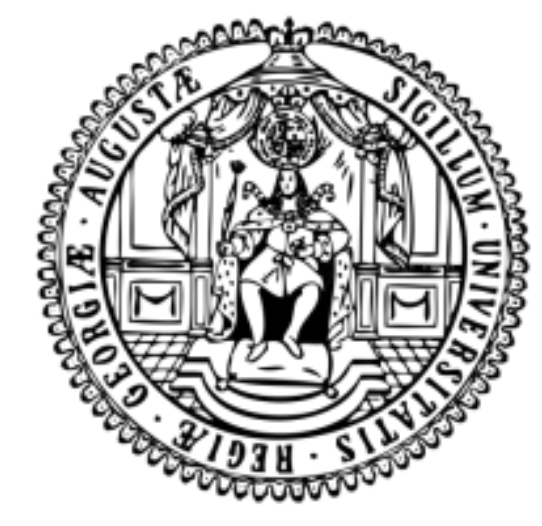

submitted by

Davide Montanari

from

Mantova, Italy

Göttingen, April 2019 



\section{Thesis Committee}

Dr. Dietmar Zinner

Cognitive Ethology Laboratory, German Primate Center, Kellnerweg 4, 37077 Göttingen

Prof. Dr. Julia Ostner

Department of Behavioral Ecology, Johann-Friedrich-Blumenbach Institute for Zoology and

Anthropology, Kellnerweg 6, 37077 Göttingen

Prof. Dr. Stefan Schulz-Hardt

Department of Economic and Social Psychology, Georg-Elias-Müller-Institute of Psychology,

Gosslerstraße 14, 37073 Göttingen

\section{Further members of the Examination Board}

Prof. Dr. Julia Fischer

Cognitive Ethology Laboratory, German Primate Center, Kellnerweg 4, 37077 Göttingen

Prof. Dr. Margarete Boos

Department of Social and Communication Psychology, Georg-Elias-Müller-Institute of

Psychology, Gosslerstraße 14, 37073 Göttingen

Prof. Dr. Eckhard Heymann

Behavioral Ecology \& Sociobiology Laboratory, German Primate Center, Kellnerweg 4, 37077

Göttingen

Referee: Dr. Dietmar Zinner

Cognitive Ethology Laboratory, German Primate Center, Kellnerweg 4, 37077 Göttingen

Co-referee: Prof. Dr. Julia Ostner

Department of Behavioral Ecology, Johann-Friedrich-Blumenbach Institute for Zoology and Anthropology, Kellnerweg 6, 37077 Göttingen

Date of the oral examination: 29.04.2019 
To my family 


\section{Contents}

Summary

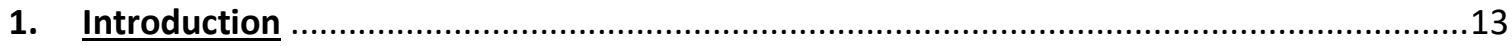

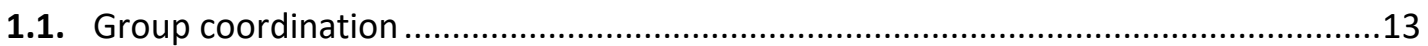

1.1.1. Collective movements to study group coordination .......................................14

1.2. Theoretical and empirical approaches to the study of group coordination .................15

1.3. Primate social groups as models to empirically study group coordination ...................18

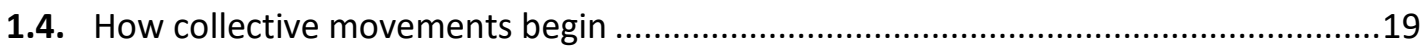

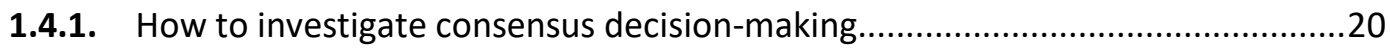

1.4.1.1. Unshared consensus decision-making to depart ...................................22

1.4.1.2. Shared consensus decision-making to depart........................................23

1.4.2. The social factors affecting group departures: the case of macaques ................25

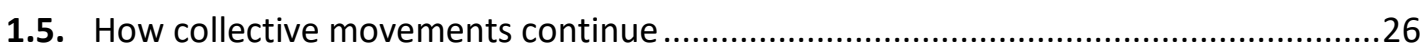

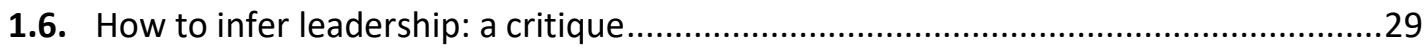

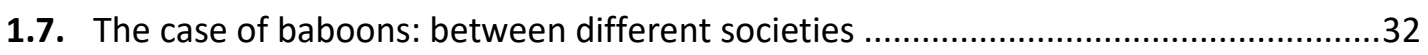

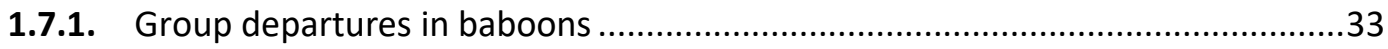

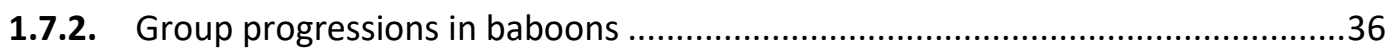

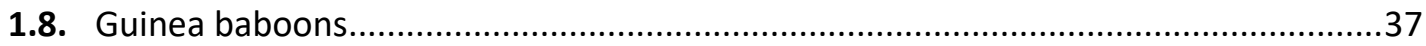

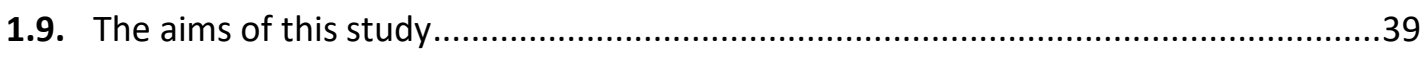

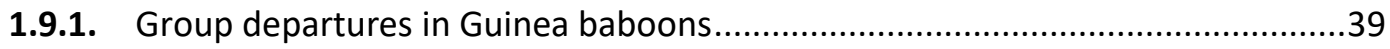

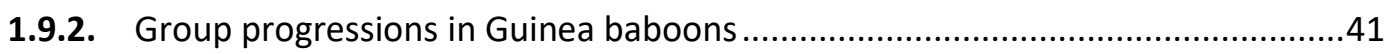

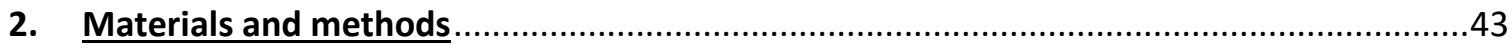

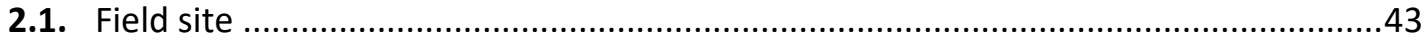

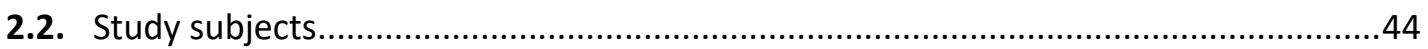

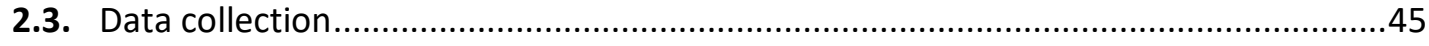

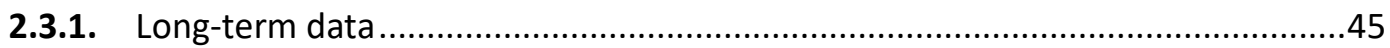

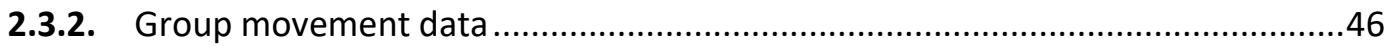

2.3.2.1. Operational definition of group departure ...........................................47

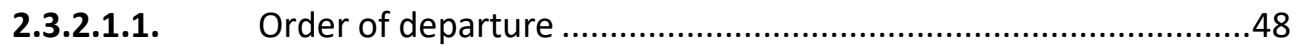

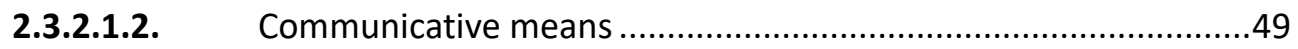

2.3.2.2. Operational definition of group progression .......................................49

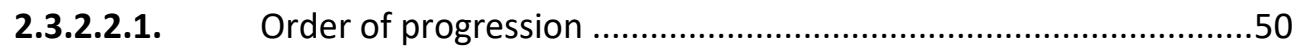

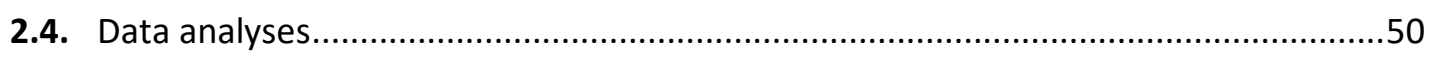

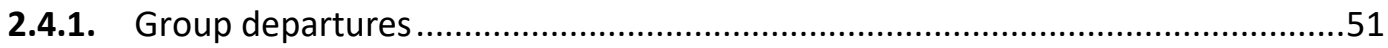

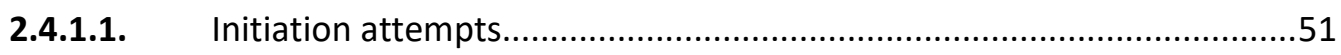

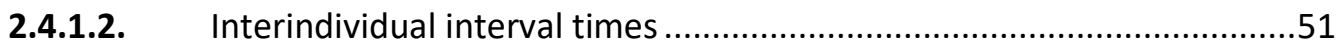

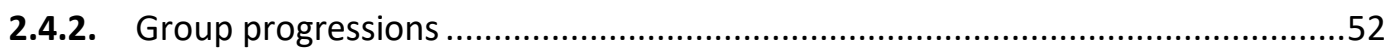

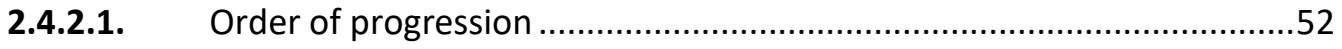

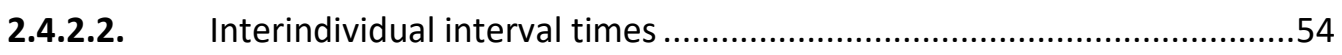

2.4.2.3. Primary and non-primary males at the edges......................................54 


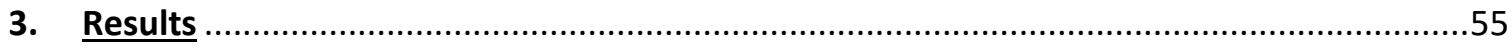

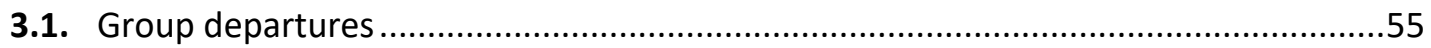

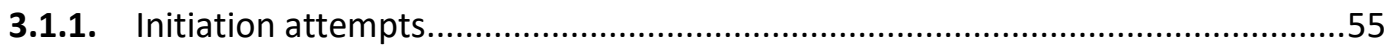

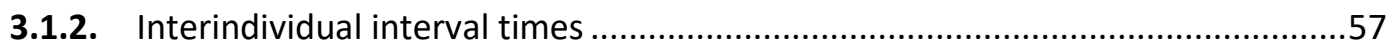

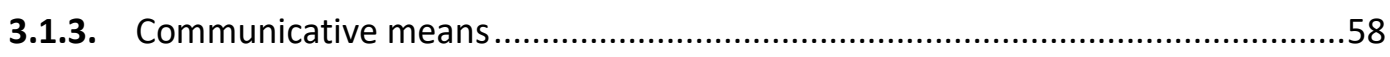

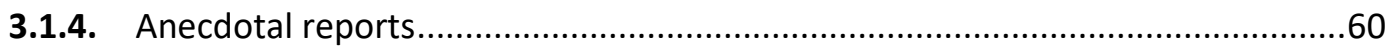

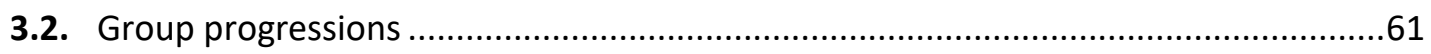

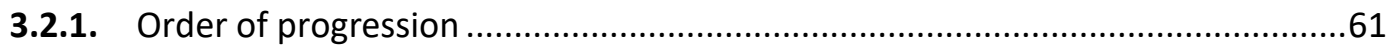

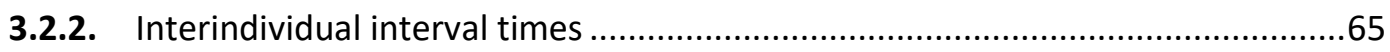

3.2.3. Primary and non-primary males at the edges..............................................66

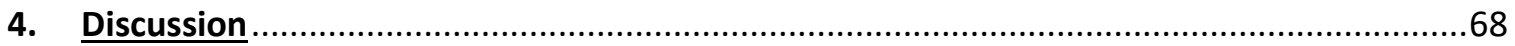

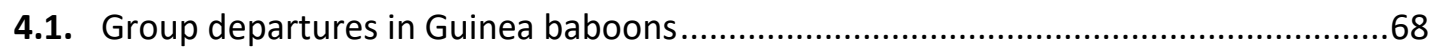

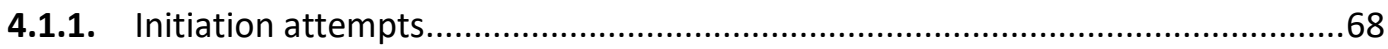

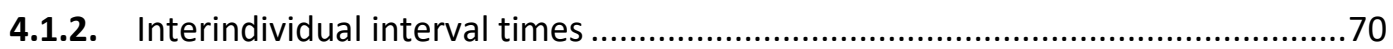

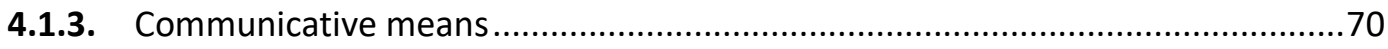

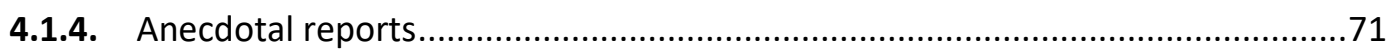

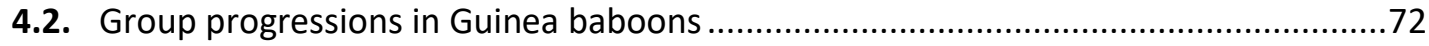

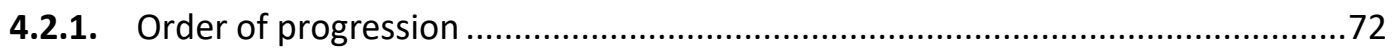

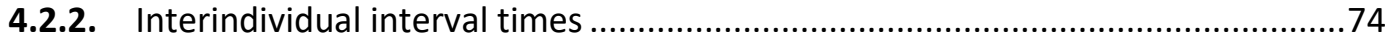

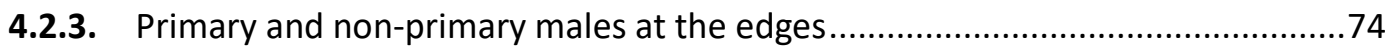

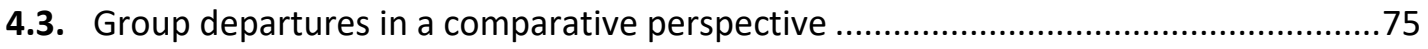

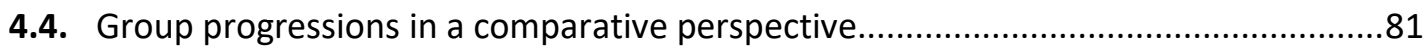

4.5. The social factors affecting group movements: the case of baboons...........................85

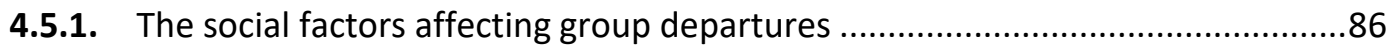

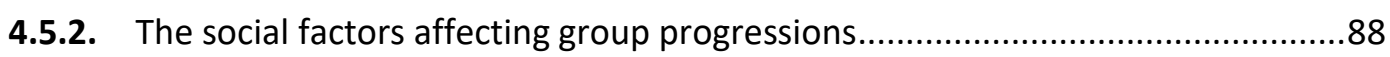

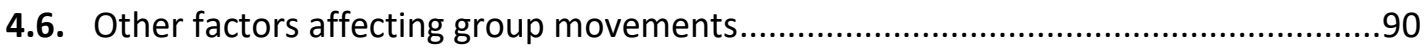

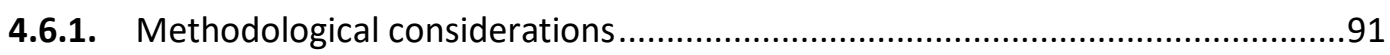

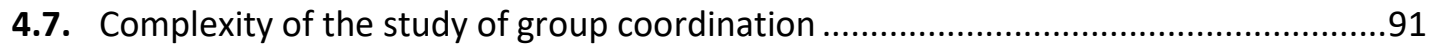

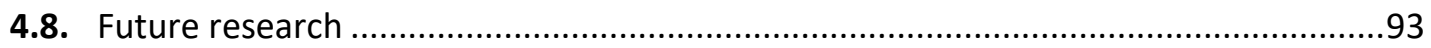

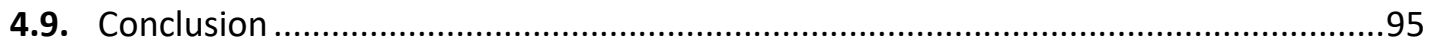

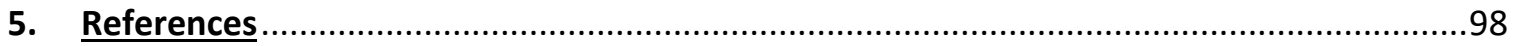

Acknowledgements

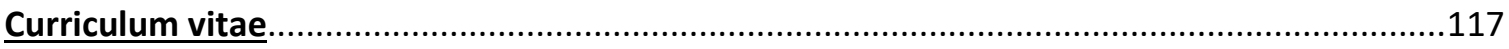




\section{List of figures}

Figure 2.1. a) The location of the field site CRP Simenti, marked as a star inside the Niokolo-Koba National Park, in Senegal. b) Home ranges of three study parties in 2013 (fixed 95\% and 50\% kernel density estimations, from Klapproth et al., in prep).

Figure 2.2. Example of a group departure. a) Baboons in a pre-departure area (photo by $\mathbf{M}$. Klapproth). b) Schematic depiction of a pre-departure area (diameter of the circle $\leq 20 \mathrm{~m}$ ). c) First attempt of initiation of group departure. One individual leaves the area. If no-one follows, the attempt is unsuccessful. d) Second attempt. One individual leaves the area. e) Other individuals follow the one that attempted. If all individuals follow, the attempt is successful.

Figure 2.3. Example of a group progression. One of the study parties is passing the check point in single-file.

Figure 3.1. Estimates of the predictors age and sex on the likelihood of attempting an initiation of group departure, from GLMM (reference category being "mature adult" and "female").

Figure 3.2. Interval times of dyads in events of group departure. Individuals not belonging to the same unit are compared to those belonging to the same unit.

Figure 3.3. Greeting captured during one of the two episodes reported. a) Both adult males are approaching each other. b) Male-male ritualized greeting interaction: mutual penis diddle. c) The male on the right turns $180^{\circ}$ and walks away followed by the male on the left.

Figure 3.4. Posterior probability distributions to progress in front, middle or rear positions according to age.

Figure 3.5. Posterior probability distributions to progress in front, middle or rear positions according to being a female, a primary male or a non-primary male.

Figure 3.6. Interval times of dyads in events of group progression. Individuals not belonging to the same unit are compared to those belonging to the same unit. 


\section{List of tables}

Table 2.1. Composition of study groups. Party sizes (i.e. total number of party members) varied due to births, deaths, disappearances, between-party transfers of individuals and difficulties in recognizing young weaned individuals.

Table 3.1. The number of initiation attempts according to the level of social organization taken as subject of data collection and the sex and the age of the individual attempting to initiate.

Table 3.2. Summary of model results. Estimated coefficients of the effect of the predictors on the likelihood of attempting an initiation of group departure, from GLMM.

Table 3.3. Summary of model results. Estimated coefficients of the effect of belonging to the same unit on the interval times between dyads of individuals within event of group departure, from LMM.

Table 3.4. The number of individuals performing the respective behaviours during group departure events.

Table 3.5. Summary of model results. The effect of age (adult; young) on the likelihood for an individual to take front, middle or rear positions during a group progression. Reference category front and adult.

Table 3.6. Estimated probabilities to progress in the front middle or rear positions of the file, according to age.

Table 3.7. Summary of model results. The effect of being a female, a primary male or a nonprimary male on the likelihood for an individual to take front, middle or rear positions during a group progression. Reference category front third and female.

Table 3.8. Estimated probabilities to progress in the front middle or rear positions of the file, according to being a female, a primary male or a non-primary male (calculated from the posterior mean values of the model).

Table 3.9. Summary of model results. Estimated coefficients of the effect of belonging to the same unit on the interval times between dyads of individuals within event of group progression, from LMM.

Table 3.10. Summary of model results. Estimated coefficients of the effect of being a female, a primary male or a non-primary male on the likelihood of progressing in the first half of the front third of a group progression, from GLMM.

Table 3.11. Summary of model results. Estimated coefficients of the effect of being a female, a primary male or a non-primary male on the likelihood of progressing in the first half of the rear third of a group progression, from GLMM.

Table 4.1. Comparative table of the findings about group departures in baboon species $(\widehat{\partial}=\mathrm{ad}$. male, $\hat{\sigma} \delta^{\hat{O}}=$ ad. males, $q=$ ad. female, $q q$ = ad. females $)$. 
Table 4.2. Comparative table of the findings about group progressions in baboon species $(\hat{\sigma}=$ ad. male, $\hat{\partial} \hat{O}=$ ad. males, $q=$ ad. female, $q Q+=$ ad. females) . 


\section{Summary}

Despite potentially diverging interests, members of social groups coordinate to maintain group cohesion. The mechanisms and processes of group coordination are modulated by species- and context-specific factors. The genus Papio (baboons) has been proven to be a good model for the investigations of group coordination processes. It comprises six closely related species, which live in different habitats and social systems. Since baboons are adapted to a largely terrestrial life and occur in habitats similar to those where our hominin ancestors evolved, group coordination processes in baboons might be also a model for group coordination in our ancestors, when language was not yet at hand. In particular the multilevel social organization of baboons potentially offers parallelisms with group coordination patterns in the multilevel human society.

My project aimed to cover the missing knowledge about the patterns of group coordination in wild Guinea baboons and discuss results in a comparative perspective. Guinea baboons live in a multilevel society, with high socio-spatial tolerance and no linear dominance hierarchy among males. The basal level of the society is the reproductive unit, which consists of one adult male ("primary male") with one or more affiliated adult females. Several units aggregate in a party, which includes also adult males without affiliated females ("non-primary male"). Two or three parties form a gang. I focused on the coordination process during group departures from a stationary state and while the group is "on the move", during group travel progressions. Specifically, the first goal was to explore who influences timing and direction of group departures. Research on other baboon species, living in various social systems, revealed a preeminent but not exclusive role of adult males during group departures, irrespective of the social system. Therefore, Guinea baboon adult males were expected initiating group departures and succeeding more than females as found in other baboon species. Alternatively, because of the relative tolerant nature of this species, both sexes might have a more equal influence on the coordination process compared to other baboon species. The second goal was to understand whether the presence of two levels of social organization in the group (unit and party) affects the coordination process in departures and progressions. In the multilevel system of Guinea baboons, individuals may need to balance the interest of maintaining spatial cohesion with members of their subgroup with overall group movement of larger social entities. Therefore, 
members of the same unit were expected to move cohesively within the party both during group departures and group progressions. The third goal was to describe the order of group members during travel progressions. Studies on group progressions of travelling baboons generally conveyed that adult males take position mainly at the front and, to a lesser extent, the rear of the travelling group, while females and juveniles occupy more often central positions. This order has been interpreted as an adaptation to predation risk, with the most risky positions at group edges. Given a similar predation pressure for Guinea baboons, they were expected to show a similar pattern of progression order as other baboon species.

Research results show that young baboons almost never attempted an initiation of group departure and adult males attempt initiations of group departures more often than adult females. This suggests that adult males have a higher influence on the decision outcome, but that adult females can still have an impact. Interval times of dyads of individuals belonging to the same unit were significantly shorter than the interval times between individuals not belonging to the same unit, both during group departures and group progressions. This means that individuals aim to keep proximity firstly with their unit members and secondly with the other party members. During group progressions, adult male Guinea baboons tend to travel occupying front positions, whereas middle positions are taken more often by adult females and young individuals. Positions at the rear of the group were equally taken by individuals of all age/sex classes. Primary males, in contrast to non-primary males, tended to keep position closer to the centre where their females and offspring were. Non-primary males travelled more frequently at the edges of travelling groups.

Taken together, these findings conform to a general consistency across baboon species in the group coordination processes, despite different social and ecological contexts. As a result, the basic mechanisms underlying coordination processes emerged already in the baboon common ancestor, or even earlier in primate history. Major determinants of the processes of group coordination appear to be social dominance, feeding opportunities, predation pressure and body features (e.g., body dimension and weight, canines).

My study, as others, revealed several theoretical and empirical issues when analysing group coordination in wild animals. One problem concerns the complexities of potentially influencing factors on group coordination during collective movements. To resolve this problem, I suggest to (i) conduct comparable studies on related species to better point out the effect of few potentially influencing factors; (ii) conduct experiments to control the effect of potential 
influencing factors on the coordination process (e.g., modifying food access); (iii) strengthen automated data collections of small scale movements (e.g., remote sensing, GPS); (iv) simulate group coordination during collective movement (e.g., agent-based modelling); (v) include anecdotal observations. Another problem regards some assumptions at the basis of most hypotheses and discussions about group coordination during collective movements in primates. Precisely, group movements are assumed to involve firm individual interests across events. These individual interests are driven by the individual fitness and set selection pressure on the system. However, this assumption of firm individual interests may not be always justifiable. In many situations different forms of group coordination could lead to the same impact on individual fitness, i.e. the basic requirements of group members will be satisfied, irrespective of the processes of group coordination. Ideally, it is required a distinction between group coordination processes under conditions of markedly divergent individual interests to those not under such conditions. I suggest a distinction between group departures from the sleeping site and other group departures during the whole day as a first step toward this purpose. 


\section{Introduction}

\subsection{Group Coordination}

Living in groups is widespread among animal species. In other words, animals of several species seek for proximity in space and time with con- or heterospecifics at least at certain times of their life (Krause and Ruxton, 2002). Many different types of grouping patterns have evolved. The theoretical categorization of these grouping patterns derives from the kind of interaction between group members (de Waal and Tyack, 2003). In some species, conspecific individuals form anonymous groups, in which the members do not necessarily individually recognize each other. Hence, unknown conspecific individuals can join and leave the group. This shift of members can encompass hundreds or even thousands of individuals (e.g., migratory bands of desert locusts, Schistocerca gregaria, Bazazi et al., 2008; flocks of European starlings, Sturnus vulgaris, Ballerini et al., 2008; or white storks, Ciconia ciconia, Nagy et al., 2018; or shoals of Atlantic herrings, Clupea harengus, Pitcher et al., 1985; or three-spined sticklebacks, Gasterosteus aculeatus, Jolles et al., 2017; Tinbergen, 1953). In other species, animals live in groups in which they individually recognize each other. Keeping track of the identity of the other group members translates into structuring social systems or societies. Here, group members interact regularly and more so with one another than with other conspecifics (e.g., majority of

primate species, Kappeler and van Schaik, 2002, Kappeler, 2019). In contrast to anonymous groups, these groups are also addressed as individualised. This dichotomy between anonymous and individualised groups is complicated by other types of group living. For example, some social species form very large colonies of close kin group members which do not appear to individually recognize each other. However, they chemically distinguish between their group members and other conspecifics (e.g., social hymenoptera, Tofts and Franks, 1992). A further group category is heterospecific groups. Members of these, often temporary, groups belong to different species (e.g., fish, birds, ungulates, primates, cetaceans, Stensland et al., 2003; Heymann, 2011).

Despite this diversity of grouping patterns and processes, the essential prerequisite for grouping is a certain degree of proximity, or cohesion, in space and time among the individuals that form the group (Krause and Ruxton, 2002). This cohesion involves a balance of benefits and costs for the individual fitness of group members. This balance of benefits and costs varies across species and shapes the grouping pattern that the species follows. On one side, group- 
living can potentially increase opportunities for mating, foraging from food resources found by others, saving energy during travel (e.g., positive hydro- or aerodynamic interactions), detecting or fighting predators more efficiently, cooperating for a broader spectrum of resources or promoting cultural transmission (Krause and Ruxton, 2002; Boos et al., 2011). On the other side, spatio-temporal cohesion between individuals means easier transmission of pathogens and higher competition for food resources or mating partners (Krause and Ruxton, 2002; Boos et al., 2011). Group coordination, i.e. the coordination among individuals in activities and travel directions, is the means to preserving cohesion within a mobile group of animals. An efficient group coordination, that is to say accurate and fast, is a key factor to maximize the advantages and minimize the costs of group-living, with a consequent impact on the adaptive power of group-living (King and Cowlishaw, 2009a; Herbert-Read, 2016).

\subsubsection{Collective movements to study group coordination}

How group members coordinate has always been an interesting aspect of animal behaviour. Already the founding fathers of ethology took interest in group coordination. As far back as in 1931, Konrad Lorenz described the attempt of a western jackdaw (Corvus monedula) to coordinate with its group members to change location. The strategy of the jackdaw was to monitor whether the other group members were following while it was taking off. If the others do not follow, the flying individual either comes back to them and stays or it tries to elicit their departure by returning and gliding low over them while quickly shaking its tail (Lorenz, 1931). Just like jackdaws, most group-living species have to move to reach resting and feeding sites, avoid predators or defend territories on a daily basis. Due to their everyday occurrence in a wide range of animal species, collective movements have been the most common model of collective actions to investigate group coordination in animal groups (Petit and Bon 2010; Fichtel et al., 2011). A definition of collective movement (or group movement) is "the outcome of a group of animals that depart and move nearly simultaneously in the same direction, preserving group cohesion until all individuals stop moving or start a different activity" (Petit and Bon, 2010). During the movement, in order to maintain group cohesion, each group member has to shape its decisions according to the behaviours of and interactions with the other group members, either directly (e.g., via visual cues) or indirectly (e.g., via trail formation) (Westley et al., 2018).

Various ecological (e.g., predator presence, resource distribution), physiological (e.g., nutritional or homeostatic needs) and social factors (e.g., dominance rank, affiliative and kin 
relationships) may influence the coordination process (see content 1.2., 1.4.2.). Additionally, the process may involve complex mechanisms, such as information exchange and negotiation (see content 1.4.1.). Since these factors and mechanisms may be subtle, a human observer can face methodological problems to detect and interpret them. Moreover, there may be theoretical problems in outlining such a complex process as animal group coordination (Conradt and Roper, 2005; King and Cowlishaw, in 2009a; King et al, 2009; Bourjade and Sueur, 2010; Petit and Bon, 2010; Pyritz et al, 2011; Smith et al., 2016; Garland et al, 2018). Examples of these problems are the investigation of consensus decision-making (see content 1.4.1., 1.4.1.1., 1.4.1.2.) or the definition of leadership (see content 1.6.). These complexities have been addressed by many studies regarding the emergence of collective movements from individual movements, in a large number of species, both in the wild and in captivity, inspiring also theoretical models (King et al., 2018).

\subsection{Theoretical and empirical approaches to the study of group coordination}

Theoretical models simulating collective behaviours have demonstrated that many of the patterns seen in nature can be qualitatively replicated involving only simple rules of thumb, such as attraction, alignment and repulsion between neighbouring individuals (Czirok et al., 1997; Couzin et al., 2002; Giardina, 2008; Czaczkes et al., 2015). These collective behaviours arise through self-organization, since the emergent global order, which is the coordination between group members, occurs spontaneously as a sum of local interactions (Couzin and Krause, 2003). A self-organized collective behaviour theoretically requires only limited cognitive ability and local knowledge of the environment and this minimum complexity at the individual level generates major complexity (King et al., 2018). Self-organization appears as a parsimonious way to explain coordinated movements in many species, especially those that form aggregations of hundreds or thousands of animals whose individual recognition is usually not evident. Several empirical studies reported that self-organization emerged as major path to group level patterns in several species groups, including: gregarious insects (e.g., German cockroaches, Blatella germanica, Deneubourg et al., 2002; desert locusts, Bazazi et al., 2008), schooling fish (e.g., three-spined sticklebacks, Jolles et al., 2017), flocking birds (e.g., European starlings, Ballerini et al., 2008), and also some mammals, whose groups are usually smaller and where individual recognition is evident (e.g., herds of domestic sheep, Ovis aries, Toulet et al., 2015; or troops of chacma baboons, Papio ursinus, King et al., 2011). Therefore, these theoretical models have 
remarkably contributed to the comprehension of the general patterns of group movements and the origins of such patterns. However, their simplicity calls into question the universality and the extent of the applicability of self-organization to natural systems (Ballerini et al., 2008; Pyritz et al., 2010). Most theoretical models to simulate collective behaviour hinge on simple assumptions that often differ significantly from the characteristics of moving animal groups (King et al., 2018).

First, these models usually assume that individuals directly react to the relative locations of other group members, whereas the information perceived by the individual and used to make decision is constrained by its sensory capabilities. Species-specific sensory capabilities potentially result in differences between species in the rules involved to make decisions at the individual level and in the transmission of information through the group (Strandburg-Peshkin et al., 2015b; Strandburg-Peshkin, 2016).

Second, the coordination during group movements often takes place within a social system. Living in a stable social system likely leads to heterogeneous social relationships and to differentiated responses between group members. Especially in cases of species with higher cognitive abilities, group members may develop highly distinct individual interests contingent with the individual's own characteristics, such as age, sex, social rank, personality traits and/or internal state (Lukas and Clutton-Brock, 2018; Fichtel et al., 2011). In this context, the characteristics of the individuals and the social system can drive to more complex patterns of coordination during group movement. Individual movement rules may depend on the individual interests and characteristics. For example, lactating plain zebra females (Equus burchellii) are more likely to initiate collective movements than non-lactating females (Fischhoff et al., 2007), less social and faster three-spined sticklebacks are more influential on group movement (Jolles et al., 2017) and a group movement of shy American cockroaches (Periplaneta americana) to a shelter is faster than a group movement of bolder individuals (Planas-Sitjà et al., 2018). In addition, the kind of relationship between the group members may shape the individual's movements (e.g., one individual may decide to follow or not the movement of a group member depending on whether it is dominant or subordinate). In one study on black-and-white ruffed lemurs (Varecia variegata), group stability seems to determine whether certain individuals are consistently initiating group movement. A dominant female of a stable group initiated collective movements more often, but no individual consistently did so in an unstable group (Overdorff et al., 2005). 
Third, group movements take place in different ecological contexts and heterogeneous habitats, which may affect individual movements and the emerging group pattern (Bonnell et al., 2019). The characteristics of a group movement can differ depending, for example, on the cause, i.e. whether the behaviour is a response to a predator attack or a physiological need (feeding, resting, etc.). They can vary in the view of the number of available sites to address a need. Also, they can change conditionally to the environmental barriers that might hinder the movement, the visual contact or the communication of group members (Bourjade et al., 2009; King and Cowlishaw, 2009b; Dostie et al., 2016; Strandburg-Peshkin et al., 2017). These aspects can set a crucial distinction between studies on captive and wild groups. Moving in small areas as compared to natural home ranges, the absence of predators and ad libitum food may contribute to a lack of ecological relevance and external validity for studies of group coordination on captive animals (Pyritz et al., 2010).

Fourth, the behavioural patterns involved for achieving or maintaining the coordination during group movements may differ according to the coordination context considered (King and Sueur, 2011). Many studies focus on the collective transitional phase between a stationary condition and a moving condition: the group "making the move" or the group departure. In these studies, data collection focuses on the order of group members departing (e.g., Sueur et al., 2017; Ramos et al., 2018), stressing the individual which moves off first, shaping what, by definition, can be regarded as an initiation of group movement. Often this research includes data on the behaviours occurring during and some minutes prior to departure, during a period known as "pre-departure" period (e.g., Bourjade et al., 2009; Bousquet et al., 2011; Walker et al., 2017). The behaviours shown during pre-departure, the number of individuals involved as well as the duration of the period may influence the group departure (Bourjade and Sueur, 2010). Some studies focus on the consequent phase, the group already "on the move" or the group progression, investigating which individuals establish where to go while progressing, and/or which position group members take within the moving group. The investigation usually concerns an analysis of the individuals ahead of the group across events, assuming that they are driving the other group members to a destination (e.g., Thornicroft's giraffes, Giraffa camelopardalis thornicrofti, Berry and Bercovitch, 2014; killer whales, Orca orcinus, Brent et al., 2015), or an analysis of the whole order of progression, aiming to understand the drivers for the optimal individual positions (Morrell and Romey, 2008) during collective movements (e.g., single-file progressions in baboons, Papio sp., Rhine and Tilson, 1987). A newer approach of 
analysis of groups on the move consists in extracting successful and failed initiation attempts at the dyadic level, from variations in inter-individual distances automatically calculated at short time periods, with new biologging methods (e.g., Strandburg-Peshkin et al., 2015a). Fewer studies focus on the ending phase. Pyritz and colleagues (2011b) stated that, theoretically, group members may face a second consensus decision about where to stop. This second decision may be independent and different from the decision during initiation. In these studies, the mechanisms underlying a collective movement are investigated by collecting data on the order of individuals changing from a moving condition to a stationary condition and their behaviours once the group movement stops (e.g., Dubuc and Chapais, 2007; Barelli et al., 2008; King et al., 2008).

Therefore, empirical data on group-living animals appears to be a crucial quantitative guideline for comprehending how the complexity of real systems influences the patterns of collective movement. Due to all these variations, a more inclusive comprehension of group coordination processes derives from the combination of the outcomes of theoretical studies with the results from empirical studies, especially those focusing on the whole course of collective movements taking place within the natural environment in which the groups live (Pyritz et al., 2010, 2011b; King et al., 2018).

\subsection{Primate social groups as models to empirically study group coordination}

Specifically, to integrate novel knowledge regarding how social species reach coordination, it is important to study group-living species that: (i) occupy diverse habitats, which vary in resource abundance, climatic seasonality and predation risk, (ii) have higher cognitive abilities, which generally imply highly diversified individual characteristics, internal states and interests, and (iii) live in stable social systems and develop heterogeneous social relationships. The order of primates, including more than 600 species and subspecies (Mittermeier, 2013), fulfils these requirements. Primate species (i) live in a wide range of habitats, from tropical rain forests to temperate mountain forests and semi-deserts, (ii) their brain size in relation to their body dimension is larger than in other mammals and vertebrates, suggesting sophisticated cognitive abilities, and they (iii) exhibit a "stunning diversity" of social systems (Kappeler and van Schaik, 2002, p. 708) as compared to most other vertebrate taxa (Fichtel et al., 2011). This social diversity involves all four aspects of a social system: social organization, social structure, mating system and offspring care system (Kappeler, 2019). The social organization of primate species 
varies in size (from solitary to several hundred individuals), sexual composition (the most basic dichotomy being between single and multimale societies) and spatiotemporal cohesion of the group (unilevel societies, fission-fusion societies and multilevel societies), with the large majority of primates living in groups with $\geq 3$ adults of both sexes. Primates also vary across species in social structure, i.e. the frequency, intensity and nature (affiliative or agonistic) of social interactions and the resulting dyadic relationships between the members of a society (the most basic dichotomy being between despotic and tolerant societies). The mating system, which describes the interactions of mating couples, varies across species too. Four fundamental mating system types are distinguished: monogamy, polyandry, polygyny and polygynandry. Lastly, the offspring care system is mostly bi-parental with mothers being the primary infant caretakers, but the exceptions are several, especially in small-sized primates where paternal or alloparental carrying of the infant is preeminent over the maternal one (Wright, 1990; Kappeler and van Schaik, 2002; Schülke and Ostner, 2012; Kappeler, 2019).

This large interspecific variability also regards closely related species. Comparing species with high genetic relatedness permits to control confounding variables, like physiological, ecological or behavioural differences, and to explore the links between the fewer ecological or social adaptive differences and their consequences within each considered species (Lee, 1999). Such interspecific comparisons consequently allow to best infer the general behavioural mechanisms used for maintaining group cohesion and solving conflicts of interest in collective action of cognitively sophisticated species. As a result, studying collective movements in primates not only permits to deepen our understanding about how individuals with distinct interests coordinate, but it promises new insights into interesting behavioural variations in the social component of group movements. Hence, it also contributes to the comprehension of how mechanisms of group coordination have evolved in complex social systems like our own (Boos et al., 2011).

\subsection{How collective movements begin}

As mentioned above, the study of group movements can be addressed focusing on different coordination contexts (the departure, the progression and the termination of a group movement), depending on the aspect of group coordination that we are interested in and on the operational conditions for data collections. To address questions regarding how group coordination arises from individual decisions despite individual conflicting interests, most 
studies have focused on individuals that start moving during group departures. For the group to depart and begin a collective movement, each group member has to make a decision between two or more alternative behaviours and to move nearly synchronically in the same direction of the other group members (King and Sueur, 2011). A group level outcome may be challenging when group members have different preferences of action. In a group of primates, individual interests tend to be heterogeneous. For instance, an old male, a growing juvenile or a lactating female usually differ in overall activity budgets and foraging strategies, like the time spent feeding or the type of food eaten (e.g., Boinski, 1991; Erhart and Overdorff, 1999). De facto, at least some group members face the choice of either accepting an individually sub-optimal outcome to stay cohesive with their group (i.e. consensus cost, Conradt and Roper, 2003, 2005), or splitting from the other individuals and losing the advantages of group life (StrandburgPeshkin et al., 2018). In such circumstances, "group members choose between two or more mutually exclusive actions to reach a consensus on the group level" (Pyritz et al., 2011b, p. 1270). This process is defined as consensus decision-making. Implying the potential choice for individually sub-optimal options, consensus decision-making affects the ability of group members to efficiently exploit resources in their habitat, with a consequent potential impact on their fitness (Herbert-Read, 2016; Strandburg-Peshkin et al., 2018). The understanding of the consensus decision-making, that is to say discovering how individual knowledge, traits and preferences are weighed within the group, is theoretically framed according to the influence of the individual group members on the decision outcome. Studies quantifying individuals' contribution to group decision outcomes usually investigate (i) the order of departing individuals across departure events, presuming that individuals initiating the movement have a preeminent influence in establishing the direction and time of the group departure, or they investigate (ii) how individuals express intentions, exchange information and negotiate during the whole process of group departure, pre-departure included, or they investigate both aspects.

\subsubsection{How to investigate consensus decision-making}

Since group members are expected to preserve cohesion, if an individual is moving away from the others, it is either followed or it will soon return to the group. Hence, in a large number of studies about group departures, the first individual moving away from the other group members is interpreted as attempting to initiate the departure of the group. When an individual attempts to initiate a group departure, it is often intuitively assumed to be an individual potentially 
capable of influencing the behaviour of others. The attempt can be successful or not, depending on whether all group members are following or not. The successful individual is the one actually followed by all group members and is supposed to be the individual that influences most the outcome of consensus decision-making, i.e. the direction and time of group departure. If the same individual consistently initiates across group departure events, it is indicated as potentially the only group member influencing the consensus decision outcome. If more individuals of the same group initiate group departures, it is suggested that more group members can influence the consensus decision outcome. As a result, studies regarding group decision-making commonly investigate the order of departing individuals. Often the focus is only on the identity of the individuals attempting an initiation of a group departure and of those successful (e.g., Van Belle et al., 2013; Lee and Teichroeb, 2016). However, this interpretation of the first individual moving in group departure and the identification of successful initiators may not tell the whole story. For example, individuals may initiate because of particular internal states, such as higher nutritional requirements, whereas their capacity to influence the decision outcome might be equivalent to one of the other group members.

Another common way to investigate consensus decision-making hinges on the analysis of the communicative means involved in a group departure. The decision-making to reach consensus among group members potentially implicates information exchange and negotiation during the pre-departure period and following departure (King and Cowlishaw 2009a; Fischer and Zinner, 2011). Individuals express intentions, exchange information and negotiate through communication, meaning that an individual emits signals and/or gives cues which are received and processed by one or many recipient individuals. The adaptive value of this information transfer allowed the ability to detect signals and cues to be evolutionarily selected (ScottPhillips, 2008). Signals are structures or behaviours with the main function of transmitting information. In the context of a group departure, some studies described behaviours like pauses and back glances, in the course of the move away, as either recruitment signals to solicit the other individuals to follow or behaviours to monitor the rest of the group (e.g., in rhesus, Macaca mulatta, and Tonkean macaques, Macaca tonkeana, Sueur and Petit, 2010; in chacma baboons, King et al., 2011; in Barbary macaques, Macaca sy/vanus, Seltmann et al., 2016). Other studies described ritualized greetings as a way to negotiate direction and timing of group movements (e.g., in hamadryas baboons, Papio hamadryas, Kummer, 1968a, 1995). Some others described vocalizations as a means to indicate readiness to leave or the trajectory of a 
collective movement (e.g., in white-faced capuchins, Cebus capuchinus, Boinski, 1993; in mountain gorillas, Gorilla beringei beringei, Stewart and Harcourt, 1994; in chacma baboons, Fischer and Zinner, 2011), or branch shaking displays as behaviours to elicit or negotiate a collective departure (e.g., in Barbary macaques, Mehlman, 1996). Alternatively or concurrently to signals, information can be transferred by cues, meaning features or behaviours reflecting the physiological or morphological state of an individual and received and processed by recipient group mates (Scott-Phillips, 2008; Fischer and Zinner, 2011). For example, a number of studies suggested that the individuals responded to the cue of another group member moving off following the movement (e.g., in chacma baboons, Stueckle and Zinner, 2008; King et al., 2011). However, the understanding of communicative means can be problematic for a researcher. The potential sources of misinterpretation are numerous. For instance, the information transfer may occasionally fail, the social environment may shape the occurrence of a communication behaviour (e.g., group size may influence the call rate, Fischer and Zinner, 2011) or the informational account of the same behaviour may vary according to local conditions that may not be obvious to the human observer (e.g., vocalizing more in densely vegetated habitats than in open ones, Cheney and Seyfarth, 1996; Ey et al., 2009).

Therefore, the analyses of the order of departing individuals and of the communicative means involved during a group departure are two ways to investigate consensus decisionmaking. A study integrating both of them, on principle, allows a better understanding of the influence of individual group members on the decision outcome.

\subsubsection{Unshared consensus decision-making to depart}

The investigation of consensus decision process leads to results that are framed within one of two possible scenarios. One of them sees a single individual with a disproportionate influence on consensus decisions, meaning that all the other members follow its decisions in an unshared group decision-making (Conradt and Roper 2005, 2009; Pyritz et al., 2011b). In this scenario, group members need to regularly monitor the actions of one individual, the decision maker (usually the most dominant), and the collective behaviour emerges without invoking more complex decision-making abilities, such as expressing preferences and weighing them within the group (Conradt and Roper, 2005).

In primates, an unshared consensus for collective movement is rare. Mountain gorillas (Gorilla beringei beringei) are one of the most cited cases. This species lives in small groups 
(average: 12.5 individuals) of both sexes, with usually only one adult male considerably outweighing the other individuals, the silverback (Gray et al., 2013). Home ranges are undefended and largely overlapping. During group movements, the silverback consistently heads in the direction of the prospective movement and the other group members have no choice but to quickly move to preserve group cohesion (Watts, 2000).

On one side, an unshared decision-making conceptually appears faster and may require simpler cognitive abilities; on the other side, it seems less beneficial to the group. Unshared decisions can be disadvantageous to the group, in terms of the low proportion of individual interests satisfied, and even to the decision-maker, in case it is badly informed (Franks et al., 2003). Modelling fitness consequences showed that unshared decision-making only pays other members when the group is small and the variation of individual information is large, even when the most socially powerful individual is the most experienced group member (Conradt and Roper, 2003). These results are concordant with results for some human societies (e.g., Glowacki and von Rueden, 2015). Since negotiation and signalling behaviours are not obvious in non-humans, especially in the past, some studies tend to "a priori" identify the dominant individual as the decision-maker in the group movement context (Conradt and Roper, 2005). However, gorillas and other similar cases of what it was generally considered unshared consensus have nowadays been associated with some form of shared communication to negotiate or facilitate the coordination. De facto, all group members of a group of mountain gorillas seem to assess their readiness to depart through an increase in grunt vocalizations, which is followed by visual and auditory information by the silverback about its location, intention to move and movement direction (Stewart and Harcourt, 1994; Watts, 2000). These considerations question the existence of a pure expression of unshared decision-making process to coordinate a collective action (Sueur and Petit, 2008a; Bourjade and Sueur, 2010; Fischer and Zinner, 2011).

\subsubsection{Shared consensus decision-making to depart}

Results can also lead to the second scenario, which sees the conflicts of interests resolved by a shared decision-making. In this case, several (partially shared) or all (equally shared) group members contribute to the decision outcome. In either partially or equally shared processes, a negotiation phase including signalling behaviours is usually required (Kummer, 1968, 1995; Leca et al., 2003; Bourjade and Sueur, 2010; Fischer and Zinner, 2011). This pooling of information 
among group members tends to produce less extreme outcomes and to increase the accuracy of the decision, a phenomenon also called "wisdom of crowds" (Sumpter et al., 2008; Conradt and Roper, 2009; Conradt, 2011). Since the consensus decision proves to be more accurate and overlaps with a larger portion of individual interests (Fischer and Zinner, 2011), shared decisionmaking processes are, at least theoretically, more beneficial for group members than accepting unshared decisions made by a single individual (Conradt and Roper 2007, Berdhal et al., 2013).

Shared consensus decisions are common in primates. Numerous studies about group coordination in primate groups revealed influencing factors that tend to affect the patterns of group departures. In many primates, such as squirrel monkeys (Saimiri oerstedi, Boinski, 1991), Barbary macaques (Seltmann et al., 2013) or vervet monkeys (Chlorocebus pygerythrus, Lee and Teichroeb, 2016), adult, supposedly more experienced, individuals initiate collective movements more often than juveniles. Two other examples of shared consensus decisions come from lemurs. Red-fronted lemurs (Eulemur rufifrons) live in small groups with philopatric females and a relatively egalitarian social structure. Adult female red-fronted lemurs attempt to initiate group movements more often but with the same recruitment success than males (Pyritz et al., 2011a). Whereas, in the small groups of another lemur species, Verreaux's sifakas (Propithecus verreauxi), adult females are philopatric too, but socially dominant over males. In this species, adult females attempt to initiate group movements more often and with a higher recruitment success than males (Trillmich et al., 2004). In howler monkeys (Alouatta pigra), all group members were reported to successfully initiate group departure, but the adult female that had the strongest set of social connections (based on spatial proximity) did it disproportionally more than all the others (Van Belle et al., 2013). There are also fewer reports of species where all group members can initiate collective movements, without a consistent influence of age and sex. This outcome is possible in species with an egalitarian social structure, such as white-faced capuchins (Cebus capucinus, Leca et al., 2003) and brown lemurs (Eulemur fulvus fulvus, Jacobs et al., 2008). Following studies in brown lemurs showed that the social structure of the group underlies the process of group departures, since individuals are most likely followed by the closest affiliated group mates (Jacobs et al., 2011a). In contrast, departing white-faced capuchins were simply followed by the nearest group mates in space, anonymously (Meunier et al., 2006).

The presence of several individuals, with potentially conflicting interests, capable of influencing the consensus decision outcome leads to a need of negotiation of time and direction 
of group movements. Therefore communicative means, as the expression of information exchange and negotiation, are expected to be particularly involved in shared decision-making. Many studies investigated communication as a mechanism conceivably contributing to group coordination (e.g., Bourjade and Sueur, 2010; Sueur and Petit, 2010; Sueur and Petit, 2008a; Leca et al., 2003; Stückle and Zinner, 2008; King et al., 2011). Contrasting results have been found within and between species. For example, back glances were first considered to have no effect in eliciting followership behaviour in rhesus macaques (Sueur and Petit, 2008a). A subsequent study revealed that rhesus macaques glancing back were less likely to successfully initiate a group departure (Sueur and Petit, 2010). A similar outcome was found in Barbary macaques (Macaca sy/vanus, Seltmann et al., 2016), whereas a positive influence of performing back glances on the success of an initiation attempt was found in white-faced capuchins (Leca et al., 2003). Apparently, an individual that glances backwards to the other group members can be perceived either as an incitement to follow or a monitoring behaviour by a hesitant individual. Pauses and vocalizations are analogous examples of behaviours with varying functions within and between species in comparable studies of group movements. The findings regarding the impact of communication on the influence on a group departure are controversial. A performed behaviour with a potential communicative function may not always find a recipient and, once it does, the kind of information perceived can vary within and between species (Seltmann et al., 2016).

\subsubsection{The social factors affecting group departures: the case of macaques}

The described examples primarily point out the influence of the characteristics of the society on the processes underlying coordinated collective actions. Even individual features, such as sex, personality traits or internal state, appear to influence the process as interacting with the social status of the individual. For example, the adult sifakas females mentioned earlier may initiate group movements more often and more successfully than males because they are socially dominant (Trillmich et al., 2004). Also, bonobo oldest females (Pan paniscus) may initiate more often because they frequently give coalitionary support to younger females (Tokuyama and Furuichi, 2017). To deepen our understanding of the social determinants regulating group coordination, it is helpful to compare closely related species living in different social systems. Studies on macaques can provide an example. The genus Macaca counts 22 species, all organised in unilevel multimale multifemale groups in which females are mostly philopatric and 
most males transfer (Thierry, 2007). However, the species also display consistent variation in social structure, in terms of degrees of dominance asymmetry and of aggression and reconciliation patterns (Thierry, 2007). For example, rhesus and Japanese macaques ( $M$. fuscata), are defined as socially intolerant with steep dominance hierarchies, Barbary and Tibetan macaques ( $M$. thibetana) present an intermediate degree of social tolerance with moderate steepness of the dominance hierarchy and Tonkean macaques are among the most egalitarian and tolerant species (Thierry, 2007). Among these five species the individuals seemingly capable of influencing a group departure differ and the social structure of the group has various impacts on the coordination process. In rhesus and Japanese macaques, old and dominant individuals appear to have preeminent influence on group departures (Sueur and Petit, 2008a; Jacobs et al., 2011b). In Barbary macaques, mainly high ranking individuals initiated group movements and followership was determined by social affiliation (Seltmann et al., 2013). In Tibetan macaques, all adults initiated a group movement and the number and ratio of successful initiations (number of successful initiations divided by the number of initiation attempts) were not correlated with social rank, but positively correlated with the frequency and intensity of affiliative interactions (Wang et al., 2016). In Tonkean macaques, nearly all group members, juveniles included, can initiate a group departure and have the same likelihood to be followed (Sueur and Petit, 2008a, 2008b). Therefore, the initiation of departures of macaque groups appears to be the result of a partially shared decision-making, with a strong influence of the highest-ranking individuals in despotic species and a larger spectrum of influencing individuals and factors in more tolerant species, up to an equally shared process in the most egalitarian subjects.

\subsection{How collective movements continue}

Few studies mix the terms "group departure" and "group progression" and use them both referring to the period around the initiation of a group movement (e.g., Dunbar, 1983; Sueur and Petit, 2008b; Lee and Teichroeb, 2016). Differently other studies consider the terms as subsequent contexts (e.g., Erhart and Overdorff, 1999; Smith et al., 2003). The consideration of both contexts allows a more exhaustive analysis of the process underlying collective movements of a given species (e.g., Trillmich et al., 2004; King and Sueur, 2011). Once the consensus decision has been reached and the group has departed, so during group travel progressions, group members have both to maintain cohesion, involving conflict management among 
individual interests, and to move to the destination according to optimal individual positions (Morrell and Romey, 2008). Therefore, another frequently investigated coordination context is the organization of the group when already on the move, during group travelling progressions.

Only recently technological advances have allowed precise remote monitoring of group behaviours. For example, high-resolution individual biologging permitted the investigation of the conflict management among individual interests and the decision-making process also during group progressions (Strandburg-Peshkin et al., 2015). The researchers installed GPS collars on $80 \%$ of the adults of a wild group of olive baboons (Papio anubis) and remotely collected data of their individual positions, every second, for two weeks. Then they analysed the individual tracks. This approach permitted to calculate distances between all pairs of individuals and extract individual movements that were followed by the other group members. Such an analysis enabled the researchers to define the quality of the decision-making process (a shared consensus) based on finer scale decisions, with high temporal resolution. All collective movements were considered, including group departures and progressions.

More traditional studies have tested whether the first position of the travelling group was consistently taken by the same individual that was initiating the group departure (e.g., Erhart and Overdorff, 1999; Trillmich et al., 2004). Rarely questioned is the possibility that, in the course of the collective movement, individuals might overtake the front position of those which initiated the group departure. This might lead to a different description of the quality of the consensus decision and the process of group coordination. For instance, one individual could consistently initiate group movements and be then overtaken by other individuals that stay in front until the termination. In such a situation, what initially seems the result of an unshared decision-making is actually a shared process with regard to the whole movement action (Pyritz et al., 2011b).

Most commonly, studies about group progressions tend not to be concerned with the departures of collective movements. These studies focus instead on the spatial positions of all group members during a collective movement. When group members travel in a directed movement (as opposed to a "feed-as-you-go, ameboid-like movements that do not necessarily require an initiator or coordination among group members", Pyritz et al., 2011b, p. 1273), they may not move to their destination in a chaotic manner, but they may choose position according to physiological, social and/or ecological constraints, such as nutritional requirements, dominance rank, kin relationships, affiliative relationships or predation risk. Theoretically, these 
drivers of spatial positioning can also be divided into position-specific, i.e. the individual chooses a specific position because of physiological, social, and/or ecological factors, or neighbourspecific, i.e. the individual chooses a specific position based on being near or avoiding other group members (Janson, 1990).

According to the hypothesis that front positions facilitate access to more and better quality food (Janson, 1990), individuals may take positions corresponding to their physiological needs, e.g., lactating or pregnant females go in front because of their higher nutritional demands (Geladas, Theropithecus gelada, Dunbar, 1983; Milne-Edwards' sifakas, Propithecus edwardsi, and red lemurs, Eulemur rufus, Erhart and Overdorff, 1999; white-handed gibbons Hylobates lar, Barelli et al., 2008). Similarly, high ranking individuals could move in front to get priority access at the new location (Sueur and Petit, 2008b). Otherwise, low ranking individuals might also go in front to get the chance to exploit a resource before the dominants arrive (e.g., western green monkeys, Chlorocebus sabaeus, Gerald, 2002; long-tailed macaques, Macaca fascicularis, Dubuc and Chapais, 2007). There might be cases where old individuals are in front of the group because of their greater experience and memory (e.g., black spider monkeys, Ateles paniscus, van Roosmalen, 1985; suggested for bonobos, Tokuyama and Furuichi, 2017). Similarly, in species in which one sex is philopatric and the other one disperses, philopatric individuals may occupy front positions because of their better knowledge of the group home range (e.g., red-fronted lemurs, Pyritz et al., 2011a). The organization of the group on the move could be shaped by predation pressures too. According to this hypothesis, the strongest individuals, adult males in most primates, could be at edge positions, while more vulnerable and less confident individuals, females and immatures, could keep other group members between themselves and potential dangers (e.g., grey-cheeked mangabeys, Lophocebus albigena, Waser, 1985; baboons, Collins, 1984, Rhine and Tilson, 1987; chimpanzees, Pan troglodytes, Hockings et al., 2006; vervets, Chlorocebus pygerythrus, Teichroeb et al., 2015). This hypothesis was supported showing that adult baboons were more consistently at the back of the group when moving away from a frightening or tense situation than in other situations (Rhine and Tilson, 1987). In addition, lions attack baboons more frequently from the direction in which group members are travelling, i.e. the front of the group (Busse, 1980; likewise a greater risk of predation in front positions was found in shoals of fish, Bumann et al., 1997). In general, the study of individual spatial patterns during collective movements reveals the adaptive costs and 
benefits of spatial choices and underlines the ecological and social pressures that drive individual positioning within a group.

\subsection{How to infer leadership: a critique}

Taking the initiative to attempt a group departure and eliciting the followership of all group members or occupying the front position of a progressing group may be the expression of an action of leading. De facto, leadership is a concept recurring very often in the literature regarding group coordination. However, we still encounter some conceptual mismatches between studies in the notion of leadership (Strandburg-Peshkin et al., 2018). Pyritz and colleagues (2011b) wrote a purpose-made article to reach a consensus in the scientific community over the terminology used about animal group coordination. They defined leadership as the action of leading by the individual, the leader, which "elicits follower behaviour (from a majority of or all group members) and exerts social influence on group members either by its rank, experience, social status/connectedness, or specific behaviour" (Pyritz et al., 2011b, p. 1273).

As adduced, a first dispute concerns terminology. An emblematic example concerns two similar studies that analysed the order of arrival at a feeding site at the termination of a group progression. Although Dubuc and Chapais (2007) found in a study on long-tailed macaques that lower ranking individuals were often ahead of the group, they did not relate this to leadership. In contrast, Barelli and collegues (2008) found in a study on gibbons that high ranking cycling females were ahead of the group and they assumed a greater leadership role of these females in coordinating group activities.

A second problem regarding the concept of leadership comes with the complexity of group movements. As leadership is often investigated in the context of group departures, it could also be investigated in other coordination contexts, as during group progressions. The intuitive thought is to ascribe leadership during group progressions to the individual ahead of the group (e.g., killer whales, Brent et al., 2015; spotted hyaenas, Crocuta crocuta, Smith et al., 2015; giraffes, Berry and Bercovitch, 2014). However, such an analysis of leadership during group departures in the same group could potentially lead to contrasting results. As already remarked, individuals may overtake the positions ahead of the group during the course of the collective movement. Therefore, to try to gain an exhaustive picture of leadership during collective movements in a given species, the study of collective movement should be as 
comprehensive as possible of the different coordination contexts. To face this issue Pyritz and colleagues (2011b) also proposed to define leadership as "stable", when overtaking occurs rarely during travelling, and "unstable", when overtaking occurs regularly. Yet, different coordination contexts might show different aspects of group coordination. During a group departure, the group may find consensus about the timing and direction of the collective movement and all group members might then be aware of the destination chosen. Several researches supported the idea of mental maps in baboon daily routes (e.g., Sigg and Stolba, 1981; Noser and Byrne, 2007). In this scenario, the front position up to the termination of the movement is not related to eliciting or influencing others' behaviours, but may be unintentional, or driven by, for example, ecological factors like predation risks. In addition, a distinction based on overtaking a front spatial position hinges on the assumption that the researcher is defining initiators and the individual ahead of the group as leaders, which may be incorrect, as discussed in the following paragraph.

In fact a third issue concerns eliciting and influencing others' behaviours, which might not be evident to the observer. Many studies simply defined the individual that initiates the collective movement as the leader (e.g., Leca et al., 2003; King et al., 2011; Wang et al., 2016; Tokuyama and Furuichi, 2017). These studies suppose that the individual taking the first position ahead of the group is actually driving the group to his intentions. Although intuitive, this assumption may not be confirmed in all species (Bode et al., 2012). Already Kummer (1968a, 1968b) observed that hamadryas baboons (Papio hamadryas) could exert influence on the travel direction of the group without being the first group member to advance. The author used the term "hidden leadership" to define the influence on collective movement exerted from spatial positions behind the first one. Also, in geladas, lactating females tend to initiate group movements, but the dominant male and female decide whether or not the group would follow (Dunbar, 1983). In addition, a collective movement might take place depending more on the motives of some, if not all, group members than on those of one initiator. The latter may simply behave as a trigger for a collective decision which has been taken, instead of behaving as a leader (Petit and Bon, 2010; Jacobs et al., 2011a; Briard et al., 2015). Bode and colleagues (2012) presented a model for the navigation of moving groups which demonstrates that leaders are not consistently found at the front of the group. Aware of this issue, Pyritz and colleagues warned that the role of a leader "should not be restricted to its spatial position during a group 
movement because individuals may also lead from behind, i.e., initiate and terminate a movement without being at the forefront of the group" (2011b, p. 1273).

A fourth complication concerns the broadness of the concept of leadership. As well as in group departures and group progressions, leadership might play a role in other situations, such as, migration, group foraging, hunting, intergroup conflict and territorial defence, and intragroup conflict resolution (Glowacki and von Rueden, 2015; Smith et al., 2016). To exhaustively describe how leadership is expressed in the studied group despite this complexity, Smith and colleagues (2016) identified five dimensions of leadership. One dimension refers to the (i) "distribution" of leadership, that is to say what proportion of group members usually makes a decision in a given context. Another dimension concerns the (ii) "emergence", i.e. whether leadership is achieved or ascribed ("emergent" or "inherent" in Strandburg-Peshkin et al., 2018). The dimension of (iii) "power" describes how influential leaders are. The (iv) "relative benefits" refer to which advantages leading the group brings. The dimension of (v) "generality" regards how and whether leadership in one context predicts leadership in another one. Although this complexity is difficult to disentangle and describe, the study of leadership should not be limited to the investigation of only one coordination context of collective movement.

To summarise, such a multifaceted and broad concept as leadership should not be bound to initiating a group departure or taking the front position in group progression. Studying leadership should involve the investigation of the mechanisms of collective behaviour and how the individual interactions give rise to the patterns we observe at the group level (Garland et al., 2018; Strandburg-Peshkin et al., 2018). A more thorough definition of leadership may be: a process to solve collective action problems where an individual (leader) repeatedly influences their group to achieve collective goals (Glowacki and von Rueden, 2015; Smith et al., 2016; Amornbunchornvej and Berger-Wolf, 2018; Strandburg-Peshkin et al., 2018). Thus, the guide to a proper leadership analysis includes focusing on the mechanisms that bring certain outcomes, e.g., being initiators or in the front position, instead of on the actual outcomes (StrandburgPeshkin et al., 2018). This study will focus on group departures and group progressions of Guinea baboons. For both analytical and conceptual issues arisen, I decided to refer only to initiators of group departure, with some deduction on decision-making processes, and to individuals occupying front positions during group progressions, avoiding inference of leader roles and leadership (as, to my knowledge, no other study about departures of group 
movements in primates did, but see e.g., Rhine et al., 1985, or Dubuc and Chapais, 2007, for other coordination contexts).

\subsection{The case of baboons: between different societies}

Baboon species have been study subjects of some of the pioneering research on group coordination in primates, which described the order of group progressions, group departures and consensus decision-making driving collective movements (in yellow, Papio cynocephalus, and chacma baboons, DeVore and Washburn, 1963; in hamadryas baboons, Kummer, 1968a, 1968b). Since then, many studies investigated group coordination in baboon species, making the genus Papio one of the most extensively documented among primates regarding this topic (Janson, 1990; Strandburg-Peshkin et al., 2015). Such investigations have been facilitated by their largely terrestrial lifestyle and home ranges often including open areas. The genus Papio includes six phylogenetic species, spread across sub-Saharan Africa, except Central- and WestAfrican rain forest, and southwestern Arabia (Zinner et al., 2013a, 2013b; Fischer et al., 2017). Whereas the care system of baboons appears bi-parental across species, with the mother investing a disproportional amount of energy and time in infant care taking compared to the father (on the paternal care taking, e.g., Busse and Hamilton, 1981; Alberts, 2016), baboon species differ in mating system, social organization and social structure, with two main models: polygynandric unilevel and monandric-polygynic multilevel societies (Anandam et al., 2013, Fischer et al., 2017).

The social system of olive, yellow and chacma baboons can vary across populations (e.g., Byrne et al., 1990), however, they usually live in a unilevel, multimale-multifemale group, named troop, which permanently consists of adult males, adult females and their offspring (Anandam et al., 2013). The society manifests a linear hierarchy, determined through agonistic interactions in males and inherited in females (Swedell, 2011; Barrett and Henzi, 2008; Anandam et al., 2013). Females tend to spend the entire life in the group into which they are born. Males tend to disperse on reaching sexual maturity (Barrett and Henzi, 2008). Females and males can form consortships during oestrous periods. Male dominance hierarchy strongly affects the access to reproduction, especially in chacma baboons, where the alpha male can monopolize the majority of mating access (Barrett and Henzi, 2008; Anandam et al., 2013). Kinda baboons (sometimes addressed as a subspecies of yellow baboons, see Barrett and Henzi, 2008; and Jolly, 2013) remain largely undocumented, but preliminary observations suggest a 
social organization similar to that of olive, yellow and chacma baboons (Anandam et al., 2013) and unique aspects of social structure (Weyher et al., 2014). Because of these similarities these four species of baboons are starting to be collectively addressed as COKY baboons (chacma, olive, Kinda and yellow baboons; Jolly, subm.)

Hamadryas and Guinea baboons (P. papio) live in multilevel societies. The smallest social entity is the reproductive unit, which consists of one male with one or more females and their offspring. In hamadryas, these one-male units (OMUs) occasionally comprise one or more "follower" males without mating access to females (Pines et al., 2011). More OMUs associate in a clan. Few clans that often share their daily range form a band. Usually the bands of a particular area aggregate at the same sleeping site and form a troop, a group of up to several hundred baboons (Kummer, 1968a; Schreier and Swedell, 2009). Males often aggressively herd females and they try to prevent the females' affiliative interactions with individuals outside the OMU (Kummer, 1968a, 1968b; Swedell and Schreier, 2009; Pines and Swedell, 2011).

Due to this variability in social systems among closely related species, baboons have also been used as a model to investigate consequences of the characteristics of the society on individual fitness (Sapolsky, 2005; Silk, 2007; Fischer et al., 2017). In addition, baboons probably evolved in the same savanna habitats of eastern Africa and at the same time as early humans, and the complexity of their social systems is similar to that which occurred in the recent evolution of Homo sp. These aspects advocate baboons as a valuable model to study human social evolution (Henzi and Barrett, 2005; Strum, 2012; Bonnell et al., 2019).

\subsubsection{Group departures in baboons}

Research on group coordination in baboon species has shown different results. An old study on wild olive baboons describes the highest-ranking male determining direction and timing of the majority of group movements, with exceptions concerning other adult males. Other group members, especially females with offspring, have varying degrees of influence on collective movement (Ransom, 1981). Nevertheless, strong evidence for shared decision-making was found in a more recent study on wild olive baboons, equipped with GPS collars (StrandburgPeshkin et al., 2015). Even though, as mentioned before, this study focused on a moving group of baboons and not strictly on the process from a general stationary condition to a moving one, they concluded that all adult group members could influence the direction of group movement. Individuals were more likely to follow when several initiators agreed on the direction and timing 
of movement. In case of diverging directional propositions at the same time, the rest of the group chose one direction over the other when the angle between the proposed directions was large, but it compromised between them if the angle was small (Strandburg-Peshkin et al., 2015). Working on the same dataset, Farine and colleagues (2016) first discovered that the next location of one individual was best predicted by the location of the four to six nearest neighbours and the location of the closest affiliated individual had a higher influence on the moving individual.

In yellow baboons, adult males have been reported to move off first and initiate group movement (Norton, 1986). However, male movements usually translate into group movements when other group members, and especially adult females, had already indicated the direction of movement and readiness to move. The most influential individuals appeared to be the highestranking female and the oldest female, with the largest matriline and middle-low social status. Individuals indicate their intentions through body and gaze orientations, rises to a high position, like climbing a tree or a rock, or movements to the group edge.

A study on wild chacma baboons reported that, in the morning, both males and females initiated group movements for leaving the sleeping site with a similar rate of success, but adult males initiated more often than females. Vocalizations, back glances, pauses or walking speed did not seem to influence the success of an initiation attempt (Stueckle and Zinner, 2008). A similar study was conducted on a different wild group of chacma baboons. The large majority of adults initiated group departures from the sleeping sites. Overall, sex or dominance did not affect the likelihood of attempting an initiation or the success of the attempt. However, the dominant male did initiate group departures significantly more than all other individuals. Back glances or vocalizations did not seem to affect the likelihood of a successful initiation, whereas pauses during an attempt of initiation reduced the prospect of a group departure. Baboons tended to follow at closer distance group mates which they shared stronger social ties with (King et al., 2011). A third study on the same species followed a different approach. It examined the individual decision-making in a moving group by means of GPS locations collected for each adult baboon of the group. The study indicated that individual movements were influenced more by specific animals than by the trajectory of the whole group. Moreover, it showed that, in individual movements, lower ranking individuals were more influenced by higher-ranking individuals. In addition, some specific individuals were much more influential than others and some other individuals more influenced by others, suggesting a potential influence of individual 
temperament on the consensus decision outcome during movement (Bonnell et al., 2017). Another study on the same species was based on a foraging experiment in the wild. The observer followed the baboons for full days but the analyses focused on the order of arrival on an artificial foraging site. The foraging sites were designed to give access to food to a small minority of individuals, which generally ended up being the dominant ones. The majority of other group members followed the dominant male despite the considerable consensus cost of travelling for no food resources. The results suggested that, in case of skewed foraging benefits, dominance has a severe influence on the collective movement. Again, baboons preferentially followed individuals they were closely affiliated to (King et al., 2008). Lastly, a pilot study on chacma baboons in Namibia has suggested that the call rate of grunt vocalization is positively correlated with the likelihood that a stationary group will depart (Fischer and Zinner, 2011).

In hamadryas baboons, OMU reproductive males (usually referred to as "leader" males, Pines et al., 2011; Swedell et al., 2008) are almost exclusive initiators of group movements and the main influencer of the decision outcome. Younger adult males appeared generally more active in initiating group departures, but the group moved only when older adult males followed from the centre the initiation attempt (Kummer, 1968a, 1968b, 1995). Within bands, adult males may perform notifying behaviours to other males (i.e. ritualized greetings) prior to departure, to solicit the others to follow them in their desired direction. Then other group members broadcast their preferences by moving a few meters towards the preferred direction or supporting the choices of others sitting facing the respective direction (Kummer, 1995).

Across studies on baboon species, the findings on the process of group decision-making vary. In general, adult males seem to have a preeminent but not exclusive role in the decisionmaking process and the initiation of a group departure. In some studies on unilevel societies, higher ranking individuals appeared to be more influential over the direction and timing of group departures than lower ranking ones. In a multilevel society, OMU leader males appear the reference for other OMU's members and in charge of the coordination of the larger social entities: clans and bands. Moreover, the impact of the communication behaviours potentially involved in coordinating group departures appears contradictory and inconclusive. The information transfer and the negotiation process seem to vary according to study conditions and study species.

\subsubsection{Group progressions in baboons}


Results about the order of group progressions have recurrent aspects across species. One of the first studies collected data on wild groups of yellow and chacma baboons. The order of group progression described in open plains was: less dominant adult males take position at the front and back edge of the group, dominant adult males, females and young juveniles occupy the centre and older juvenile males take position between the centre and the edges (DeVore and Washburn, 1963). A similar pattern of progression was described some years later in wild yellow baboons (Rhine, 1975). Adult males took position either at the front or the rear of the group. Dominant ones were mainly in the front and subordinate males mainly in rear positions. Adult females tend to be spread across front, middle, and rear progression positions (Rhine, 1975). Two similar studies were conducted a few years later on two other troops of wild yellow baboons, focusing on adult male positioning (Rhine and Westlund, 1981) and on younger individual positioning (Rhine et al., 1981). Results confirmed that dominant males were disproportionately more often in the front and subordinate males in the back. Also, sick and older individuals progressed at the back (Rhine and Westlund, 1981). Small juveniles tended to be centrally located and large juveniles were located "somewhat to the front" (Rhine et al., 1981, p. 475). Another study approached the analyses of spatial patterns in yellow baboons combining moments of travel and rest (Collins, 1984). Observations revealed that males tended to travel in front of the group independently of dominance rank. Rear positions appeared to be taken in relation to individual mobility. Individuals most frequently seen at the rear were one female during late pregnancy, a mother with a new born infant, a sick female and the oldest adult male (Collins, 1984).

The pattern of progression was also investigated in wild chacma baboons. Chacma adult males were most often found in the front part of progressions and they were about equally often found in the centre and rear of the group (Rhine et al., 1985; Rhine and Tilson, 1987). Walking immatures tend to occupy central positions during progression and adult females did not exhibit a clear pattern in the order of progression across events (Rhine and Tilson, 1987). A newer study did not focus on group progression order, but it analysed the GPS data of each adult chacma baboon of one habituated wild group while foraging. The results revealed that the individuals tended to shift positions within the group. Dominant individuals usually took central positions during moving and foraging activities. In particular, high-ranking females were closer to the centre of the group than were males (Dostie et al., 2016). 
The tendency for adult males to occupy front positions was also confirmed for olive baboons (Rhine and Westlund, 1981; Rhine and Tilson, 1987). The same data collected on olive baboons equipped with GPS collars mentioned above also revealed that, although individual positioning is highly dynamic, subadults (younger individuals were not collared, so they were not included in the analyses) were closer to the centre than adults (Farine et al., 2017). Dominant individuals tended to take more central positions than subordinates and, in general, the individual that is in proximity with a larger number of group mates ends up in central positions (Farine et al., 2017).

Kummer (1968a, 1968b, 1995) described the individual positioning during progression in the multilevel society of hamadryas baboons. Although he considered only very few events, the description showed points of convergence with the individual positioning described in baboons living in unilevel societies. Precisely, in the event of two OMUs walking in a line, the males took the front and rear of the group. When the group in single-file progression was larger, adult and subadult males were much more likely to occupy front positions while they took rear positions with a frequency equal to chance. Generally younger adult males were reported more in the front and older adult males more in the rear of the group.

Overall, a quite similar age-sex positioning in progression orders occurred across different studies, troops, species, social systems and habitats. Adult males more often occupy the front positions of the group. Moreover rear positions are taken more frequently than central ones, in several studies. Despite such consistency, a progressing baboon group also appeared as a fluid system in which each individual occasionally occupies all positions in the progression order. In addition, between all these studies describing non-random positioning during group travel progressions in baboons, there is one study that, over nine years of data sampling on wild yellow baboons, found most progression orders to be essentially random (Altmann, 1979).

\subsection{Guinea baboons}

Together with Kinda baboons, Guinea baboons are the least explored baboon species. Guinea baboons represent the north-western extreme in the distribution of genus Papio. Like hamadryas baboons, they live in a multilevel society, based on monandric-polygynic reproductive units. The nomenclature used for the different nested level of social organization is different between the two species but comparable. The units consist of one adult male, the "primary" male, one or more adult females and dependent offspring. Often units comprise one 
or more additional adult or subadult males, addressed as "secondary" males (76.5\% of cases, Dal Pesco et al., in prep.). Secondary males have frequent affiliative non-sexual interactions, such as contact sitting, grooming or infant handling, with the other unit members. Several units team up in a party, which further includes adult males without consistent affiliative interactions with specific units, classified as "unaffiliated". The party can be seen as the equivalent of the clan level in hamadryas. Few parties associate with each other in a gang (Fischer et al., 2017). Whereas the same level of social organization is named band in hamadryas.

While the social organization resembles that of hamadryas baboons, the social structure differs considerably. Agonistic interactions between parties or gangs are rare and different gangs use largely overlapping home-ranges. Aggressive behaviours are also rare between males and females ( 0.1 events $/ \mathrm{h}$ ), occurring mainly between a primary male and one of its females. Females counter aggress in $20 \%$ of the occasions (Goffe et al., 2016; Fischer et al., 2017). Adult males do not form linear dominance hierarchies and maintain long-lasting friendly relationships with other males, based on occasional grooming, support in agonistic interactions and high spatial tolerance (Patzelt et al., 2014; Kalbitzer et al., 2015; Fischer et al., 2017). Females have greater spatial freedom and leverage in their association patterns than in hamadryas baboons. Females can engage friendly relationships with other females as well as with males outside their reproductive unit (Goffe et al., 2016). Female reproductive state does not affect grooming or aggression occurrences. Intersexual relationships are not strongly affected by female reproductive state either and appear much looser than in hamadryas and chacma baboons (Kalbitzer et al., 2015; Goffe et al., 2016). The social relationships between the male with "its" females are relatively stable. Mate fidelity is high (98.6\%) and the reproductive skew is low (Goffe et al., 2016). Fidelity has also been confirmed by recent paternity analysis, which revealed that the primary male sires $89.5 \%$ of the offspring within its unit (Dal Pesco et al., in prep). A social network analysis on interindividual spatial associations suggests the social relevance of secondary males within a party reporting that they usually are within a 5 meters proximity of more party members than primary males (i.e. higher degree centrality, Goffe et al., 2016). Both sexes have been reported to disperse between parties or gangs, however a study on population genetics found evidence that males are the more philopatric sex, in contrast with the COKY baboons (Kopp et al., 2015). Hence the Guinea baboon social system appears unique among baboon species, with major aspects being the multi-level social organization and the 
comparatively high social tolerance (Patzelt et al., 2014; Fischer et al., 2017). How they coordinate during group movement remains still unexplored.

\subsection{The aims of this study}

The collection of studies and the concepts presented indicate the theoretical and empirical complexity of studying the coordination of collective movements and the variety of methods that have been used to disentangle such complexity. In my study I investigated the initiation and course of group movements in wild Guinea baboons, focusing on two classical coordination contexts: group departures from a stationary condition and single-file group travel progressions. The aim was to analyse the processes and describe the patterns of coordinated group movements of such a unique baboon species. Notably, after the pioneering research on hamadryas baboons, my study complemented the investigation of group departures and group progressions in a multilevel primate society with up to date quantitative analytical approaches. Moreover, I put results into a comparative framework with other baboon species. I tried to elucidate interspecific similarities and Guinea baboon peculiarities and to assess whether and how the social system of baboon species shapes group coordination during collective movements.

\subsubsection{Group departures in Guinea baboons}

In order to study group departures I followed three approaches. First, I described which individuals attempted initiations of group departure and which ones were more successful. In general, I assumed that individuals which initiate group departures would change consistently across events due to the very weak dominance hierarchy and a comparatively high tolerant structure. Then, the description of these individuals was based on three potential influencing factors. The first was age. As in the majority of other primate species, the largest and more experienced individuals, i.e. the adults, were predicted to be the only ones capable of eliciting a group departure. The second factor was sex. I envisioned two contrasting scenarios. Considering the findings from analyses of group departures in other baboon species, and especially considering the dynamics described in the multilevel society of hamadryas baboons, I expected that males would attempt to initiate more often and with a higher success rate than females. Whereas, taking into account the comparatively high social tolerance of Guinea baboons and the findings from other tolerant primate species (e.g., white-faced capuchins, brown lemurs, 
Tonkean macaques), I expected that individuals of both sexes would attempt initiations of group movements with the same frequency and equal chances of success. The third factor was based on four elements. (i) In chacma baboons, male dominance hierarchy can correlate with both access to mating partners and influence on group decisions (King et al., 2008). (ii) In olive baboons, an individual that maintains spatial proximity with a larger number of group members ends up in more central spatial positions within the group (Farine et al., 2017). (iii) In Guinea baboons, there is no evidence of linear dominance hierarchy between adult males of Guinea baboons (Kalbitzer et al., 2015). (iv) Unit composition is determined by the affiliative interactions between group members (Goffe et al., 2016). Taking these four arguments into account, I attributed different categories of a variable named "individual association" to the group members: non-primary males were given the lowest value $(=1)$ and the other unit members were given increasing values according to the dimension of the reproductive unit (i.e. how many adult females belong to a given unit). In case individuals with a higher mating success were more influential during group departures (e.g., chacma dominant males in King et al., 2008), I expected primary adult males of large reproductive units to attempt to initiate more often and with a higher success rate than other party members. Whereas, in case unit members tended to stay cohesive, I expected non-primary males to be the first ones attempting to initiate more often and with a higher success rate than individuals belonging to a unit.

The second approach consisted of investigating the impact of communication during group departures. I quantified the occurrence of the behaviours commonly considered as signals or cues in the context of group departures in other studies: back glances, branch shaking displays, greetings, pauses and vocalizations (e.g., Kummer, 1968a, 1995; Boinski, 1993; Stewart and Harcourt, 1994; Mehlman, 1996; Sueur and Petit, 2010; King et al., 2011; Fischer and Zinner, 2011; Seltmann et al., 2016). In case communication behaviours would play a role in the coordination of a group departure, I assumed the expression of these behaviours to correspond to a potentially influential role of the performing individual on the time and direction of group departures. Hence, individuals attempting initiations should display communicative means more often. However, the use of communication behaviours during group coordination across species and studies is highly diversified, inconsistent and contradictory. I could not make any prediction on the kind of communication behaviour involved in group departures of Guinea baboons and on its informational account. 
With my third approach I explored whether and how the presence of two levels of social organization, the unit and the party, affects the coordination process. I analysed the cohesiveness of the party members. I considered that social affiliation is often an important driver of following behaviours, as already documented in some species (e.g., olive baboons, chacma baboons, brown lemurs). Moreover, the departure process described in hamadryas multilevel society relies on unit member cohesiveness: OMU males negotiate to preserve cohesion between OMUs and the other OMU members preserve cohesion within the OMU. Therefore, l expected unit members to depart cohesively within the party.

\subsubsection{Group progressions in Guinea baboons}

In my investigation of the second context, group progressions, I aimed to describe the order of individuals within the moving party across events. The order of single-file travel progressions of Guinea baboons may follow one of the non-random progression formations previously described for other species. However, since Guinea baboons live in a tolerant social structure, with weak dominance hierarchy and rare competition over food (personal observation), I assumed that individuals would also not compete for positions in the progression order to profit from a newly reached food resource. Also, since baboons seem to know their home range well (they do not repeatedly cover huge distances to find resources, average home ranges of the study subjects is between 25 and $36 \mathrm{~km}^{2}$, Klapproth et al., in prep.; Noser and Byrne, 2007), I assumed that a progressing group would not need to be led to destination by the most experienced individuals (the oldest). Previous studies on the order of baboon single-file progressions have found a quite consistent pattern described above and mainly hypothesized to be driven by predation pressure. Our study area hosts potential baboon predators (see content 2.1.). As mentioned before, individual predation risk in a moving group has been empirically shown to be dependent on the spatial positions within the group: individuals in peripheral, and especially frontal, positions are at higher predation risk than those in the centre of the group. Therefore, adult females and young individuals should be more motivated to travel in central positions than the largest, strongest and most experienced (thus, "should be more confident" in Rhine and Tilson, 1987 p. 120) individuals, the adult males. In fact, adult females and youngsters are more susceptible to attacks or separation from the group due to their body size, strength and, concerning juveniles, their inexperience. Then, the adult males could travel in front and rear positions under most circumstances. 
In addition, I tested whether the order of individuals in a progressing party correspond to the multilevel social organization. As for group departures, I expected that unit members continue to travel cohesively after departing. I then considered that, in olive baboons, more central spatial positions are occupied by the individuals that maintain cohesion with a larger number of group members (Farine et al., 2017). I also considered two expectations regarding the order of progression: (i) adult males at the edges and females and young ones more central in the progressing group and (ii) members of the same unit spatially cohesive. In case the results confirmed these predictions, I also predicted a difference in the positioning patterns between adult males. Non-primary males should take front or rear positions. Primary males could either take front or rear positions with the other adult males, or they could travel in central positions close to the females and young ones of their units. Therefore, I assumed non-primary males would move at the extreme front and rear positions of the party, whereas I assumed primary males would move in more central positions, closer to their affiliated unit members. 


\section{Materials and methods}

\subsection{Field site}

The fieldwork was conducted in the surroundings of the field station "Centre de Recherche de

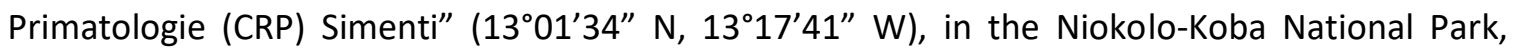
south-eastern Senegal (Figure 2.1.a). The park covers around $9.130 \mathrm{~km}^{2}$, from $16 \mathrm{~m}$ to $311 \mathrm{~m}$ of altitude. A highly seasonal climate characterizes the region. Most of the rainfall occurs during a single rainy season, from June until October (from 800 to $1100 \mathrm{~mm}$ per year: Madsen et al., 1996; Mbow et al., 2004). The annual mean temperature varies around $30^{\circ} \mathrm{C}$ and maximum temperatures peak over $45^{\circ} \mathrm{C}$. The site comprises different vegetation types. The banks of the Gambia River are dominated by dense gallery forests limiting visibility to a few meters. Close to the river, several flood plains constitute the "mares", which are seasonally flooded grasslands surrounded by riparian vegetation. The vegetation changes as the distance from water sources increases: from gallery forest to large areas of dry deciduous woodlands and different types of savanna. Visibility is good in open areas, especially during the dry season. Around Simenti, Guinea baboons live sympatrically with other four primate species: Senegal bushbabies (Galago senegalensis), West African green monkeys (Chlorocebus sabaeus), Temminck's red colobus (Piliocolobus temminckii), and patas monkeys (Erythrocebus patas). Several potential predators inhabit the area despite a decrease in their population sizes during recent decades: lions (Panthera leo), leopards (Panthera pardus), African wild dogs (Lycaon pictus), spotted hyenas (Crocuta crocuta) and West African crocodiles (Crocodylus suchus) (Di Silvestre et al., 2000; Kane, 2014; Ndao and Henschel, 2011). 


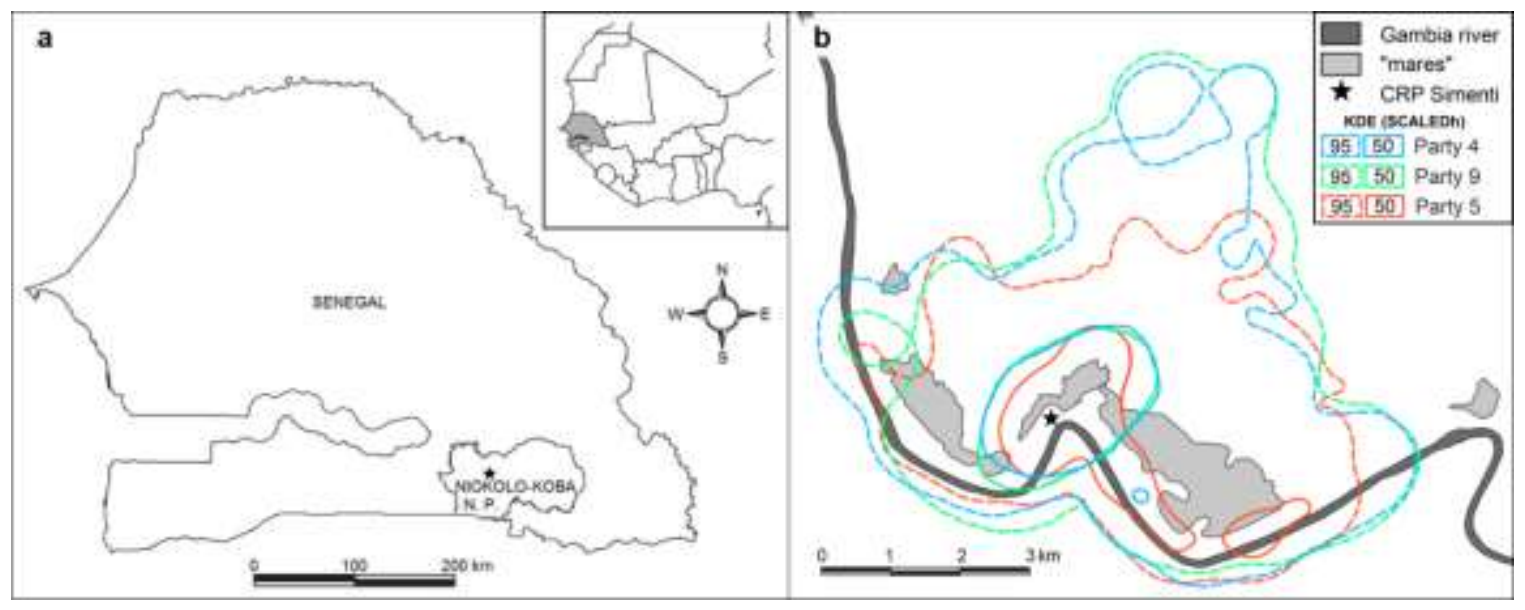

Figure 2.1. a) The location of the field site CRP Simenti, marked as a star inside the Niokolo-Koba National Park, in Senegal. b) Home ranges of three study parties in 2013 (fixed 95\% and 50\% kernel density estimations, from Klapproth et al., in prep).

\subsection{Study subjects}

The community of Guinea baboons around CRP Simenti comprises more than 400 individuals, including gangs varying in the degree of tolerance to human presence. The study subjects were fully habituated baboons belonging to five parties, forming two gangs (Table 2.1.). Baboons could be approached at very close distance, up to $1 \mathrm{~m}$ or less, and they were individually identified using body features. However, the identification of young weaned individuals (i.e. small, medium and large juveniles) was not always possible, due to their rapidly changing body features and independence from adults. The home ranges of the parties covered on average $30.3 \mathrm{~km}^{2}$ of largely overlapping territories (Kernel density estimations 95\%, from Klapproth et al., in prep; Figure 2.1.b). 
Table 2.1. Composition of study groups. Party sizes (i.e. total number of party members) varied due to births, deaths, disappearances, between-parties transfers of individuals and difficulties in recognizing young weaned individuals.

\begin{tabular}{|c|c|c|c|c|c|}
\hline \multirow{2}{*}{$\begin{array}{l}\text { Gang } \\
\text { "Mare" }\end{array}$} & \multirow{2}{*}{$\begin{array}{l}\text { Party } \\
\text { "4" }\end{array}$} & \multirow{2}{*}{$\frac{\text { Number of units }}{2-3}$} & \multicolumn{2}{|c|}{ Number of adults } & \multirow{2}{*}{$\begin{array}{r}\text { Size } \\
15\end{array}$} \\
\hline & & & $5 \sigma^{\lambda}$ & $3 q$ & \\
\hline & “9" & $5-6$ & $12 \hat{0}$ & $17 \stackrel{+}{+}$ & 45 \\
\hline & “10” & $1-2$ & $2 \sigma^{\lambda}$ & 2 ㅇ & 8 \\
\hline \multirow[t]{2}{*}{ "Simenti" } & $" 5 "$ & $3-4$ & $10 \overbrace{}^{\lambda}$ & 9 ㅇ & 25 \\
\hline & "6" & $4-5$ & 12 ठิ & $11 q$ & 38 \\
\hline
\end{tabular}

\subsection{Data collection}

Data collection was conducted from January to August, in 2016 and 2017, for a total of 16 months, 6 days per week. Observation days started before sunrise (at 6:00 or 6:30) to try to locate the baboons at the sleeping site. The selected party of baboons was located by means of VHF radio transmitter collars, attached to 1 to 3 adult males per party. The baboon sleeping sites always consisted of few tall neighbouring trees, often in densely vegetated areas (e.g., gallery forest). The location of the sleeping site changed almost every night within the home range of the party. After encountering the baboons, behavioural observations lasted until 14:00, allowing a good guess on the whereabouts of the baboons the following morning.

\subsubsection{Long-term data}

This study is part of the only long-term research project on wild Guinea baboons. Every day, all researchers working at CRP Simenti collect census, rare event, social event, ad libitum, scan and $20 \mathrm{~min}$ focal follows data and faecal samples of the baboons. These data are used to investigate the demography, reproductive success, association data, behavioural patterns and more (Altmann, 1974). I followed such general data collection protocol. Data were recorded on Samsung Note 3 handhelds through installed electronic forms, created using Pendragon 7.2 software (Pendragon Software Corporation, USA). I integrated the female-male association from these general data into my project. This information was then validated analysing focal follows and ad libitum data on copulations, grooming bouts, contact-sit bouts and aggressions. Since primary male status was determined by the preferential interactions of adult females with the 
respective male (Goffe et al., 2016), the female-male associations allowed to determine male status (primary or other) and unit composition on a daily basis.

\subsubsection{Group movement data}

I collected additional data on group movement with the all-occurrence sampling method (Altmann, 1974). Two types of events were distinguished during the group movement process: group departures and group progressions (see below). The data collection of these events had priority over the collection of other data, which was instantly dropped if such events took place. During the data collection on group movements, the description of the individuals was founded on four characteristics: age, sex, unit identity and individual association.

$\neg$ age: individual age categories were based on a visual evaluation of body size, development of secondary sexual traits and tooth status. Categories: "infant", "yearling", "small juvenile", "medium juvenile", "large juvenile", "subadult", "young adult", "mature adult", "old adult". The broader term "adult" individual refers to subadults, young adults, mature adults and old adults, and "young" individual refers to infants, yearlings, small juveniles, medium juveniles and large juveniles.

$\neg$ sex: male or female.

$\neg$ unit identity: it is the ID of the unit which an individual belongs to. All members of the same unit were labelled with a unit ID, which name corresponds to the name of the unit primary male. Non-primary adult males (i.e. secondary and unaffiliated ones) and young individuals which could not be unambiguously identified as members of one unit were labelled by their own IDs. Unit identity allows analyses on the cohesiveness of unit members within the moving party.

$\neg$ individual association: this trait includes the delineation of non-primary males (individual association = "1") and primary males (individual association > " 1 ") and the delineation of unit members as members of units with increasing number of females. "1" = non-primary adult males, " 2 " = primary males, adult females and young individuals belonging to a unit comprising one adult female, " 3 " to " 7 " = individuals belonging to a unit comprising two to six adult females. 


\subsubsection{Operational definition of group departure}

A group departure occurred when a group of baboons was collectively leaving a confined area where they had been stationary for a set time. Most of the previous studies on baboon group departures were conducted on morning departures from sleeping sites, because the baboons slept almost every day in the same site, most often an open area as a cliff or a plateau (e.g., Kummer, 1968a; Byrne et al., 1990; Stueckle and Zinner, 2008; King et al., 2011). Since the baboons of the study groups changed sleeping site almost on a daily basis and slept on tall trees, mainly in dense forests, regular observations of the morning departure of whole groups were not possible. Thus, I collected data on events of group departures throughout the day, whenever visibility allowed and certain a priori defined parameters were met.

The group had to consist of one or more complete units or a complete party, meaning that I excluded situations in which some members of the unit were inside the considered area and some others were outside. The confined area where the individuals stayed stationary before a group departure was named the pre-departure area. The pre-departure area was maximum $20 \mathrm{~m}$ in diameter. The individuals had to be isolated from conspecifics outside the area for at least $20 \mathrm{~m}$, to avoid potential influences on individual movements by proximate baboons not considered in the departure event. The measure of $20 \mathrm{~m}$ was chosen considering five elements. First, analogous studies on other primates used comparable distances: $10 \mathrm{~m}$ with white-faced capuchins (Leca et al., 2003), $10 \mathrm{~m}$ with Tonkean and rhesus macaques (Sueur and Petit, 2008a, 2008b), $15 \mathrm{~m}$ in red-fronted lemurs (Pyritz et al., 2011a), 11 and $18 \mathrm{~m}$ with Barbary macaques (Seltmann et al., 2013). Second, body size of Guinea baboons is larger than the mentioned species, which justifies an increment of the measure. Third, the measure had to allow the observer's visibility on all individuals in the pre-departure area in the most common conditions. Fourth, generally, when the individual was not considerably changing activity, it was moving only up to $10 \mathrm{~m}$, whereas when it was changing location and/or activity, it was moving more than $20 \mathrm{~m}$. Fifth, the spatial association patterns of adult males of the same party were frequently within $20 \mathrm{~m}$, whereas those not of the same party were rarely within $20 \mathrm{~m}$ (Patzelt et al., 2014). The individuals had to stay stationary, either feeding, resting, or socializing in the predeparture area for at least 15 minutes, to ensure a certain degree of independence in timing and direction from the previous movement that brought the individuals to that pre-departure area (comparably to e.g., Leca et al., 2003; Sueur and Petit, 2008a, 2008b; Pyritz et al., 2011a; 
Seltmann et al., 2013). I excluded movements prompted by predation risks, alarm calls or social interactions such as threats or chases (Figure 2.2).

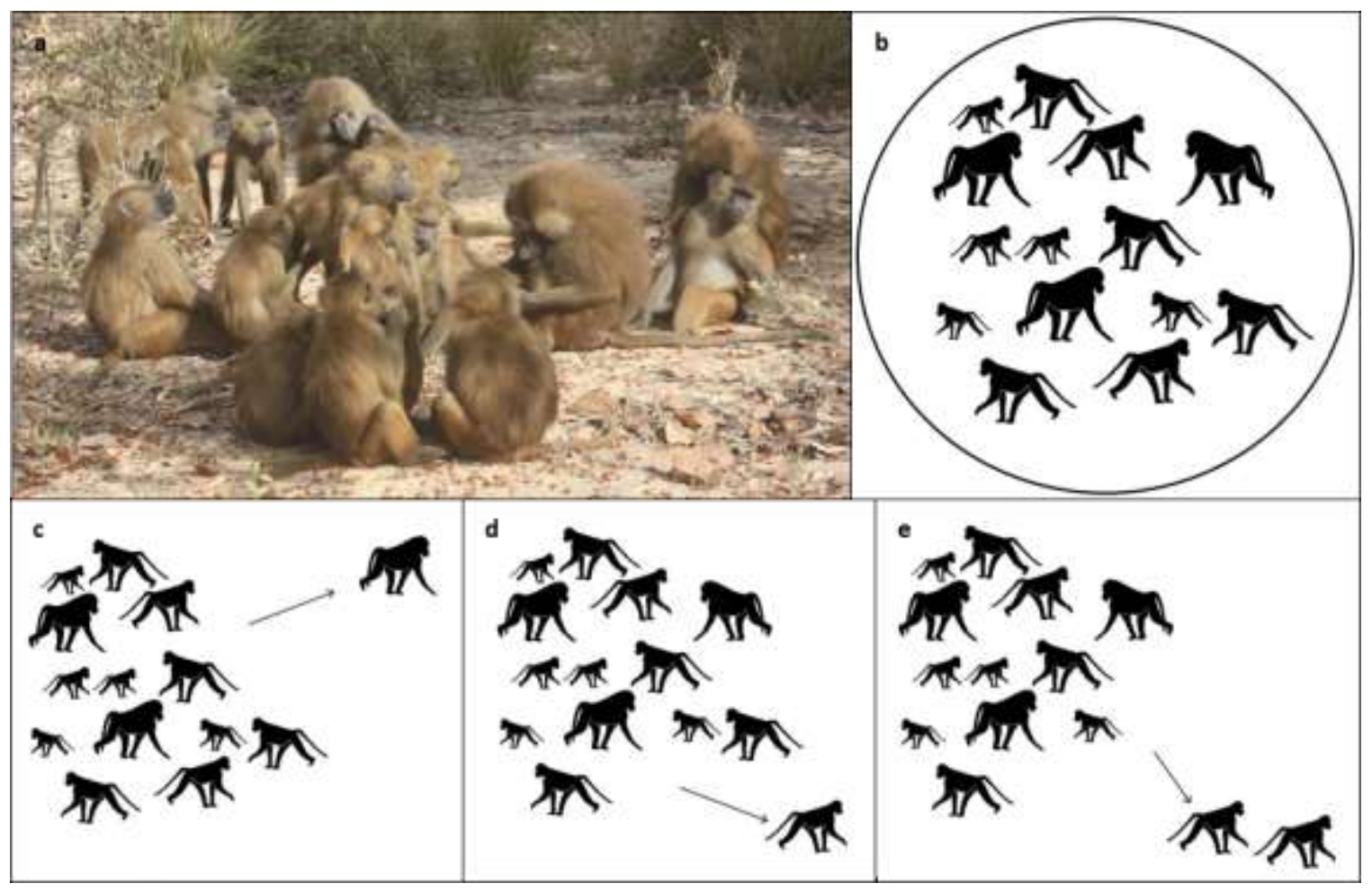

Figure 2.2. Example of a group departure. a) Baboons in a pre-departure area (photo by $M$. Klapproth). b) Schematic depiction of a pre-departure area (diameter of the circle $\leq 20 \mathrm{~m}$ ). c) First attempt of initiation of group departure. One individual leaves the area. If no-one follows, the attempt is unsuccessful. d) Second attempt. One individual leaves the area. e) Other individuals follow the one that attempted. If all individuals follow, the attempt is successful.

\subsection{Order of departure}

When the parameters mentioned above were met, I voice recorded the identity of all individuals moving away from the pre-departure area and the starting time and the direction of their movements. The first individual leaving the area was defined as attempting an initiation of group departure. The individuals moving away from the pre-departure area in the same direction of another one, within a 5-minute interval time, were considered followers. Yet, when an individual was directed more than $45^{\circ}$ left or right from the direction chosen by the previous individual and/or was starting to move away more than 5 minutes after the previous individuals, it was coded as attempting another initiation of group departure. Therefore, the initiation 
attempt could be successful, when all individuals in the pre-departure area followed it, or not. All individuals of the subject group were hence classified as successful initiators, unsuccessful initiators or followers. Unsuccessful initiators were consecutively coded either as followers, successful initiator or, again, unsuccessful initiators on the following initiation attempt. Coding two successful initiators in one event implied group fission.

\subsection{Communicative means}

Data collection focused also on the occurrence of specific individual behaviours addressed in previous studies as signals to maintain cohesion and coordinate the group (e.g., Kummer, 1968a, 1995; Stewart and Harcourt, 1994; Sueur and Petit, 2010; Seltmann et al., 2013). The following behaviours were recorded when performed by the individual attempting an initiation and/or by other individuals of the subject group:

$\neg$ Back glance: once the individual has started to move away from the pre-departure area and it looks back in the direction of other group members. Empirically defined as the turn of the head of more than $90^{\circ}$ towards the direction of the pre-departure area.

$\neg$ Branch shaking display: rapid repeated bouncing in place while the individual stands quadrupedal grasping a flexible branch, shaking it (Mehlman, 1996).

$\neg$ Greeting: "exchange of non-aggressive signals that consist of species-specific behavioural patterns, $[\ldots]$ ranging from touches and embraces to genital manipulation and same-sex mounts" (Dal Pesco and Fischer, 2018, p. 88).

$\neg$ Pause: once the individual has started to move away from the pre-departure area and it stops moving for more than 2 seconds within the first 20 meters of movement.

$\neg$ Vocalizations: individual call, classified per type: keck, grunt, roar grunt, scream, bark, wahoo (Maciej, 2013; Fischer et al., 2017).

\subsubsection{Operational definition of group progression}

A group of baboons travels between locations mostly moving on the ground. The movement could be a directed movement in a definable direction or a more disperse and slower movement often combined to a feeding activity. A group progression occurred when all individuals of one or more complete parties were positioned in an approximate single file and jointly moving in a definable direction. Single-file travel progressions occur along both delimited pathways, as roads (Figure 2.3.), and extensive open areas. As for group departures, I collected data on events of 
group progressions throughout the day, whenever visibility allowed and certain a priori defined parameters were met. The progressing group had to consist of one or more complete parties. The data had to be collected at least 30 minutes after the end of a previous event of group progression, to guarantee independence of individual positions between consecutive events.

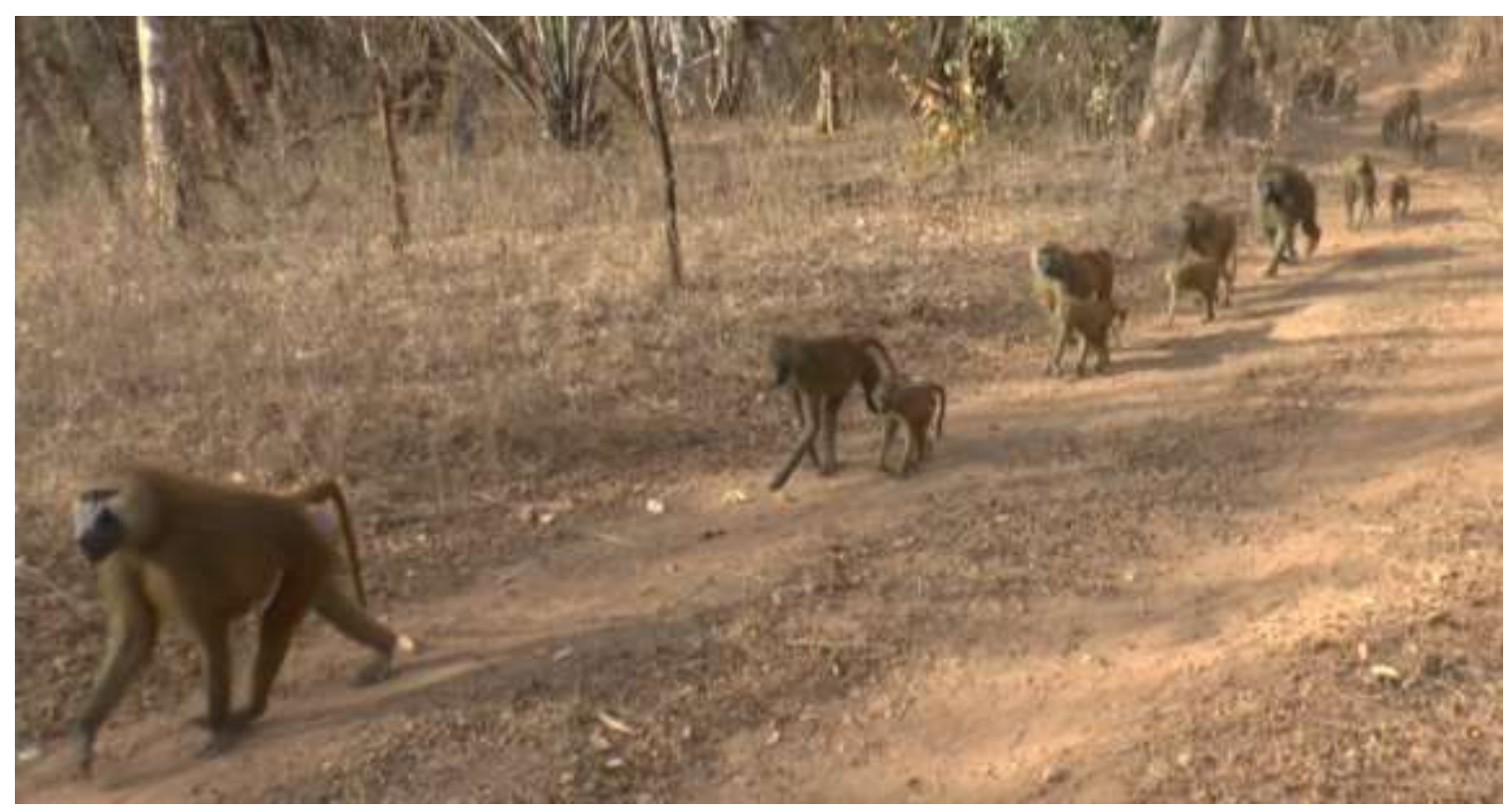

Figure 2.3. Example of a group progression. One of the study parties is passing the check point in single-file.

\subsection{Order of progression}

When the parameters mentioned above were met, I advanced a few meters in front of the moving group, stopped and set a visual reference on the landscape in front of the coming group (check point). When each baboon crossed this point, I voice recorded its identity and time of crossing.

\subsection{Data analyses}

All models and plots were fitted in R (version 3.5.0; R Core Team, 2018), using RStudio interface (version 1.1.383; RStudio Team, 2016). The only exception concerns the representation of posterior probability distributions of the order of group progression. These plots were created with MATLAB (version 9.4; The MathWorks, Inc., 2018). 


\subsubsection{Group departures}

\subsubsection{Initiation attempts}

I first tested whether the likelihood of attempting an initiation of group departure was influenced by sex, age and/or individual association. To do this, I ran a Generalized Linear Mixed Model (GLMM; Baayen, 2008) with a binomial response variable and logit link function. Sex, age and individual association were included as fixed effects, individual identity and event as random effects (both random intercept components) and time of the day as a polynomial predictor variable. To prevent any scaling issue, I applied a z-transformation on the time of the day. I used the function glmer provided by the R package Ime4 (version 1.1-17; Bates et al., 2015), setting the optimizer to 'bobyqa' to prevent convergence issues. To test if the full model fits better than a simpler alternative with a likelihood ratio test (Dobson, 2002), I compared the deviance of the full model with the deviance of the model containing only the random effects and the time. The $p$-values for the distinct effects were derived comparing the full model with the model reduced of the predictor of interest, using the function drop1, argument 'test' set to "Chisq". To get the confidence intervals for the different regression coefficients, I used a bootstrap procedure using the function bootMer provided by Ime4 (nboots $=1000$ ). In a second step, with the same procedure, I tested whether the same set of independent variables was affecting the success of the initiation attempts.

\subsubsection{Interindividual interval times}

In order to approximate distances between individuals and to investigate the individual spatial association within the party, I calculated interval times between all dyads of individuals in each event comprising one or more parties. To test whether interval times were influenced by unit identity, I used a linear mixed model (LMM; Baayen, 2008) into which I included identical or different unit identity (i.e. individuals belong or not to the same unit) as fixed effect and individual identity for each one of both individuals of the pair as random effects. The model was fitted using the function Imer of the R package Ime4 (version 1.1-17; Bates et al., 2015).

I verified whether the assumptions of normally distributed and homogeneous residuals were met by visually inspecting a qqplot and a plot of the residuals against the fitted values. Because the interval times were highly skewed, they were natural-log transformed. Only after the transformation, both plots indicated that the assumptions were met. I tested model stability by excluding subjects one by one from the dataset and comparing the model estimate outcomes 
of these subsets with those outcomes of the full dataset. This revealed no influential subjects. I checked the significance of the full model compared to the null model, obtained by dropping the fixed effect, with the R function anova (argument test "Chisq"; Dobson, 2002; Forstmeier and Schielzeth, 2011). The models were fitted using Maximum Likelihood, rather than Restricted Maximum Likelihood, to allow for a likelihood ratio test (Bolker et al., 2008). The p-value for the fixed effect was based on a likelihood ratio test comparing the full with the reduced model, with the function drop1, argument 'test' set to "Chisq" (Barr et al., 2013). Confidence intervals of the estimates were obtained with the function confint.merMod of R package Ime4.

\subsubsection{Group progressions}

\subsubsection{Order of progression}

I divided the sequence of individuals into equal thirds. This three-way partition allows testing the orders of group progressions found in the other studies, such as oldest or dominant individuals occupying front positions, or adult males taking place in the front and the back of the group. For the statistical comparison between observing an individual Guinea baboon moving in the front (first third), middle (second third) or rear (third third) section of a group progression, I used a multinomial Logit regression model, with a random intercept (Fahrmeir et al., 2013, Chapter 7.5.1., 7.6.2.). Progression-location were coded into three categories (front, middle and rear), with the probability of belonging to the category conditioned on explanatory information, namely age as a binomial factor: adult and young; and sex and individual association summarized in one variable with three terms: female, primary male, non-primary male ("f_pm_npm"). The model was estimated by means of Bayesian methods. Posterior densities of the regression coefficients were obtained from Markov-chain Monte Carlo (MCMC) procedures, using the R package MCMCgImm (Hadfield, 2010). From the resulting posterior samples of progression-location regression coefficients, the distribution of the relative frequency (i.e. a probability denoted with $\mathrm{p}$ ) to observe a progression-location $\mathrm{k}=1,2,3$, conditional on age = adult, was calculated as:

$$
\mathrm{P}_{s}(\text { progression }- \text { location }=k \mid \text { age }=\text { adult })=\frac{\exp \left(\hat{\beta}_{\text {adult }, k}\right)}{\sum_{j=1}^{3} \exp \left(\hat{\beta}_{\text {adult }, j}\right)}
$$

where adult is the reference category of the binary age factor, and as: 


$$
\mathrm{P}_{s}(\text { progression }- \text { location }=k \mid \text { age }=\text { young })=\frac{\exp \left(\hat{\beta}_{\text {adult }, k}+\hat{\beta}_{\text {young }, k}\right)}{\sum_{j=1}^{3} \exp \left(\hat{\beta}_{\text {adult }, j}+\hat{\beta}_{\text {young }, j}\right)^{\prime}}
$$

for age = young, where coefficient $\beta_{\text {young, }, k}$ is the coefficient for changing the age factor from adult to young.

Following the same procedure, the distribution of relative frequency to observe progression-location $\mathrm{k}=1,2,3$, conditional on $\mathrm{f} \_p m \_n p m=$ female, was calculated as:

$$
\mathrm{P}_{s}\left(\text { progression }- \text { location }=k \mid \mathrm{f} \_ \text {pm_npm }=\text { female }\right)=\frac{\exp \left(\hat{\beta}_{\text {female }, k}\right)}{\sum_{j=1}^{3} \exp \left(\hat{\beta}_{\text {female }, j}\right)},
$$

where female is the reference category of the f_pm_npm factor, and as:

$$
\mathrm{P}_{s}\left(\text { progression }- \text { location }=k \mid \mathrm{f} \_ \text {pm_npm }=\text { primary male }\right)=\frac{\exp \left(\hat{\beta}_{\text {female }, k}+\hat{\beta}_{\text {primary male }, k}\right)}{\sum_{j=1}^{3} \exp \left(\hat{\beta}_{\text {female }, j}+\hat{\beta}_{\text {primary male }, j}\right)^{\prime}}
$$

for $\mathrm{f} \_\mathrm{pm} \_\mathrm{npm}=$ primary male, where coefficient $\beta_{\text {primary male }, k}$ is the coefficient for changing the f_pm_npm factor from female to primary male, and as:

$\mathrm{P}_{s}\left(\right.$ progression - location $=k \mid \mathrm{f} \_\mathrm{pm} \_n \mathrm{~nm}=$ nonprimary male $)=\frac{\exp \left(\hat{\beta}_{\text {female }, k}+\hat{\beta}_{\text {nonprimary male }, k}\right)}{\sum_{j=1}^{3} \exp \left(\hat{\beta}_{\text {female }, j}+\hat{\beta}_{\text {nonprimary male }, j}\right)^{\prime}}$

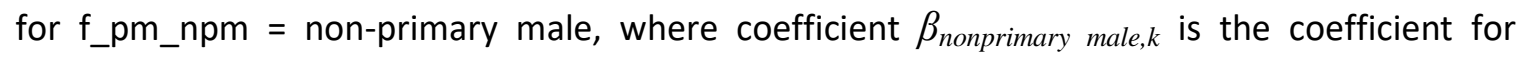
changing the f_pm_npm factor from female to non-primary male.

Index $s=1, \ldots, S$ denotes the sample from the posterior density. To ensure the identification of the model, one progression-location category $k \in\{1,2,3\}$ has to be selected as a reference category (Fahrmeir et al., 2013, Chapter 6), which I selected as front.

For the Bayesian model fitting algorithm, all prior distribution assumptions were kept unchanged with respect to default options (namely Gaussian and inverse Gamma priors). MCMC sampling from the posterior distribution was performed for 40000 iterations, with 15000 burnin iterations and a thinning by each 10th iteration. Therefore, the final posterior is based on 2,500 draws. I extracted posterior densities for the probability to belong to each third, for a 
given age and/or f_pm_npm class, and high posterior density intervals to further describe the effect of age and f_pm_npm on the probability to belong to a given progression-location category.

\subsubsection{Interindividual interval times}

Once more, I investigated the spatial association within the progressing party. To approximate distances between individuals, I extracted interval times between all dyads of individuals in each event of group progression. To test whether interval times were influenced by unit identity, I used the same procedure applied to the dataset of group departures (see content 2.4.1.2.).

\subsubsection{Primary and non-primary males at the edges}

In addition, I ran a post-hoc test to investigate whether non-primary males were occupying edge positions during group progressions compared to primary males. To do this, I divided the sequence of individuals of the front third and the one of the rear third in two equal parts. I ran a GLMM with a binomial response variable and logit link function. I used the function glmer provided by the R package Ime4 (version 1.1-17; Bates et al., 2015). f_pm_npm was introduced as one fixed effect with three terms: female, primary male, non-primary male. Individual identity was included as a random effect. Model diagnostics were performed by creating scaled residuals through simulations from the fitted model with the function simulateResiduals (number of simulations: 1000), provided by the R package DHARMa (version 0.2.0; Hartig, 2017), and by plotting the residuals against the predicted response from the model, using the function plotSimulatedResiduals, provided by the R package DHARMa. The plot permits to detect deviations from uniformity in $\mathrm{y}$-axis direction and performs a quantile regression, which provides $0.25,0.5$ and 0.75 quantile lines across the plots. $P$ values for the individual effects

were based on likelihood ratio tests comparing the full with the respective reduced models ( $R$ function drop1, Barr et al., 2013). 


\section{Results}

\subsection{Group departures}

I collected data in 121 events of group departure. The events involved a total of approximately 1776 participants, either initiators or followers (in 2 events I could individualize only the first 10 and 29 departing baboons, not the whole departing group). The level of social organization taken as subject of data collection varied among events: 33 events involved only 1 complete unit, 48 events involved more than 1 complete unit, and 40 events involved 1 complete party ( 3 of them more than 1 party).

\subsubsection{Initiation attempts}

In total I sampled 146 attempts of group departure: 52 (35.6\%) conducted by adult females, 91 (62.3\%) by adult males and $3(2.1 \%)$ by juveniles. Twenty-three attempts of initiation were not successful (15.8\%) (Table 3.1.). In 2 events, the individuals in the departure area split during group departure, after two successful initiation attempts within the same event. The identity of the attempting individuals varied greatly across the events. Fifty-eight different individuals attempted to initiate a group departure: 28 adult males, 27 adult females and 3 juveniles. The individual that attempted the most was a primary male, 11 times, followed by another primary male, attempting 7 times, and other 4 primary males and 1 non-primary male, attempting 6 times each. The 2 females that attempted the most did it 5 and 4 times each.

Table 3.1. The number of initiation attempts according to the level of social organization taken as subject of data collection and the sex and the age of the individual attempting to initiate.

\begin{tabular}{lcccc}
\hline departing subject & initiation & adult female & adult male & young \\
\hline one unit & successful & 15 & 16 & 2 \\
& unsuccessful & 4 & 1 & 0 \\
more units & successful & 18 & 32 & 0 \\
\multirow{2}{*}{ party } & unsuccessful & 2 & 6 & 1 \\
& successful & 9 & 31 & 0 \\
\hline
\end{tabular}


Overall, the predictors, age, sex and/or individual association, had a clear impact on the probability of attempting an initiation of group departure (likelihood ratio test comparing full and null model: $\left.\chi^{2}=71.882, \mathrm{df}=6, \mathrm{P}<0.001\right)$. More precisely, I found that being a male and being an adult strongly increased the likelihood of attempting an initiation. There was no significant difference between adult age categories with regard to the frequency with which baboons attempt initiations of group departure (Table 3.2., Figure 3.1.). Estimated variance components for the random effects were: individual identity $=0.048$, and event $=0.000$.

Table 3.2. Summary of model results. Estimated coefficients of the effect of the predictors on the likelihood of attempting an initiation of group departure, from GLMM.

\begin{tabular}{lccccccc} 
& Estimate & Std. Error & $\mathrm{Cl}_{\text {lower }}$ & $\mathrm{Cl}_{\text {upper }}$ & $\chi^{2}$ & Df & $\mathrm{P}$ \\
\hline Intercept & -2.533 & 0.365 & -3.334 & -1.816 & $(1)$ & $(1)$ & $(1)$ \\
sex Male & 1.082 & 0.229 & 0.674 & 1.563 & 15.878 & 1 & $<0.001$ \\
age Old adult & 0.255 & 0.309 & -0.468 & 0.826 & $66.818^{(2)}$ & 4 & $<0.001^{(2)}$ \\
age Subadult & -0.029 & 0.313 & -0.785 & 0.588 & $(2)$ & & (2) \\
age Young adult & -0.224 & 0.252 & -0.763 & 0.231 & (2) & & (2) \\
age Young & -3.630 & 0.725 & -4.555 & -2.604 & (2) & (2) \\
ind. association & 0.036 & 0.078 & -0.130 & 0.188 & 0.207 & 1 & 0.648 \\
z.time & 0.099 & 0.101 & -0.115 & 0.352 & (1) & (1) & (1) \\
I(z.time^2) & -0.053 & 0.063 & -0.239 & 0.050 & 0.770 & 1 & 0.381 \\
\hline (1)
\end{tabular}

${ }^{(1)}$ not shown because of having a very limited interpretation; ${ }^{(2)}$ equal values because they refer to different terms of the same variable 


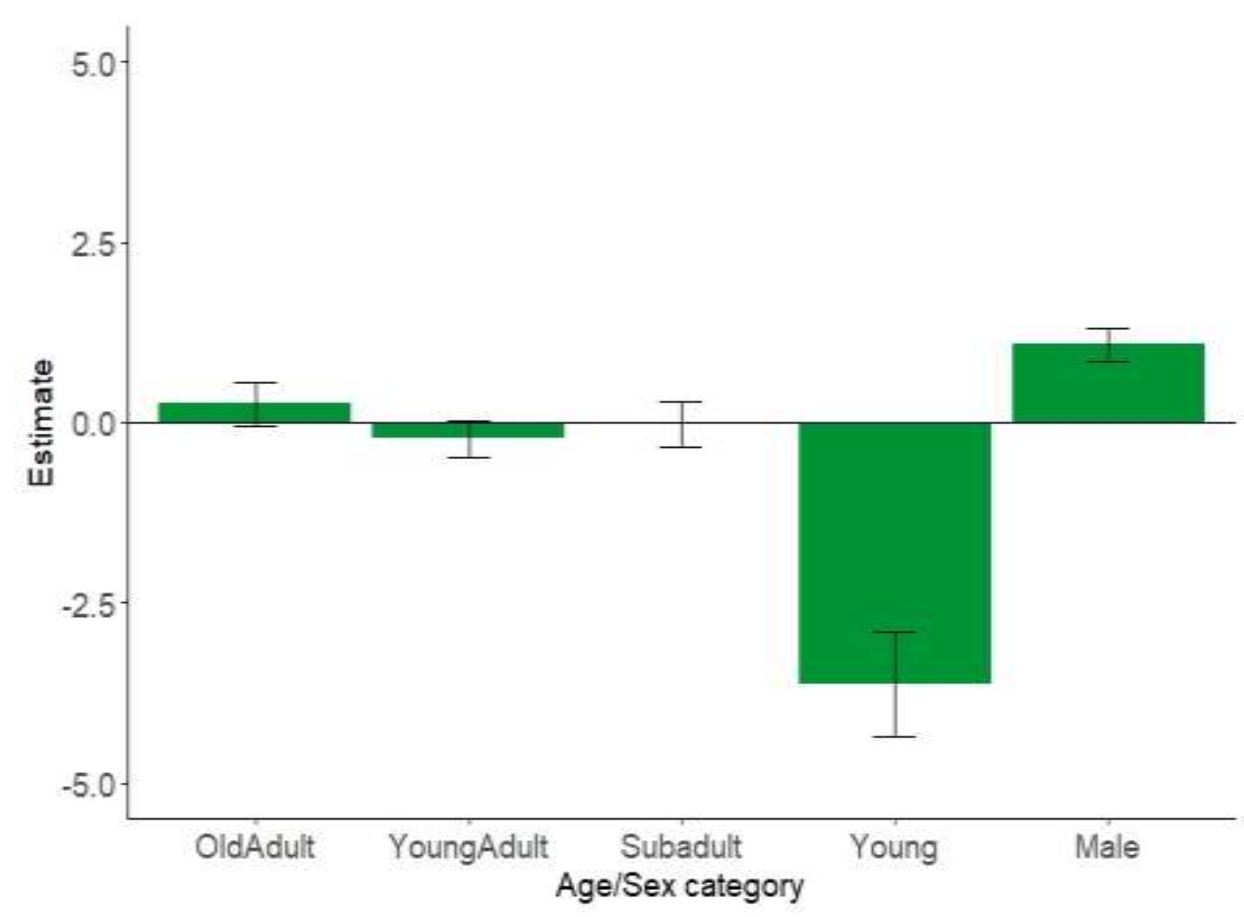

Figure 3.1. Estimates of the predictors age and sex on the likelihood of attempting an initiation of group departure, from GLMM (reference category being "mature adult" and "female").

Subsequently, I created a dataset with the individuals attempting an initiation of group departure. I excluded the attempts made by young individuals, to avoid convergence issues due to the low value of age category "young" ( 3 attempts) compared to the other age categories ( subadult $=19$, young adult $=29$, mature adult $=77$, old adult $=18$ ). Between the 52 attempts of initiation by adult females, 42 of them (80.8\%) were successful, while, between the 91 attempts of adult males, 79 of them (86.8\%) were successful. Once failed, an individual that attempted to initiate tried again only 2 times on 23 occurrences of unsuccessful attempts. The comparison of the full and null model revealed that the predictors, age, sex and/or individual association do not explain the success of an attempt of initiation of group departure (likelihood ratio test: $\chi^{2}=$ 3.309, $d f=5, P=0.653)$.

\subsubsection{Interindividual interval times}

From the dataset on 121 events of group departure, I then considered only the 40 events involving one complete party or more. I calculated the interval times between all dyads of individuals within event: 7814 dyads in total. Overall the full model was significantly different from the null model (likelihood ratio test: $\chi^{2}=172.81, d f=1, P<0.001$ ). Specifically, the interval 
time between two individuals belonging to the same unit was significantly shorter than the interval time between two individuals not belonging to the same unit (Table 3.3., Figure 3.2.). Estimated variance components for the random effects were: individual one identity $=0.138$, and individual two identity $=0.023$.

Table 3.3. Summary of model results. Estimated coefficients of the effect of belonging to the same unit on the interval times between dyads of individuals within event of group departure, from LMM.

\begin{tabular}{lccccccc} 
& Estimate & Std. Error & $\mathrm{Cl}_{\text {lower }}$ & $\mathrm{Cl}_{\text {upper }}$ & $\chi^{2}$ & $\mathrm{Df}$ & $\mathrm{P}$ \\
\hline Intercept & 5.152 & 0.050 & 5.049 & 5.252 & $(1)$ & (1) & (1) \\
belonging to same unit & -0.551 & 0.042 & -0.632 & -0.469 & -13.24 & 7690.287 & $<0.001$ \\
\hline \multicolumn{2}{ll}{ not shown because of having a very limited interpretation } & & &
\end{tabular}

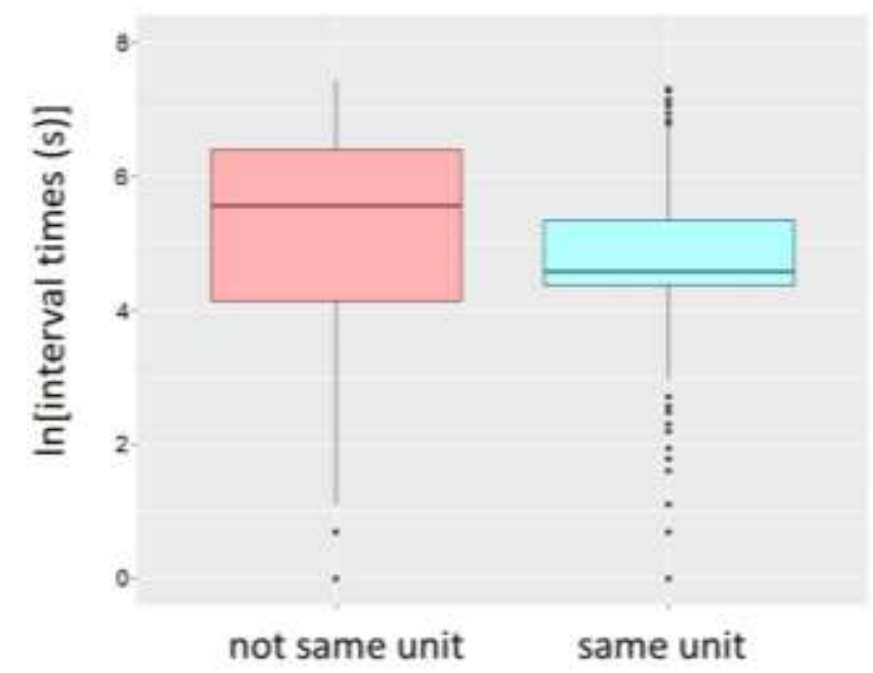

Figure 3.2. Interval times of dyads in events of group departure. Individuals not belonging to the same unit are compared to those belonging to the same unit.

\subsubsection{Communicative means}

In the 121 departure events, I observed the considered behaviours in 96 events, performed by 327 participants on, approximately, 1776 participants. Among the 146 initiation attempts, 84 baboons that were attempting to initiate a group departure performed at least 1 of the behaviours of interest. 
Back glances were performed by 44 individuals while departing in 34 events: 17 adult females, 22 adult males, 5 juveniles. Among the individuals which attempted to initiate, 23 displayed back glances and 19 were successful (82.6\%).

I also observed 70 branch shaking displays, across 38 group departure events. Considering that branch displaying can be performed only when the respective individual is in a tree, I divided the events according to the number of individuals in a tree or on the ground before the departure event. In 54 departure events, at least one adult individual was in a tree before departure. During 33 events of these 54 (61.1\%), at least one individual branch displayed. In the other 67 events (of 121), all baboons involved in the group departure were on the ground. In 5 of these 67 departures, 1 or 2 adult males climbed a tree and displayed, before leaving the area. The individuals displaying were 64 adult males, 3 adult females, 2 middle juvenile males, and 1 small juvenile female. In 24 events, the individual attempted branch display and was successful 19 times (79.2\%). In 21 events, the first adult male to depart branch displayed.

Forty-six individuals greeted another individual during 28 group departure events: 18 adult females, 26 adult males, 2 juveniles. Eighteen greetings were performed by the individual attempting an initiation and it was successful 16 times (88.9\%).

Two hundred and one individuals paused during the first $20 \mathrm{~m}$ of walk of departure, in 57 events: 90 adult females, 63 adult males, 48 juveniles. Fifty individuals which attempted an initiation of group departure paused and 40 of them were successful (80.0\%).

In 52 group departure events, 96 individuals vocalized while departing: 34 adult females, 52 adult males, 10 young individuals. In 33 events, the individuals that attempted an initiation, vocalized and 28 of them were successful (84.8\%). The vocalizations were 61 times "grunts", 22 times "roar grunts" (accompanying a branch display), 8 times "wahoos", twice a "keck" (by two females attempting an initiation and passing by their primary males) and once a "bark" (Table 3.4.). 
Table 3.4. The total number of individuals performing the respective behaviour across group departure events. The total number is differentiated per age/sex classes. "Initiation att." shows the number of individuals performing that behaviour while attempting to initiate a group departure, whereas "successful att." indicates the number of individuals performing that behaviour during a successful attempt of initiation of group departure.

\begin{tabular}{lcccccc}
\cline { 2 - 7 } & total & adult female & adult males & young & initiation att. & successful att. \\
\hline back glance & 44 & 17 & 22 & 5 & 23 & 19 \\
branch display & 70 & 3 & 64 & 3 & 24 & 19 \\
greeting & 46 & 18 & 26 & 2 & 18 & 16 \\
pause & 201 & 90 & 63 & 48 & 50 & 40 \\
vocalization & 96 & 34 & 52 & 10 & 33 & 28 \\
\hline
\end{tabular}

\subsubsection{Anecdotal reports}

As mentioned, the baboons of the study groups changed their sleeping sites almost on a daily basis. Often baboons chose to sleep in the dense gallery forest on the riverbanks or along the borders of a mare. Sometimes, they chose less densely vegetated areas, farther away from water sources. On two days, I found party 5 at sunrise in one specific sleeping area. The situation did not match my criteria for data collection because the baboons were spread over an area with a diameter larger than $20 \mathrm{~m}$. Members of different units slept in different trees. However, the area was open enough to allow visual monitoring of all party members. On both days, a very similar series of events took place. Each reproductive unit slept in a different tree from the others. The units descended from the trees a few minutes after sunrise and spent approximately $30 \mathrm{~min}$ at the base of the respective sleeping trees, resting, grooming or playing. During this period, few individuals (e.g., an adult female, or a non-primary male) moved 30-50 m away from the sleeping trees, without eliciting any reaction from the other individuals. All of a sudden, one of the four primary males of the party (the same one on both occasions) stood up and started to walk towards the location of another reproductive unit, leaving his unit members. After approximately $30 \mathrm{~m}$, he approached another primary male (this individual changed between the two events), which, meanwhile, moved a few meters towards the approaching male. They both grunted and mutually greeted each other with penis diddles. After greeting, the first primary male turned $180^{\circ}$, heading back to the starting point, he passed by his unit members grunting and continued walking (Figure 3.3.). When he was 2-3 $\mathrm{m}$ away from the other 
unit members, his affiliated females, their offspring and one non-primary male followed him, and all other party members did the same, shortly after.
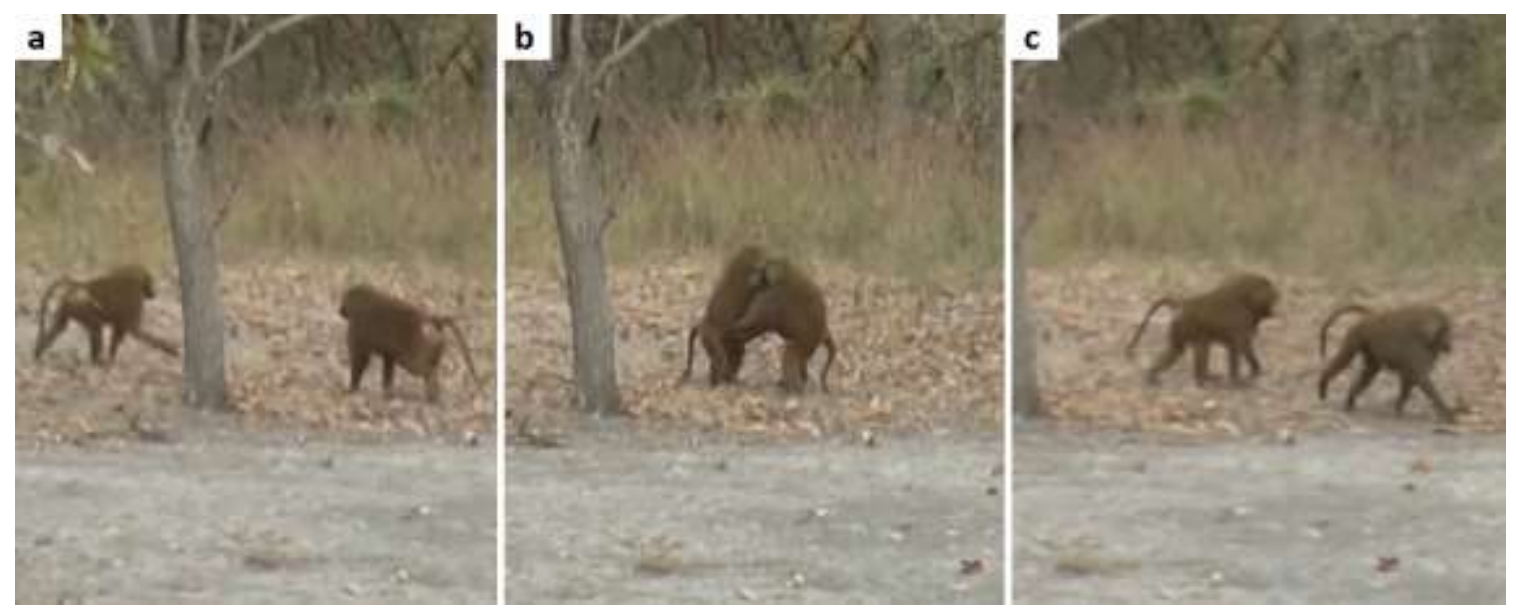

Figure 3.3. Greeting captured during one of the two episodes reported. a) Both adult males are approaching each other. b) Male-male ritualized greeting interaction: mutual penis diddle. c) The male on the right turns $180^{\circ}$ and walks away followed by the male on the left.

\subsection{Group progressions}

I collected data on 100 events of group progression. Seventeen events involved more than one party. Party 4 and party 10 were the smallest parties and they were included in the data collection only when joining other parties. The number of events in which these parties were involved was very low (party 4: 7 events, party 10:6) compared to those in which party 5, 6 and 9 were involved (party 5: 47 events, party 6: 27, party 9: 37). Therefore, I excluded the individuals belonging to party 4 and 10 from the analyses, to make them comparable between parties. Eleven events involved portions of a party (party 9 for 10 times, party 5 one time) and, in 6 of them, the progressing group consisted of only 2 units.

\subsubsection{Order of progression}

To a visual inspection of the data sampled, every individual appeared capable of occasionally occupying all positions of the progression order. However, the order of progression was not random. Among all events, the first individual was an adult male 86 times, an adult female 9 times and a young individual 5 times. The last individual was an adult male 53 times, an adult female 25 times and a young individual 22 times. In 4 of the 6 events involving only two units, 
the 2 primary males were the first and last individual of the order. Overall, the model outcomes revealed that age explains at least part of the positioning of individuals during group progressions (i.e. 95\% posterior density intervals do not include 0; Table 3.5.).

Table 3.5. Summary of model results. The effect of age (adult; young) on the likelihood for an individual to take front, middle or rear positions during a group progression. Reference category front and adult.

\begin{tabular}{lccccc} 
& Posterior mean & $\mathrm{Cl}_{\text {lower }}$ & $\mathrm{Cl}_{\text {upper }}$ & effective sample size & $\mathrm{P} \mathrm{MCMC}$ \\
\hline middle and adult & -0.338 & -0.526 & -0.141 & 538.0 & $<0.001$ \\
rear and adult & -0.247 & -0.436 & -0.054 & 574.7 & 0.001 \\
middle and young & 0.542 & 0.177 & 0.886 & 648.9 & 0.004 \\
rear and young & 0.430 & 0.085 & 0.759 & 801.0 & 0.016 \\
\hline
\end{tabular}

From the resulting posterior samples of progression-location regression coefficients (column "Posterior mean"), the distribution of relative frequency (i.e. estimated probabilities, Table 3.6.), was calculated following the formulas explained in Methods, content 2.4.2. For example:

probability for an adult to progress in the front

$$
\frac{\exp \left(\hat{\beta}_{\text {adult }, k}\right)}{\sum_{j=1}^{3} \exp \left(\hat{\beta}_{\text {adult }, j}\right)}=\frac{1}{(1+\exp (-0.338)+\exp (-0.247))}=0.401
$$

or, probability for a young individual to progress in the back

$$
\frac{\exp \left(\hat{\beta}_{\text {adult }, k}+\hat{\beta}_{\text {young }, k}\right)}{\sum_{j=1}^{3} \exp \left(\hat{\beta}_{\text {adult }, j}+\hat{\beta}_{\text {young }, j}\right)}=\frac{\exp (-0.247)+\exp (0.430))}{(1+\exp (-0.338+0.542)+\exp (-0.247+0.430))}=0.350
$$

Adults were located definitely more in front positions than middle or rear. It was also more likely to find adults in rear positions than in the middle of the group. Young individuals were clearly less likely to take front positions compared to the other two categories (Figure 3.4.). 
Table 3.6. Estimated probabilities to progress in the front middle or rear positions of the file, according to age.

\begin{tabular}{lccc}
\cline { 2 - 4 } & front & middle & rear \\
\hline adult & 0.401 & 0.286 & 0.313 \\
young & 0.292 & 0.358 & 0.350 \\
\hline
\end{tabular}
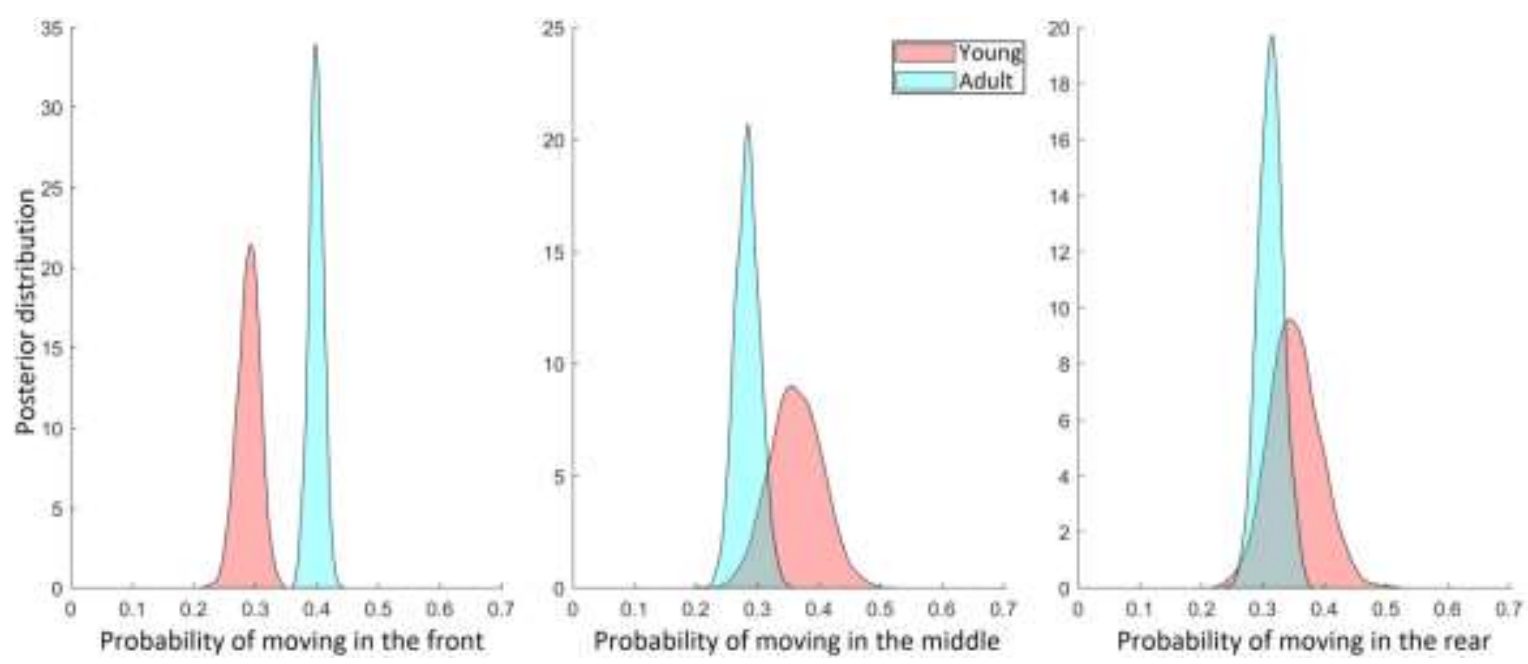

Figure 3.4. Posterior probability distributions to progress in front, middle or rear positions according to age.

I then considered only adult individuals for testing the effect of being a female, a primary male or a non-primary male (f_pm_npm) on the position taken by individuals during group progressions. Following the same procedure, the model results revealed that also sex and the distinction between primary and non-primary males explain variability in the order of group progression (Table 3.7). 
Table 3.7. Summary of model results. The effect of being a female, a primary male or a nonprimary male on the likelihood for an individual to take front, middle or rear positions during a group progression. Reference category front third and female.

\begin{tabular}{lccccc} 
& Posterior mean & $\mathrm{Cl}_{\text {lower }}$ & $\mathrm{Cl}_{\text {upper }}$ & effective sample size & P MCMC \\
\hline middle and female & 0.057 & -0.212 & 0.303 & 602.1 & 0.679 \\
rear and female & 0.050 & -0.214 & 0.313 & 600.4 & 0.710 \\
middle and primary male & -0.439 & -0.912 & 0.060 & 593.8 & 0.086 \\
rear and primary male & -0.276 & -0.755 & 0.189 & 541.3 & 0.262 \\
middle and non-primary male & -1.240 & -1.758 & -0.817 & 535.1 & $<0.001$ \\
rear and non-primary male & -0.968 & -1.430 & -0.563 & 542.2 & $<0.001$ \\
\hline
\end{tabular}

As for age, I calculated the distribution of relative frequency for sex/male status (Table 3.8.). Adult females were occurring more in middle positions of the group progression order, even though being quite evenly distributed across thirds. Primary males mainly took front positions during group progressions, occurring least in middle positions. Similarly, non-primary males had the strongest tendency to move in the front third, occurring in the middle very rarely and less than primary males and females (Figure 3.5.).

Table 3.8. Estimated probabilities to progress in the front middle or rear positions of the file, according to being a female, a primary male or a non-primary male (calculated from the posterior mean values of the model).

\begin{tabular}{lccc}
\cline { 2 - 4 } & front & middle & rear \\
\hline female & 0.321 & 0.341 & 0.338 \\
primary male & 0.403 & 0.275 & 0.322 \\
non-primary male & 0.586 & 0.180 & 0.234 \\
\hline
\end{tabular}



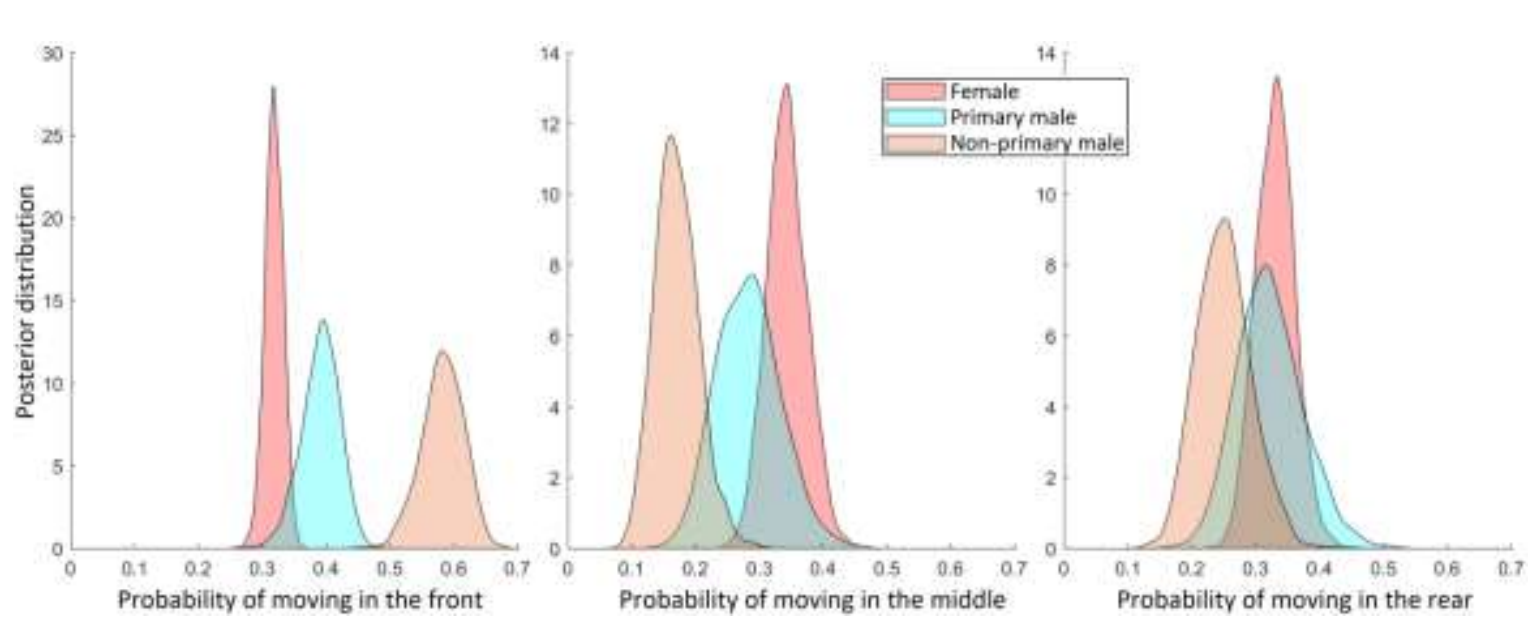

Figure 3.5. Posterior probability distributions to progress in front, middle or rear positions according to being a female, a primary male or a non-primary male.

\subsubsection{Interindividual interval times}

I used the same procedure used for the dataset of group departures on the dataset from the events of group progression. Again, I excluded the individuals belonging to party 4 and 10 from the analyses, to make them comparable between parties. Overall the full model was significant as compared to the null model (likelihood ratio test: $\chi^{2}=1119.6, \mathrm{df}=1, \mathrm{P}<0.001$ ). During group progressions, as well as during group departures, belonging to the same unit predicted shorter interval times between individuals within the event (Table 3.9., Figure 3.6.). Estimated variance components for the random effects were: individual one identity $=0.094$, and individual two identity $=0.075$.

Table 3.9. Summary of model results. Estimated coefficients of the effect of belonging to the same unit on the interval times between dyads of individuals within event of group progression, from LMM.

\begin{tabular}{lccccccc} 
& Estimate & Std. Error & $\mathrm{Cl}_{\text {lower }}$ & $\mathrm{Cl}_{\text {upper }}$ & $\chi^{2}$ & $\mathrm{Df}$ & $\mathrm{P}$ \\
\hline Intercept & 3.014 & 0.045 & 2.924 & 3.103 & $(1)$ & (1) & (1) \\
belonging to same unit & -1.087 & 0.031 & -1.148 & -1.025 & -34.83 & 7412.423 & $<0.001$
\end{tabular}

${ }^{(1)}$ not shown because of having a very limited interpretation 


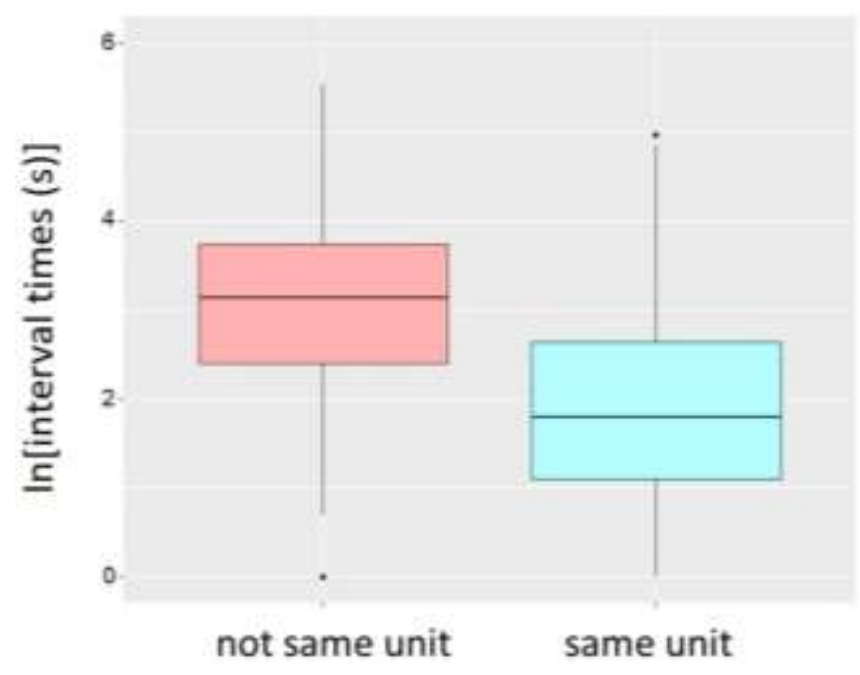

Figure 3.6. Interval times of dyads in events of group progressions. Individuals not belonging to the same unit are compared to those belonging to the same unit.

\subsubsection{Primary and non-primary males at the edges}

As a post-hoc test, the GLMM concerning the front third revealed that non-primary males were taking position significantly more in the front half of the first third, as compared to females and primary males, which tended to progress in the half closer to the middle of the group (Table 3.10.).

Table 3.10. Summary of model results. Estimated coefficients of the effect of being a female, a primary male or a non-primary male on the likelihood of progressing in the first half of the front third of a group progression, from GLMM.

\begin{tabular}{lccccc} 
& Estimate & Std. Error & $\chi^{2}$ & Df & $P$ \\
\hline Intercept & -0.401 & 0.158 & $(1)$ & $(1)$ & (1) \\
primary male & 0.460 & 0.273 & $25.673^{(2)}$ & 2 & $<0.001^{(2)}$ \\
non-primary male & 1.321 & 0.250 & (2) $^{(2)}$ & (2)
\end{tabular}

${ }^{(1)}$ not shown because of having a very limited interpretation; ${ }^{(2)}$ equal values because they refer to different terms of the same variable

The same test applied to the rear third, showed that non-primary males were taking position significantly more in the back half of the rear third, as compared to females and primary males, which again progressed in the half closer to the middle of the group (Table 3.11.). 
Table 3.11. Summary of model results. Estimated coefficients of the effect of being a female, a primary male or a non-primary male on the likelihood of progressing in the first half of the rear third of a group progression, from GLMM.

\begin{tabular}{lccccc} 
& Estimate & Std. Error & $\chi^{2}$ & Df & $P$ \\
\hline Intercept & -0.196 & 0.112 & $(1)$ & $(1)$ & (1) \\
primary male & 0.227 & 0.211 & $17.388^{(2)}$ & 2 & $<0.001^{(2)}$ \\
non-primary male & 0.976 & 0.230 & (2) $^{(2)}$ & (2) & (2)
\end{tabular}

${ }^{(1)}$ not shown because of having a very limited interpretation; ${ }^{(2)}$ equal values because they refer to different terms of the same variable 


\section{Discussion}

\subsection{Group departures in Guinea baboons}

\subsubsection{Initiation attempts}

In a group of wild Guinea baboons, the initiation of collective movements appears not to concern only one individual or one sex. Not all group members attempted an initiation though. Juveniles and infants almost never tried to initiate a group departure ( 3 attempts in 146). Therefore, it seems that adults are the only ones which are able to influence timing and directions of group departures. Adult individuals presumably have greater experience and knowledge of the home range compared to juveniles. This means that they can develop mental maps and preferences for destinations that young individuals probably do not develop yet (Noser and Byrne, 2007). Furthermore, an attempt of initiation implies an exposure to the edges of the group or even beyond them. In all likelihood younger individuals are more susceptible to predation which may lead them to prefer more central, thus safer, positions within the group.

Among adults, males attempted initiation more often than females. In general, adult male baboons weigh twice as much as the other individuals (Cords, 2012), have larger canines and carry a grander mantle of hairs. They also are dominant over juvenile males and females and adult females, regardless of rank (Bentley-Condit \& Smith 1999; Cheney and Seyfarth, 2007). Because of their larger size compared to adult females and youngsters, adult males may have higher absolute nutritional requirements. These needs can motivate males to trying to elicit the group to depart towards food resources more frequently. In addition, social dominance generally translates into a particularly high freedom of action and influence on the behaviour of other group members (King et al., 2009b). De facto, dominance hierarchy usually affects the visual attention of group mates such that the highest ranking individuals are observed more attentively than others (Pannozzo et al., 2007). As a result, even expressing analogous behavioural patterns, dominant individuals would be more influential on group coordination than the subordinates. The consensus decision-making process during group departures may be one of the social contexts in which an individual can take advantage of its social status to better satisfy its interests. Moreover, adult males are less vulnerable to predators because of their body size and features such as long sharp canines (Cowlishaw, 1994). Thus, they may be less hesitant in moving off and attempting an initiation of group departure than adult females and 
youngsters. Since mothers are the primary infant caretakers, another possibility is that females behave differently when they have a young offspring. Only the adult females in this condition may avoid initiating because of the risks of the action for the young one, whereas the other females may do it as much as adult males.

Despite males attempting substantially more initiations, females still attempted in $35.6 \%$ of the cases and no evidence of difference between sexes was found in the capacity of actually triggering the departure of the whole group when moving off. Adult female Guinea baboons are in condition of greater spatial and social freedom as compared to other baboon species (Goffe et al., 2016; Fischer et al., 2017; see content 1.8.). Considering the influential capacity of females, the coordination of group departures appears to be a context where the comparatively higher social tolerance of this species emerges.

Moreover, in my study, the initiation attempt of a group departure was highly likely to be successful (123 successful initiation in 146 attempts). This outcome may be the result of group members with similar and well synchronized interests. That is to say that previous group activities (energy consumption), environmental conditions, time of the day, or other factors eventually synchronize individual motivations and thus further activities. Otherwise, there may be events of group departure with larger range of choices, in which a more complex consensus decision-making process should take place, and events that may involve only trivial, if any, decisions about direction and timing of collective movement. For example, once the group has already started moving in one known direction, it may stop to rest or feed for a break. At this point the group may depart again as soon as one individual moves off in the known direction. Or else, the group may briefly split in subgroups. In this case, all members of the subgroup know where they have to go for reunifying the group. The subjects of data collection may depart as soon as one individual moves in the known direction of the further group members. These different conditions likely vary the negotiation and consensus decision-making involved in the coordination of the group. Therefore conducting data collection about group departures throughout the day, as I did, can potentially confound data from these different kinds of events and conceal the processes and patterns of coordination before group departures.

The attempts of group departure initiation and their success are usually considered as expressions of individual influences on the consensus decision-making process (content 1.4.1.; e.g., Van Belle et al., 2013; Lee and Teichroeb, 2016). Following this interpretation, Guinea baboons partially share the decision-making process. In fact, young individuals do not have the 
possibility to influence the process of group departure. Adult females and adult males both influence the process, which appears only rarely negotiated (i.e. low number of unsuccessful initiation attempts). Adult males appear to influence the process more than females, being more active in the initiation attempts.

\subsubsection{Interindividual interval times}

My data show that the pattern of following a departing group member was not random. When one unit member made the move and departed, its unit members tended to follow before the members of other units within the party. This suggests that unit members keep spatial cohesiveness within the party during group departures.

\subsubsection{Communicative means}

In social primates as baboons one would expect information transfer and negotiation during the group decision-making process, thus a certain communication in the course of a group departure (content 1.4.1.). However, none of the generally considered behaviours, i.e. back glances, branch shaking displays, greetings, pauses and vocalizations (content 1.4.1.; Sueur and Petit, 2010; King et al., 2011; Seltmann et al., 2016; Kummer, 1995; Boinski, 1993; Fischer and Zinner, 2011), appeared to be systematically involved in a departure event. Each one of them was coded in less than half of the observed departure events. The only exception might be the branch shaking display. If we consider that branch shacking displays can be performed only when in a tree and we take into account only the group departures with at least one individual in a tree, one or more branch shaking displays occurred in 33 events out of 54 (61.1\%). Nonetheless, the meaning of this proportion remains obscure without knowing the frequency to which Guinea baboons shake branches in other contexts. Moreover, the success of an attempt of initiation did not seem to depend on the expression of communication behaviours. While attempting an initiation, 84 baboons (out of 146) performed at least one of the five communication behaviours considered. Among these individuals, between $79.2 \%$ and $88.9 \%$ (values per each one of the five behaviours) of them were successful (Table 3.4.). These values are in line with the overall success rate $(84.2 \%)$ of initiation attempts in my study. Therefore, none of the behaviours increased the chances for an attempting individual of being followed by the group. 
Overall, it seems that one individual simply moving off was sufficient to serve as an example and to trigger a group departure. The low rate of occurrence of these potential communication behaviours suggests that (i) the decision-making process may be very little negotiated. Otherwise, (ii) during the coordination process Guinea baboons could exchange information and negotiate by means of (as well) other communication behaviours. These behaviours may be difficult for a human observer to detect (e.g., frequency of cues as standing up, or grunts by stationary individuals). Besides, (iii) information exchange and negotiation to reach consensus among group members may be required only in group departures with a large spectrum of choices. As mentioned above, only few events of group departure may need an actual group decision-making process, and, in many daily departure events, the timing and direction of travel may be already known by the group members (e.g., branch drag displays in bonobos occur only before long distance travel, Schamber et al., 2017). Lastly, (iv) whether and which communicative means serve to coordinate the group may depend on environmental conditions (e.g., King and Cowlishaw, 2009b, Dostie et al., 2016). As branch shaking displays are much more likely performed when the group departs from a tree, vocalizations may occur at higher rate in densely vegetated areas because visibility is reduced, or in periods of food scarcity that lead to larger distances between group members. Furthermore, vocalizations should not be uniquely categorized because of the context-specific expressions of the different types (Cheney and Seyfarth, 2018). For example, baboons produce particular loud calls ("contact wahoos" or "clear barks") when they lose contact with specific group members or the whole group (e.g. in chacma baboons, Fischer et al., 2002; Ey et al., 2007). Differently, baboons use grunt calls during various affiliative interactions (reviewed in Rendall et al., 1999).

\subsubsection{Anecdotal reports}

Previous studies on baboon group departures often focused on morning departures from the sleeping site (Kummer, 1968a; Stueckle and Zinner, 2008; King et al., 2011). In the early morning, finding a whole party of Guinea baboons before a group departure, in a situation that met my parameters, was nearly impossible. The main reasons were difficulties of seeing all party members from one same location, since the groups were spread. However, during the two morning departures that I observed primary males initiated the group departure and, just before "making the move", they greeted primary males from a respective second unit. As discussed in the previous contents, the data collected following my operational definition do not 
describe a similar behavioural pattern during group departures. One reason may simply be that, most often, Guinea baboons do not follow this pattern when the group is about to depart, but they adopt it occasionally. Nonetheless, it may also be that, at least sometimes, group departures during the day require different, if any, kind of consensus decisions. The baboons may thus purposely follow specific behavioural patterns only when needed. As hypothesized above, during a morning departure the group may have to decide when and where to go among a spectrum of options, whereas, if already on the way, a group departure may just be the end of a break during a travel of known destination for, at least, all adult group members. Despite the limited interpretation that a dataset of two samples can provide, these episodes may be of relevance when resembling closely the dynamics described in other species, e.g., hamadryas baboons (Kummer, 1968a, 1995; see content 4.3.).

\subsection{Group progressions in Guinea baboons}

\subsubsection{Order of progression}

The results of my study suggest that, when a party of wild Guinea baboons moves in single-file progressions, the individuals do not repeatedly take positions following an exact order, but they shift positioning across events. Party members can occasionally occur in all positions within the line. Nevertheless, group members tend to have a non-random order of progression. Overall, age, sex and male status appear to be factors shaping the order of progression. Adult individuals occupied clearly more the front than young ones. Young individuals took middle positions more often than adults and avoided the front ones the most. Rear positions were occupied slightly more often by young individuals than by adults, but the difference was not substantial. Among adults, females were quite evenly distributed along the progressing party, yet with a slight tendency for central positions. Males were definitely more in front positions and less in central positions and this disposition was more pronounced for non-primary males than for primary males. Rear positions were quite uniformly occupied by adult females, primary and non-primary males.

On one hand, baboons in front positions may reach the resource at destination before and outcompeting the other group members. Consequently, adult males may impose themselves in front positions, since they plausibly require a greater absolute amount of food than adult females and young individuals because of their larger body size. However, a more frequent presence of adult males in rear positions than in middle positions contradicts this 
hypothesis. On the other hand, baboons in front positions may face higher predation risk (Busse, 1980). Therefore, adult males may be more numerous at the front and at the rear because they are less vulnerable to predators because of to their body size and features (Cowlishaw, 1994). In contrast, the positions in the centre of the group are the safest locations (Rhine and Tilson, 1987; Ron et al., 1996; Hockings et al., 2006). Young individuals and adult females may occupy middle positions more often than adult males because of their higher susceptibility to predation attacks. One possibility is that adult males end up in peripheral positions to reduce the risks of predation attacks to the group, even if they increase their individual risk of being attacked. If the individual spatial positioning of adult males is to serve a protective function, the behaviour of adult males can be defined as altruistic. The debated topic of altruism refers to social interactions between two or more conspecifics and involves actions or traits that are costly for the actor and benefit the recipient individual(s) (van Schaik and Kappeler, 2006). Such behaviours do not seem reciprocated by the recipients in following actions. Therefore, their evolutionary stability is difficult to explain in terms of fitness consequences (extensive discussion in Kappeler and van Schaik, 2006). Generally, adult males should gain future higher benefits by communally defending weaker individuals of their group than the disadvantage of being at higher individual risk during single-file travel progressions. For example, adult females may reciprocate these altruistic acts with future affiliative and mating interactions or the other adult males may offer coalitionary support in future conflicts. Another possibility is that the local adjustments of individual positioning are a response to differences in fearfulness. If adult females and young baboons are more fearful, their motivation to take central positions should be higher than for adult males. However, adult males place themselves between the threat and the group in contexts other than group progressions, e.g., when the baboons detect predators or when a human observer inadvertently scares a group member (Kummer, 1968a; Busse, 1980; Cowlishaw, 1994; personal observations). Therefore, the hypothesis of an intentional altruistic behaviour seems plausible. In addition, Guinea baboons take the rear positions of single-file progressions quite independently of age, sex or male status. This outcome may be influenced by the individuals that struggle to keep the pace of the others for their impaired physical conditions, for instance due to old age, late pregnancy or injuries. Furthermore, as previously mentioned, adult females are the primary caretakers of young individuals. Their quite uniform distribution may be the result of naturally occupying front positions except when they have to keep proximity with their offspring in the centre-back of the group. Another consideration 
concerns methodological aspects. The division of the order of progressing individuals in three parts, which I applied, may be a coarse approximation. In a group of 30 individuals, each of the three parts comprises ten individuals. This approach cannot reveal, for example, whether the last 10 positions are actually uniformly occupied by two categories of individuals, or the half of the partition closer to the centre is taken by one category and the marginal half is occupied by the other category. Finer scale analyses on a fluid order of single-file progressions, moreover collected on three different groups, would have required a larger dataset.

\subsubsection{Interindividual interval times}

In the group progressions that I observed, baboons tended to follow their unit members at closer distance than party members of other units. As in case of group departures (content 4.1.2.), during group progressions, Guinea baboons preserved the spatial cohesion of the unit within the party.

\subsubsection{Primary and non-primary males at the edges}

Adult males are mainly in the front and they occupy less central positions, where young individuals and adult females tend to travel more frequently. Moreover, members of the same reproductive unit tend to stay spatially cohesive during group progressions. Hence, since primary males should be more interested in staying closer to their female and young unit members than non-primary males, primary males should be found close to females and offspring in central positions more frequently than non-primary males. My study supports this hypothesis when looking at the front and rear thirds of the progressing group. Primary males were found closer to the centre than non-primary males. In contrast, non-primary males appeared to be the peripheral animals in a group progression of Guinea baboons.

This pattern of non-primary males in peripheral spatial positions emerged despite their apparent spatial integration within the party. Secondary males are usually surrounded by more party members than primary males (proximity $<5 \mathrm{~m}$; i.e. higher degree centrality, Goffe et al., 2016). Also, the tendency of primary males to stay close to their females is apparently inconsistent with the high spatial freedom of adult females (56\% of the scans there were no adult males within $5 \mathrm{~m}$ of an adult female; Goffe et al., 2016). One possibility is that the resultant spatial patterns may originate from a sort of subordination of non-primary males towards primary ones. In chacma baboons, the highest ranking males are those with higher 
access to mating (Barrett and Henzi, 2008; Anandam et al., 2013). Also in yellow and olive baboons, dominance hierarchy is one of the influencing factors on reproductive success (Alberts et al., 2003; Danish and Palombit, 2014; Walz, 2016). Even though there is no linear dominance hierarchy among adult male Guinea baboons, the social influence of primary males (i.e. males with access to reproduction) on other party members may be higher than that of non-primary males. Thus, the dichotomy between primary and non-primary males may also express a difference in social influence on group members. Primary males may take safer positions closer to the centre, leaving non-primary males to the riskier peripheral positions of the group. This would also be in line with the hypothesis that dominant individuals prefer safer central positions as they can displace competitors from food sources when they arrive after front positioning individuals (Farine et al., 2017). Otherwise, the observed spatial pattern during group progressions may result from a conflict of interest internal only to primary males between occupying front positions, thus obtaining priority access in the new feeding patches, and keeping close proximity with their unit members.

\subsection{Group departures in a comparative perspective}

In short, the analyses of group departures indicate that adult male Guinea baboons initiated group departures more frequently than other group members. Still, adult females initiated about one third of departures. Therefore, Guinea baboons seem to partially share the consensus decision-making. Furthermore, communication by means of particular behaviours was apparently not needed and, once one individual moved off, it had high chances of being followed by all group members. As a result, the coordination process during group departures did not seem to be negotiated. Individuals did not follow group members randomly but they followed their unit members before other party members. 
Table 4.1. Comparative table of the findings about group departures in baboon species $(\hat{\partial}=\mathrm{ad}$. male, $\hat{o} \hat{o}=$ ad. males, $q=$ ad. female, $q q=$ ad. females $)$.

\begin{tabular}{|c|c|c|}
\hline $\begin{array}{l}\text { Baboons } \\
\text { (Papio sp.) }\end{array}$ & Social system & Group departures \\
\hline $\begin{array}{l}\text { Guinea } \\
\text { (P. papio) }\end{array}$ & $\begin{array}{c}\text { Monandric-polygynic multilevel } \\
\text { Female dispersal }\end{array}$ & $\begin{array}{l}\hat{\partial} \text { initiate more often than } q+q, \\
\text { unit members stay cohesive }\end{array}$ \\
\hline $\begin{array}{l}\text { Olive } \\
\text { (P. anubis) }\end{array}$ & $\begin{array}{l}\text { Polygynandric unilevel } \\
\text { Male dispersal }\end{array}$ & $\begin{array}{l}\text { Highest ranking }{ }^{\lambda} \text { initiates more often, } \\
\text { adult group members can influence }{ }^{1} \text {. } \\
\text { Shared decision-making influenced by number }{ }^{2} \text {, } \\
\text { social affiliation influences followership }{ }^{3}\end{array}$ \\
\hline $\begin{array}{l}\text { Yellow } \\
\text { (P. cynocephalus) }\end{array}$ & $\begin{array}{l}\text { Polygynandric unilevel } \\
\text { Male dispersal }\end{array}$ & $\begin{array}{c}\qquad \delta^{\Uparrow} \text { initiate, } \\
\text { other group members can influence }{ }^{4}\end{array}$ \\
\hline $\begin{array}{l}\text { Chacma } \\
\text { (P. ursinus) }\end{array}$ & $\begin{array}{l}\text { Polygynandric unilevel } \\
\text { Male dispersal }\end{array}$ & 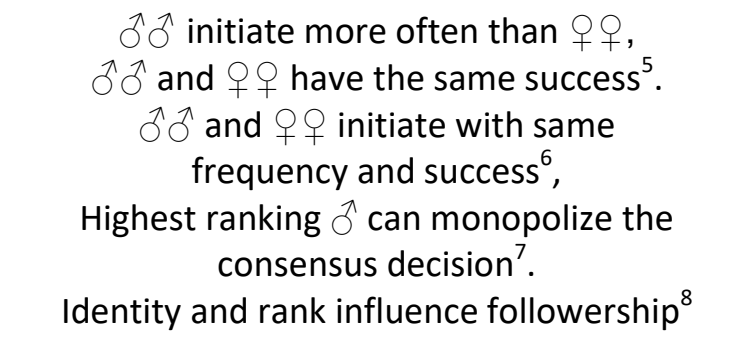 \\
\hline $\begin{array}{l}\text { Kinda } \\
\text { (P. kindae) }\end{array}$ & $\begin{array}{l}\text { (Polygynandric unilevel } \\
\text { Male dispersal) }\end{array}$ & No data \\
\hline $\begin{array}{l}\text { Hamadryas } \\
\text { (P. hamadryas) }\end{array}$ & $\begin{array}{l}\text { Monandric-polygynic multilevel } \\
\text { Female dispersal }\end{array}$ & $\begin{array}{l}\text { Decision-making and initiations by } \hat{\partial} \partial^{\lambda} \\
\text { others can influence, notifying behaviours, } \\
\text { unit members stay cohesive }{ }^{9}\end{array}$ \\
\hline
\end{tabular}

The coordination process during group departures conforms, at least partially, to findings in all baboon species investigated so far. Studies on olive and yellow baboons described the adult males as the major initiators of group departures and adult females as active influencers of the decision outcome (Ransom, 1981; Norton, 1986). The highest ranking male in olive baboons initiated departures more often than the other individuals. The highest ranking female yellow baboon influenced the direction and time of group departures more than the other females while departures were started by a male. In both species, the adult group members were affecting the decision outcome with communication behaviours like body and 
gaze orientations or movements to the edges of the group (Ransom, 1981; Norton, 1986; content 1.7.1.). In Guinea baboons, the group coordination process differs because it is not affected by dominance hierarchy and it does not involve specialized communicative means. In fact, dominance hierarchy usually affects the capacity of influencing group mates' behaviours (King et al., 2009b; Pannozzo et al., 2007), but Guinea baboons have apparently no linear male dominance hierarchy and their overall social structure appears more tolerant than that of COKY baboons. The difference in the performance of communication behaviours during the coordination process is more enigmatic, since "social tolerance is predicted to be associated with enhanced cognitive skills that underpin communication and coordination" (Joly et al., 2017, p. 1). In the course of group coordination, communicative means should be involved or not in relation to the need of information transfer and negotiation among group members. Plausibly, not all group departures require a consensus decision-making process of the same relevance. As discussed above, my dataset includes group departures following certain fixed parameters but potentially requiring different patterns and mechanisms of consensus decisions. My data collection possibly included only a few, if any, group departures involving relevant communication for a consensus decision. In general, differences in data collection and data analyses may be a reason for differences in the outcomes. Nonetheless, the decision-making process can be generally defined as partially shared, with comparable contributions by adult males and females to those found in Guinea baboons.

In a study of chacma baboons, morning departures were mainly initiated by adult males which attempted more than females but had the same success rate (Stueckle and Zinner, 2008). As in Guinea baboons, adult chacma baboon females initiated about one third of group departures. The observed pattern was mildly influenced by dominance hierarchy, with a trend for more dominant individuals to attempt more initiations and make more successful attempts. Similar to my study, the analysis of communicative means did not show any signs of negotiation during the coordination process (Stueckle and Zinner, 2008). Another study on chacma baboons suggested that all adults could initiate group departures and they did so with uniform frequencies and success chances, regardless of sex, dominance rank or age (King et al., 2011). Hence, these baboons appear to share the decision-making process more equally than the baboons of the other aforementioned studies. Anyway, with the highest number of successful initiation attempts, the dominant male seemed to have a stronger impact on the consensus decision outcome (King et al., 2011). Baboons tended to follow the individuals they were more 
closely affiliated to (King et al., 2011). Once more, neither vocalizations nor back glances turned up mediating the coordination of a group departure, but pauses appeared to have a negative effect on eliciting followership (King et al., 2011). The results of a third study concluded that, when the dominant male had a firm interest in going to one location, it recurrently directed the consensus decision to its own interest (King et al., 2008). The other group members generally followed the male, despite the individual cost of spending energy to reach a place where only the dominant individual(s) can feed (i.e. consensus costs). The study showed the relevance of group cohesion in terms of consensus costs faced by the majority of group members and the strong impact of the dominance hierarchy in conditions of strong individual interests. However, this pattern is confined to a foraging experiment that restricted food access to very few group members (mainly the dominant male). This situation is not common under natural conditions. In instances of less extreme conflicts of interests, the dominant individuals may not monopolize the consensus decision outcome. Moreover, in this study baboons preferentially followed individuals they were socially affiliated to (King et al., 2008).

In hamadryas baboons, which live in a multi-level nested society as Guinea baboons, females of OMUs seemed to coordinate with their primary male and the primary males reached a consensus at the clan level (Kummer, 1968a, 1995). Only adult males have been observed to take part in the negotiation for the direction and timing of coordinated departures of several OMUs. Kummer (1968b) described the negotiation process as an initiator-decider (ID) system. Younger adult males were apparently more active in attempting initiations of group departures (initiators), but older adult males seemed to decide when and where to go (deciders; Kummer, 1968b). Hence, the decision-making process during group departures from the sleeping site can be defined as partially shared. With older males being the deciders, age among adult males seemed to have an effect that I did not find in Guinea baboons. Adult hamadryas males appeared to communicate during the process. The most common interaction was the notifying behaviour: approaching another individual followed by the presentation of the hindquarters and leaving again (Kummer, 1995). Although this ritualized greeting is used also in other contexts, (e.g., conciliations among rivals) during morning departures, the function seems to be an invitation for the recipient to come along. The rate of expression of notifying behaviours increased considerably during morning departures as compared to other contexts (Kummer, 1995). The description of the morning departures in hamadryas baboons is very similar to the two morning departures that I observed in Simenti. Only primary males appeared to be involved 
in interactions between the different units and the males greeted each other as to elicit the recipient to follow. The degree of intimacy during the greeting changed from presenting the hindquarters to a mutual penis diddling, which is in consonance with the findings about general greeting behaviours in the two species. In hamadryas baboons, adult males do not usually greet with physical contact, while male Guinea baboons do in 93\% of the cases (Dal Pesco and Fischer, 2018). In contrast to hamadryas baboons, adult females initiated group departures $(34.2 \%$ of successful initiation). Adult females induced the followership of their males and other unit members and, occasionally of the whole party. The differences between the group coordination in hamadryas and Guinea baboons may be due to different methods of investigation. The description of the hamadryas group departures concerns only morning departures from the sleeping site, whereas my observations on Guinea baboons do not include group departures from the sleeping site, but from sites where they had been stationary during the day, feeding, resting or socializing. Kummer and Stolba were puzzled about how clans of the same band could systematically depart together from the same sleeping site, separate for hours and re-unite at noon at the same waterhole despite several ones being available in the area (Kummer, 1995). They suggested that the decision about the general destination for the day was reached at the sleeping site, before splitting simply by the direction in which the baboons departed (Kummer, 1995). It has not been explored yet whether hamadryas baboons leave adult females to occasionally initiate a group departure after a break along the way to an already known final destination. As already mentioned, the "matters" a group of baboons has to decide upon may vary from one group departure to another. It is plausible that the decision-making process may impact baboons' life more when the group has to decide direction and timing of group departure than when the group has stopped to rest or feed half way to a destination already agreed previously. Group departures from the sleeping site are more likely to fall into the first situation, whereas the group departures during the day, as those I observed, may not need elaborate, if any, consensus decision-making. This hypothesis is supported by the few morning departures that I witnessed. There, the involved mechanisms seemed similar to those in hamadryas baboons. Instead, the group departures implying attempts and initiations by females are supposed to have little margin of options. When the group already knows their next destination, it is not a question of where and when to go but, in case, of only when to go. Thus any adult may have equal chance of being the first one to move and being followed. Moreover, many group departures of Guinea baboons involved less than one party (66.9\% of events), 
despite the fact that the whole party is cohesive most of the time. This means that the baboons of the party that I studied often temporarily split, by at least few dozen meters, to reunite later in the day. During these fission-fusion dynamics of the parties, adult baboons appear to know where their party members are located. In the case that all adult baboons know where the other party members are, every adult may be able to move and be followed in order to reach the other baboons. A second possibility is that adult female Guinea baboons may impact the group decision-making because of the higher degree of social tolerance of Guinea baboons compared to hamadryas baboons. Precisely female Guinea baboons are not coerced to maintain constant close proximity to their males (higher spatial freedom) and they can avoid advances by adult males (greater leverage in their association patterns) (Goffe et al., 2016). This freedom of movement and choice of adult female Guinea baboons may also be reflected in the group movement context. They may attempt to initiate group departures because they are free to move away from the other group members, their primary male included, in contrast to what happens in hamadryas baboons. If this is the case, their frequency of initiation attempts could be potentially equal to the one of adult males and lowered only by their greater involvement in offspring caretaking.

Few recent studies analysed individual movements by means of GPS devices and inferred the mechanisms underlying the consensus decision-making (e.g., Strandburg-Peshkin et al., 2015; Bonnell et al., 2017; Farine et al., 2017). One study found that the movement of each chacma baboon was more influenced by the movements of specific individuals than by the trajectory of the whole group (Bonnell et al., 2017). Thus, followership was not random but individualized, since individuals tended to follow specific group members more than others. Precisely, individual movements were biased by the dominance hierarchy in the group since the movements of lower ranking animals were more influenced by the movements of higher ranking individuals (Bonnell et al., 2017). In addition, some individuals were more influential than others on the movements of group members, independent of age (among adults), sex or social status (Bonnell et al., 2017). This suggests that differences in individual temperament may affect the consensus decision outcome during collective movements (Bonnell et al., 2017). The other study of this kind worked on a group of olive baboons with GPS collars (Strandburg-Peshkin et al., 2015). During collective movements, the influence on individual movements was not affected by sex, age (only adults were collared) or dominance hierarchy, suggesting that the consensus decision-making was highly shared among group members (Strandburg-Peshkin et al., 2015). 
Also here, individuals tended to follow group members with whom they were strongly socially affiliated (Farine et al., 2017). The benefits of a GPS based approach are that it can be applied both to situations when the group is initially stationary, and when it is already moving. However, this approach targets finer scale consensus decision than the more traditional approaches focusing on group departures (Strandburg-Peshkin et al., 2018). The aim of these newer studies is to understand the characteristics of the individuals proposing a direction and the conditions under which they succeed to be followed or not. What is peculiar is the focus is on the negotiation among moving group members on a finer spatiotemporal-scale, e.g., going one way or another around an obstacle. In contrast, the traditional approach focuses on stationary situations where the baboons have to decide when and where to move off, supposedly targeting a destination out of sight and over a longer time-scale. The scale of the decision can impact the mechanisms underpinning the decision-making process and makes the results of the two approaches hardly comparable (Strandburg-Peshkin et al., 2018).

\subsection{Group progressions in a comparative perspective}

Whether baboons move in a random progression order across events or whether the group members follow a recurrent order has long been matter of investigation (Rhine, 1975; Altmann, 1979). The only study documenting a chaotic order of progression was then proved using questionable statistical analyses (Altmann, 1979; Rhine and Westlund, 1981). The emerging pattern of progression order of Guinea baboons consists of adult males occupying mainly front positions, the centre of the group represented more by adult female and youngsters, and rear positions quite evenly taken by all categories of baboons. In addition, members of the same unit generally travelled spatially and temporally close to each other and non-primary males occupied peripheral positions significantly more than primary males. 
Table 4.2. Comparative table of the findings about group progressions in baboon species $\left(\sigma^{\lambda}=\right.$ ad. male, $\hat{\partial} \hat{\sigma}=$ ad. males, $q=$ ad. female, $q q=$ ad. females $)$.

\begin{tabular}{|c|c|c|}
\hline $\begin{array}{l}\text { Baboons } \\
\text { (Papio sp.) }\end{array}$ & Social system & Group progressions \\
\hline $\begin{array}{l}\text { Guinea } \\
\text { (P. papio) }\end{array}$ & $\begin{array}{l}\text { Monandric-polygynic multilevel } \\
\text { Female dispersal }\end{array}$ & $\begin{array}{l}\text { Front: } \hat{\partial} \hat{\partial} \\
\text { Middle: } \rho+q \text { and young } \\
\text { Rear: } \hat{\partial} \hat{\partial}, \phi+q \text { and young } \\
\text { Unit members stay cohesive, } \\
\text { non-primary } \partial^{\lambda} \delta^{\lambda} \text { take peripheral positions }{ }^{0}\end{array}$ \\
\hline $\begin{array}{l}\text { Olive } \\
\text { (P. anubis) }\end{array}$ & $\begin{array}{l}\text { Polygynandric unilevel } \\
\text { Male dispersal }\end{array}$ & $\begin{array}{l}\text { Front: } \hat{\partial} \\
\text { Middle: } \phi Q+\text { and young } \\
\text { Rear: } \hat{\partial}, \phi Q+\text { and young }\end{array}$ \\
\hline $\begin{array}{l}\text { Yellow } \\
\text { (P. cynocephalus) }\end{array}$ & $\begin{array}{l}\text { Polygynandric unilevel } \\
\text { Male dispersal }\end{array}$ & 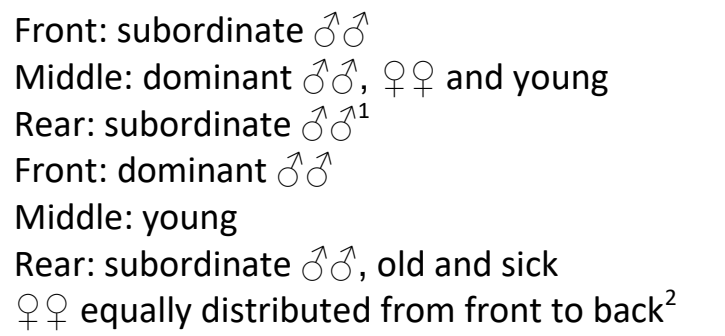 \\
\hline $\begin{array}{l}\text { Chacma } \\
\text { (P. ursinus) }\end{array}$ & $\begin{array}{l}\text { Polygynandric unilevel } \\
\text { Male dispersal }\end{array}$ & 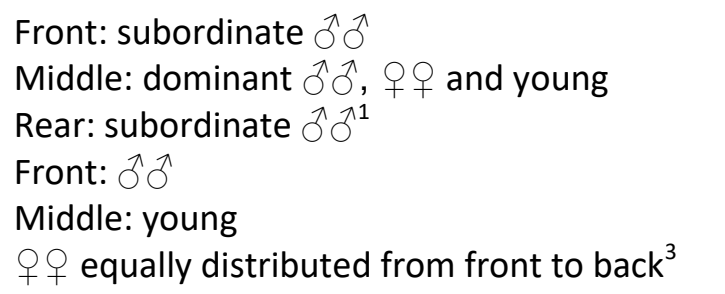 \\
\hline $\begin{array}{l}\text { Kinda } \\
\text { (P. kindae) }\end{array}$ & $\begin{array}{c}\text { (Polygynandric unilevel } \\
\text { Male dispersal) }\end{array}$ & No data \\
\hline $\begin{array}{l}\text { Hamadryas } \\
\text { (P. hamadryas) }\end{array}$ & $\begin{array}{l}\text { Monandric-polygynic multilevel } \\
\text { Female dispersal }\end{array}$ & 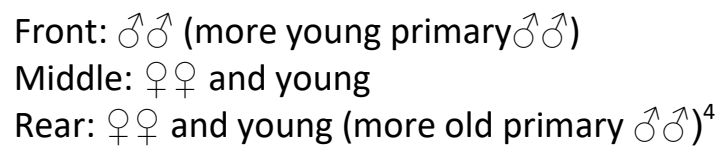 \\
\hline
\end{tabular}

${ }^{0}$ current study. ${ }^{1}$ DeVore and Washburn, $1963 .{ }^{2}$ Rhine, 1975; Rhine and Westlund, 1981; Rhine et al., 1981. ${ }^{3}$ Rhine et al., 1985; Rhine and Tilson, 1987. ${ }^{4}$ Kummer 1968a, 1968b, 1995.

Yellow, chacma and olive baboons have been reported to keep non-random positioning patterns while travelling in single-file progressions. Both yellow and chacma baboons were initially described progressing with subordinate adult males at the margins, dominant males, adult females and young individuals in the centre and older juvenile males in-between these 
two sections (DeVore and Washburn, 1963). The indicated description is part of a much broader study on the behaviour and ecology of baboons. Even though such report on yellow and chacma baboons was not systematic and with a large dataset on single-file group progressions, the pattern described has several points in common with the findings of several other studies (e.g., Rhine and Tilson, 1987; Kummer, 1968a, 1995), including the current one on Guinea baboons. As in other studies, these yellow and chacma adult male baboons are described at peripheral positions and adult females and young individuals are mainly in the middle. Furthermore, the difference in spatial positions due to the male social rank (i.e. higher ranking central and lower ranking peripheral) may be related to the difference in spatial positioning between primary and non-primary male Guinea baboons, due to the aforementioned inference of a difference in social influence depending on male status. Group progressions of wild yellow baboons turned into main study subjects a few years later. In the course of group progressions, dominant males took position mainly in the front, subordinate males and sick/older individuals occupied the rear and adult females were spread across front, middle and rear positions (Rhine, 1975; Rhine and Westlund, 1981). Subsequently, the analyses on yellow baboon group progressions focused on younger individuals and found that small juveniles took central positions and larger juveniles tended more to front ones (Rhine et al., 1981). Despite some differences, the general pattern observed in progressing yellow baboons resembles the one of Guinea baboons. First, adult males occupy more frequently the front and, to a lesser extent, the rear. Second, adult females are quite uniformly spread from the front to the back. Third, young yellow baboons appear to travel more in central positions than adults. In contrast to the study on yellow baboons, my analyses on group progressions did not differentiate between small juveniles and larger ones. In any case, it is most likely that, as individuals get older, they start to progressively move in positions other than the central ones, especially in the case of males. Another study focused on spatial positioning in yellow baboon groups combining all kinds of travelling instances, in contrast to single-file progressions only (Collins, 1984). Once more, adult males were seen mostly in the front of the group, but in this study no effect of dominance rank was found. Rear positions were again taken by individuals with lower mobility, like a late-stage pregnant female, a sick female or the oldest male (Collins, 1984). As yellow baboons, also chacma group progressions were further analysed in later studies and showed points of similarity (Rhine et al., 1985; Rhine and Tilson, 1987). Adult chacma baboon males predominantly occupied front positions, but they were about uniformly distributed in central and rear positions. Young 
individuals more frequently occupied central positions and adult females were equally spread across front, middle and rear positions. The pattern of progressing order is again comparable to the pattern in Guinea baboons. The only difference concerns the tendency of primary and nonprimary male Guinea baboons to occupy rear positions more than central ones. This difference may be due to predation pressure. The authors that obtained these findings on chacma baboons mentioned a high presence of lions, also documented by Busse (1980). This population of chacma baboons may have adapted their pattern of progression order to discourage lion attacks, which happen usually from the front (Busse, 1980; Rhine et al., 1985; Rhine and Tilson, 1987). Some studies investigated group progressions also in olive baboons. They confirmed the tendency for adult males to travel mainly in front positions and, to a lesser extent, in rear positions (Rhine et al., 1985; Rhine and Tilson, 1987).

Another study on chacma baboons focused on spatial patterns while foraging (Bonnell et al., 2017). In addition to the difference in context, which is foraging and not travelling, this study differed in the kind of data gathered and analysed. Instead of traditional observational data, it considered GPS data manually collected at regular intervals for each adult member. Bonnell and colleagues (2017) emphasized the fluidity of the spatial organization within the group. They also noted a tendency for dominant individuals to occupy more central positions. In particular, high ranking females took positions closer to the centre. To some degree, these observations are similar to the difference in spatial positioning that I found in Guinea baboons. Primary males are the individuals with access to mating, as dominant chacma baboon males, and they were found closer to the central positions than non-primary males, which are adult males without access to mating as low ranking chacma baboons. In Guinea as in chacma baboons, adult females were found in central positions more often than adult males. Differently from the study on chacma baboons, in a study by Strandburg-Peshkin et al. (2015) and Farine et al. (2017), almost all adult members of the troop were equipped with GPS collar and data collection was thus automatized. Also, not only single-file group progressions but all collective movements were analysed. Individual positioning was found to be highly dynamic. Dominant and subadult (the youngest individuals they had data of) baboons tended to occupy locations closer to the centre of the group, irrespective of sex (Farine et al., 2017). The results on group progressions of Guinea baboons are, at least to some extent, in line with these findings on more general collective movements. In fact young Guinea baboons and primary males are closer to the centre than nonprimary adult males. 
When a travelling hamadryas baboon group comprised several OMUs, adult and subadult males appeared to favourably occupy front positions, without a preferential difference between middle and rear positions. Younger adult males were reported more at the front and older ones more at the rear of the group (Kummer, 1968a, 1968b). My study did not test for adjustments of individual positioning in response to finer age categories than adult and young. Overall, hamadryas baboon progression order seems alike the one of chacma baboons under particular predation pressure, precisely from lions (Busse, 1980; Rhine et al., 1985; Rhine and Tilson, 1987). As well as for chacma baboons, the positioning pattern during progressions of Guinea baboons may differ also because of a lower predation pressure by lions as compared to hamadryas baboons. An anecdotal report describes the positioning of hamadryas baboons during a single-file progression moving off from their sleeping site. The group comprised only two OMUs isolated form other baboons. After a process of consensus decision-making engaging only the two adult males, all baboons left in a single-file progression. The youngest primary male was the first individual and the oldest was the last baboon of the progression (Kummer, 1968a, 1995). During my period in the field, I was able to work a few times with two units because the subject party had split. In these situations, the pattern of progression order was identical to the positioning described for hamadryas baboons in 4 out of 6 events: the primary males in the first and last positions of the group.

\subsection{The social factors affecting group movements: the case of baboons}

Several of the reported studies on animal collective movements indicated the characteristics of the society as important influencing factors on the patterns and mechanisms of group coordination (e.g., Trillmich et al., 2004; Sueur and Petit, 2008a; Jacobs et al., 2011b; Tokuyama and Furuichi, 2017; contents 1.4.1.1., 1.4.1.2., 1.4.2.). For example, it has been hypothesised that dominant individuals usually have a greater influence on the decision-making process in despotic species, and a more shared process takes place in egalitarian species (Leca et al., 2003; Sueur and Petit, 2008a; Seltmann et al., 2013). Baboons differ in several aspects of their social system across species: unilevel or multilevel social organization, different degrees of social tolerance, different mating systems and dispersal patterns. They also present some conserved characteristics across species, like adult male dominance over other group members. The relations between the characteristics of a species' social system and its process of group coordination are difficult to disentangle. The main issue is the multifaceted nature of both social 
system and group coordination. Social systems can differ according to the social organization, social structure, mating system and/or offspring care system (Kappeler and van Schaik, 2002; Kappeler, 2019; content 1.3.) and group coordination can be distinguished in aspects of consensus decision-making to depart or to terminate, collective movements at larger or smaller scales, joining process or followership, order of progression and possibly others (Pyritz et al., 2011b; Strandburg-Peshkin et al., 2017; Sueur and Petit, 2008b; Rhine and Tilson, 1987). Comparing closely related species narrows the potential influencing factors due to a minor variability in the physiology, ecology and behaviour between species (content 1.3.).

\subsubsection{The social factors affecting group departures}

The study of group coordination in Guinea baboons aimed to analyse group departures in a baboon multilevel social organization. Such a social organization is also found in hamadryas baboons and appeared to affect the coordination process (Kummer, 1968a). OMU members seemed to coordinate with their own primary male and the primary males reached a consensus at the clan level (Kummer, 1968a, 1995). In the aforementioned anecdotal reports from Simenti there are important similarities with hamadryas baboons. Differently, the results from the larger dataset on group departures of Guinea baboons did not show many similarities with the coordination process of hamadryas. These analyses indicated that females could induce the followership of their males and, occasionally of the whole party. Probably such difference may be due to different kinds of group departures considered in the studies: "from the sleeping site" and "only departures of second social level entities (clans or parties)" in hamadryas baboons versus "all along the day journey" and "departures of first and second social level entities (units and parties)" in Guinea baboons.

Following the description of the morning departures of hamadryas baboons, the multilevel organization may also have an impact on the behaviours shown during pre-departure. In a group capable of recurrent splitting and without a linear dominance hierarchy among males, individuals could require more complex coordination mechanisms, involving communicative means. In contrast, unilevel groups of olive, yellow and chacma baboons seem to avoid the use of communication behaviours to coordinate a group departure. Instead, they apparently use a simpler rule-of-thumb such as following the closest affiliated individuals (King et al., 2011). The absence of a consistent use of communicative signals in my study contradicts this supposed relationship between multilevel social organization and presence of communication behaviours. 
However, the different procedure of data collection could have led to conceal the use of signals in the group departures where it is actually required. Consequently, it could also shield the relation between social organization and communicative means involved in group coordination.

The social organization of Guinea baboons shapes the spatio-temporal cohesiveness of individuals while departing. As the analysis of the interval times between departing individuals revealed, same-unit members stay close to each other within the party. Such a result has also to be considered as influenced by the social structure, since, for a Guinea baboon, the members of its unit are usually its closest affiliated individuals within the party.

All studied baboon species share, to various degrees, a higher influence of adult males than other group members on the coordination process of group departures. This result is in line with the larger body size, as a proxy for decreased predation risk, and social dominance of adult males on group members of other age-sex categories. Also, different social structures may be a reason for the supposed higher influence of adult female Guinea baboons in the patterns of group departure as compared to hamadryas baboons. Guinea baboons show more tolerant social relationships than hamadryas baboons, with more intense affiliative interactions and rarer conflicts within and between sexes (Patzelt et al., 2014; Kalbitzer et al., 2015; Goffe et al., 2016; Fischer et al., 2017). On the contrary, in hamadryas baboons the OMU reproductive male impedes to adult hamadryas baboon females to move away from them (Kummer, 1968a; Polo and Colmenares, 2012; Goffe et al., 2016), thus it might be difficult for an adult female to move off and initiate a group movement. In addition, the difference in social structure between Guinea and hamadryas baboons may have driven to the different kinds of communication behaviours. During morning departures, the kinds of greeting that Guinea baboons may use to elicit followership seemed physical and intimate (content 3.1.4.), whereas in hamadryas they appeared not to involve physical contact (Kummer, 1995). This is in line with a more general difference in greeting behaviours between the two species (Dal Pesco and Fischer, 2018).

In macaques, the social dominance hierarchy can affect the expression of communicative means, since dominant individuals do not need to signal their intentions as subordinates do (Sueur and Petit, 2008a). In baboons, adult males are generally assumed dominant over females, so one would expect females to communicate their intention to move more frequently than males. In Guinea baboons, however, there is no difference between sexes in the performance of the communication behaviours during the initiation of group movements. In a sense, this result contradicts the general dominance of adult males over females in Guinea 
baboons and aligns with a particularly tolerant social structure already shown in other contexts than group departures. On another note, the apparent absence of communication behaviours in the coordination process of Guinea baboons contrasts with the hypothesis that social tolerance should be associated with enhanced communication actions to coordinate (Joly et al., 2017).

Sex dispersal is often indicated as one of the driving factors in the influence on the timing and direction of collective movements (e.g., lemurs, Pyritz et al., 2011a; Thrillmich et al., 2004) because the philopatric sex should possess a better territorial knowledge of the group home range, and therefore have a higher influence (Pyritz et al., 2011a). Kummer (1968) already expected a major female influential role in the coordination processes of the other baboon species, which presented male-biased dispersal in contrast to hamadryas baboons. In macaques and baboons, sex-biased dispersal does not seem to impact the coordination process. Probably, in these species the knowledge of the home range and its resources does not differ much between philopatric and dispersing individuals.

\subsubsection{The social factors affecting group progressions}

In addition to group departures, I explored the order of group members during single-file progressions. Particular similarities were found between hamadryas and Guinea baboons, the species organized in a multilevel social system. In hamadryas baboons, it was suggested that, when the travelling group is small, for instance only two OMUs, the order of progression is recurring, with one adult male at the front and one adult male at the back, but, when the travelling group is larger, the order of progression is more flexible and the adult males in front positions exceed those in the back. I found some evidence of a similar pattern but a larger dataset is needed to confirm it. Additionally, I found that the order of progression reflected the multilevel social organization of the species with members of the same unit travelling cohesively within the party, as during group departures.

More generally, across studies on baboon group progressions, there seems to be a recurrent pattern of individual positioning concerning adult males that preferentially occupy front positions and, frequently and to a lesser extent, rear positions. The results of this study are in line with this pattern. In several species front positions during travel appear to be taken because of nutritional requirements (e.g., geladas, Dunbar, 1983; Milne-Edwards' sifakas, Propithecus edwardsi, and red lemurs, Eulemur rufus, Erhart and Overdorff, 1999; white-handed gibbons, Barelli et al., 2008). Frontward positions may permit directional guidance to desired 
destinations and allow priority access to food resources at destination. Therefore, dominant individuals may take advantage of their social influence to satisfy their interests. This hypothesis was strongly supported by the foraging experiment on chacma baboons (King et al., 2008). This hypothesis is also corroborated by the social dominance of adult male baboons over all other age-sex categories, independently of species-specific social characteristics. This would not explain why adult males have often been reported more at the back of the group than in central positions (although always being even more frequently in the front than in the back). In addition, seeing front positions as simply advantageous would neglect the idea that front positions are the most dangerous (Rhine and Tilson, 1987; Busse, 1980; Bumann et al., 1997). Therefore factors other than, or additionally to, social characteristics should play a role in shaping a progression order as the one recurring across baboon species (see content 4.6.).

As dominant individuals are often reported to take front positions, in some studies they are reported to occupy central positions too, leaving subordinates to the peripheries (e.g., DeVore and Washburn, 1963; Bonnell et al., 2017; Farine et al., 2017; Morrell and Romey, 2008). This spatial pattern is frequently explained as the outcome of an individual interest for safety. As mentioned above, peripheral positions are more exposed to predation pressures and dominant individuals may use their social status to gain safer positions. When Guinea baboons were travelling in single-file progressions, I observed primary males taking positions closer to the centre of the group than non-primary males. Considering the positive relation between reproductive success and dominance found between males of other baboon species (especially in chacma baboons: Barrett and Henzi, 2008; Anandam et al., 2013; but also in yellow and olive baboons: Alberts et al., 2003; Danish and Palombit, 2014; Walz, 2016), primary male Guinea baboons, reproductively more successful, may be generally dominant over non-primary males, reproductively less successful, despite the absence of a linear dominance hierarchy among them. Hence, primary males may seek safer positions and be able to leave non-primary males at the edges as expression of their dominance social status. However, such interpretation would call into question other factors than social structure to explain the overall higher presence of adult females and young individuals than adult males in middle positions, since adult males are generally considered socially dominant over the other age-sex categories across baboon species (Bentley-Condit \& Smith 1999; Cheney and Seyfarth, 2007). 


\subsection{Other factors potentially affecting the coordination of group movements}

The overview about group coordination in baboons shows some interesting similarities across species, such as a preeminent role of adult males in initiating group movements or their prevalence over other age-sex categories in the front positions of a progressing group; but also some differences within and between species, like chacma baboons showing both shared and unshared decision-making, depending on food distribution, or a progression order with a prevalence of adult males in front, as compared to central and back positions, in contrast to a greater number of adult males in front and, to a lesser extent, back positions, as compared to central ones. These consistencies and differences are suggested to be shaped by some nonsocial factors. In general, a group of animals should be able to respond "optimally" to environmental contingencies. The two major contingencies are the distribution of resources and predators in space and time (van Schaik and van Hooff, 1983).

Baboon group coordination appears constrained by food availability. The studies on chacma baboons (King et al., 2008) showed that an artificially clumped food distribution can alter a normally partially shared decision-making (Stueckle and Zinner, 2008) to unshared decision-making, with a strong impact of the dominant male, since he is the individual which benefitted most from the clumped food resource (King et al., 2008, 2011).

Likewise, whether as a result of cooperative behaviour or differences in fearfulness, the recurrent emerging pattern of progression order seems influenced by predation risks. Both chacma and yellow baboons progressed with adult males mainly in front positions and, to a lesser extent, rear positions. Nevertheless, when the group was moving out of an area of severe fright, the baboon showed a completely reversed pattern than the usual one, with more adult males in the back of the group (Rhine and Tilson, 1987). Moreover, one population of chacma baboons consistently showed more adult males in front positions, with no difference in adult males between central and rear positions (Rhine et al., 1985; Rhine and Tilson, 1987). This order was probably due to a particularly high risk of lion attacks compared to the areas where the usual pattern of progression was found (Rhine et al., 1985; Rhine and Tilson, 1987).

Other individual aspects have been commonly pointed out as influencing factors of group coordination processes, such as the physiological state or personality traits. Certain individual conditions could impact the individual influence on the decision-making process, the likelihood of attempting an initiation and/or being followed and the spatial position during single-file progressions. There are several examples: olive baboon females with offspring and 
the oldest female yellow baboon were influencing group departures initiated by the male (Ransom, 1981; Norton, 1986), individual temperament and personality may play a role in the coordination process of chacma baboons (Bonnell et al., 2017) and sick, older or late pregnant yellow baboons were reported to progress in rear positions (Rhine and Westlund, 1981; Collins, 1984).

\subsubsection{Methodological considerations}

Given the potential impact of environmental factors on group coordination, comparisons of captive and wild groups have to be treated with caution. While studies on captive groups can offer advantages for studying the underlying mechanisms and the processes of group coordination in greater details, they may lack external validity (Pyritz et al., 2010). Studies in natural conditions may not capture the complete picture either. For example, the presence of human observers is usually discouraging predators (Kummer, 1968b; Busse, 1980; personal experience) and thus it can modify an important influencing factor of group coordination. In addition, the variability in the procedures of data collection and data analyses is a general issue that is limiting comparability in many topics. Group coordination is not an exception. For example, the order of progression of yellow baboons first revealed a certain pattern (Rhine, 1975), then denied (Altmann, 1979) and subsequently confirmed (Rhine and Westlund, 1981), because of differences in the analyses. Also, among the mentioned studies, confronting and discussing together the outcomes of researches based on traditional observational data collection with those based on simultaneous individual GPS data is troublesome despite the conclusions touch the same topics (e.g., Stueckle and Zinner, 2008; Strandburg-Peshkin et al., 2015).

\subsection{Complexity of the study of group coordination}

All the points that have been discussed so far propound the complexity in describing the patterns and understanding the processes of group coordination. Group movements are a multifaceted subject. Numerous studies were short-termed and focused on single aspects of group coordination during collective movements (e.g., Rhine, 1975; Stueckle and Zinner, 2008; Strandburg-Peshkin et al., 2015). As shown, studies focusing on the initiation attempts of group departures may misinterpret the coordination process when they do not explore communication behaviours during pre-departure and departure (e.g., mountain gorillas, Stewart 
and Harcourt, 1994; Watts, 2000; content 1.4.1.1.). Also, an analysis of the initiation attempts in hamadryas baboons by itself would have revealed a major influence on timing and direction of group departures of younger adult males. Instead, a more thorough investigation of the group departure and pre-departure process suggested a major role of older adult males on the consensus decision outcome, despite them following the attempts of younger adult males. Broadly speaking, collective movements rely on several interacting behavioural processes underlying information transfer, initiation attempt, followership or spatial positioning. The processes are informative about how group members coordinate, but they can be difficult to identify. Establishing the quality of the decision-making process on a spectrum from equally shared to unshared is only a part of the description of a group coordination process. Understanding how group members negotiate, when they decide, who between them influences the outcome and why it does so is equally crucial.

Further, all these aspects of group coordination strongly intertwine with social, environmental, physiological, personality-related and practical determinants (content 4.5., 4.6.). Not only, these species- and context-specific factors are also likely to covary. For example, a social factor such as dominance rank in chacma baboons appears to have variable impact depending on the distribution of food resources (King et al., 2008; King et al., 2011; Stueckle and Zinner, 2008). Given such a number of potentially influencing factors, it is not surprising that the coordination during group movements is a highly flexible process and that it is demanding to discern recurrent patterns. The identification of the respective most important variables and the comprehension of their relative importance remain therefore difficult.

An additional complication concerns the operational definitions for data collection. For instance, despite a good set of defining parameters, probably group departures are not all equally relevant for the fitness of group members. One can imagine that often there is no need for individuals to put much effort in consensus decision-making and group coordination. The differences in the group departure process found between Guinea and hamadryas baboons may be due to a difference in the kind of group departures analysed, as discussed before (contents 4.3., 4.5.1.). If, as in the case of baboons, at least all adult members of the group know their home-range very well, and if they can find food going both left or right, or leaving now or five minutes later, it remains questionable whether the selective pressure on making optimal decisions is as strong as usually assumed when studying group coordination. Setting parameters 
to systematically distinguish between more and less relevant group departures is at least challenging.

\subsection{Future research}

As of today, studies on group coordination have generally investigated what patterns of group cohesion and group decision-making are functional for group stability and the survival of group members. So far, studies have usually revealed only major processes regarding one or few aspects of group coordination. The systematic investigation of similarities and differences in interspecific comparisons promises new insights into the principles that underlie consensus decision processes and individual spatial positioning within animal groups and in general into how group coordination arises. A complete comparative approach requires analogous studies on different species. However, the large number of species- and context-specific influencing factors will continue to present unexplained variability and singularities which hamper successful integrations. A comparative perspective on closely related species can restrain the influencing factors and facilitate meaningful syntheses. In particular, baboon species can be considered good models for the investigation of the determinants of group coordination processes. Despite a close genetic relatedness, they adapted to a wide variety of habitats and developed social characteristics differing in many aspects, i.e. organization, structure and mating system (content 1.3.). Baboons are also chosen as analogous models for hominin evolution mainly due to a largely terrestrial life and their adaptation to habitats similar to those where our ancestors lived. A specific interest on multilevel social organizations offers the possibility to unravel the coordination process at different social levels with potential parallelisms with the multilevel societies of Homo sp. Thus, Papio species as subjects of research on group coordination can offer insights into at least the basic patterns and influencing factors characterizing the group coordination processes of early hominins.

Disentangling the relative importance of numerous potential influencing variables requires large datasets. Data collections should be precise and consistent with potentially influencing variables such as day time, season or environmental conditions, as far as practicable. It should also follow comparable parameters, e.g., the distances and the timings of operational definitions, a distinction between morning group departures and "on-the-way" group departures. When possible, researchers should prefer to collect a large amount of data on a low number of subject groups to reduce intrinsic variability between individuals and groups which 
negatively impacts the power of statistical models. Frequencies of behaviours during the context of interest often require a comparison with the frequencies of the same behaviours in other contexts. On top of this, in the field of group coordination, theoretical definitions still present a large variation, which restrains comparability and synthesis between studies.

Other observational approaches can provide interesting insights too. Experimental studies can prove the flexibility of the group coordination process according to a variation of potential influencing factors (e.g., food provisioning in wild chacma baboons, King et al., 2011). The advances in GPS and remote sensing technologies offer the chance of simultaneously tracking many individuals and their predators. High resolution habitat mapping can improve our understanding of group movement choices through the visualization of group movements among food and water resources, physical obstacles and shelters. These new methods will certainly lead to larger and more detailed datasets with a higher spatial and temporal resolution. The automated data collection by sensors and the following analyses automated by algorithms can speed up the study protocol. The new procedures can also detect finer-scale movement decisions. However, such data collections are constrained by battery power, they require invasive procedures to apply the devices and they lack the capacity of collecting a range of ecological occurrences (e.g., predator detection) and individual behaviours (e.g., communicative means) that may be crucial properties of the group coordination process.

Therefore, the most complete depiction of how a subject group coordinate would require habitat mapping, individual GPS tracking and more traditional systematic and quantitative observational methods. In addition, quite dated studies proved their validity over time and the importance of anecdotal observations to fully capture dynamics of group coordination. The description of the morning departures of hamadryas baboons (as maybe the anecdotal reports of this study, content 3.1.4.) reveals details of how group coordination emerges that are very complex to detect with today's quantitative approach. Therefore, I suggest that a complete research on such a complex topic would benefit also from descriptions of anecdotal observations (Strum, 2012).

To find out more on how ecological and social factors affect group coordination, experiments would be necessary. Since experimental approaches in the context of group movements are difficult with wild animals, it is particularly challenging to find clear evidence for the impact of certain factors on group coordination processes. A possible alternative might be to run simulations in agent-based models, where potential factors affecting the process of group 
coordination can be manipulated. Such approaches have to be based on the empirical data available from filed studies, such as this one on Guinea baboons. Simulations can help to test hypotheses derived from field work but also to develop further hypotheses which can then be tested in the field. The variation of potentially influencing factors in a simulation allows investigating the effects of these factors on the coordination process and the impacts of certain group coordination patterns on the fitness of group members (e.g., Seller et al., 2007; Sueur et al., 2009; King et al., 2011; Mann, 2018; Sueur et al., 2011).

\subsection{Conclusion}

In my study, I described and analysed some of the processes and patterns characterizing collective movements in Guinea baboons. The results contribute to a broader picture of collective movements in baboons, in particular in a multilevel society. Moreover, my study elucidates the social determinants impacting group coordination through comparing baboon species.

The results revealed that only adult Guinea baboons initiated group departures and males did so more frequently than females. During departure, the individuals did not show persistent usage of the communicative means usually considered as informative to coordinate the group in other species. Similar general patterns have been reported in other baboon species, despite consistent differences in social systems and habitats. A description of two morning departures presents particular similarities with the departure process described for the only other baboons living in a multilevel society, the hamadryas baboons.

When a party was moving in a single-file progression, Guinea baboons did not recur in appointed places from the beginning until the end of the progression. The individuals occasionally occupied all positions of the order. Nevertheless, I found evidence of non-random individual distribution. Adult females and young individuals appeared more frequently than adult males in the centre of the group. Adult males preferentially occupied front positions and, to a lesser extent, rear positions. In addition, non-primary males occupied consistently the extreme positions of the single file (front and rear), whereas primary males were significantly closer to the centre of the group. All investigated baboon species conform to this or similar positioning patterns within the progression order.

During both group departures and group progressions of Guinea baboons, members of the same units tended to keep spatial cohesiveness within the party. Similarly, in hamadryas 
baboons, adult females stay in the proximity of their "leader" male throughout the day and, also in COKY baboons, individuals generally seem to keep proximity to those which they are more affiliated to.

Under a comparative perspective, the findings on group coordination in baboons show substantial consistency across species and studies. The social characteristics that seem to most influence the coordination of baboon group movements are characteristics shared across species, such as adult male dominance over the other group members or predominant maternal care of the offspring. It appears more controversial the effect on group coordination of those social aspects which differ between species, such as the presence of multiple levels in the social organization, or the overall tolerance of the social structure. For instance, Guinea baboon females can initiate group departures whereas hamadryas baboon females most likely cannot. This difference may be due to the higher social tolerance of Guinea baboon males towards females, or it may be a consequence of considering different group departures, morning departure, as in hamadryas baboons, versus departures from stationary states during day journeys, as in Guinea baboons. Another example concerns the cohesiveness of the members of the same unit within the party, which can be the outcome of the process of following the closest affiliated individuals that has been reported in unilevel societies.

More broadly, my results and the comparisons with other studies that I discussed suggest that sexual dimorphism, predation pressure and food availability (distribution of food in space and time) are the main factors affecting the processes and patterns of group coordination. Since there is evidence of this across baboon species, these are most probably general factors already present in the common ancestor of the extant baboon species. Group coordination has a strong impact on the stability of the group and the survival (fitness) of its members, so it is possible to assume that some selection pressure has shaped the various processes of group coordination. Thus, the underlying mechanisms of group coordination are most likely strongly rooted in the species capacity to cope with diverse environments.

However, my study and the results of studies on primate group coordination processes in general showed the several empirical and theoretical complexities of this field of research. Group movements are a multifaceted subject as they consist of group departures, communication, group progressions, small-scale movements and maybe more aspects. These aspects are probably affected by social, environmental, physiological and personality-related factors, which may not only act influencing the coordination processes but also interacting with 
others. The complexity of the field is also reflected by the need of consistency in the terminology and operational definitions (e.g., Pyritz et al., 2011b). Moreover, biological centred studies of group movement usually assume fitness relevance and a strong selective pressure on making optimal decisions. Nevertheless, the adaptive value was rarely shown and the direction and timing of group movements may also be irrelevant for the individual.

To confront these issues, I suggest incorporating as many aspects of group movements as possible in future studies, which should follow analogous protocols on different species. The focus on closely related species could reduce the number of potentially influencing factors. Ideally the studies should integrate multiple approaches. Empirical evidence should be collected on longer scale movements, as in more traditional studies, and on smaller scale movements, with automated data collections (e.g., remote sensing, GPS). When possible, experimental approaches should be applied to control potentially influencing factors on group coordination. Also, the inclusion of anecdotal observations can be meaningful. The collected empirical evidence could then help to simulate group coordination during collective movements in agentbased models. A coordination of the empirical and theoretical approaches could lead to the refinement or development of hypotheses. Finally, researchers drawing conclusions should also keep a very critical view on the assumptions about the relevance of group movements for the individual fitness. 


\section{5. $\underline{\text { References }}$}

Alberts, S. C. (2016). The challenge of survival for wild infant baboons. American Scientist, 104, 366-373.

Alberts, S. C., Watts, H. E., \& Altmann, J. (2003). Queuing and queue-jumping: long-term patterns of reproductive skew in male savannah baboons, Papio cynocephalus. Animal Behavior, 65, 821-840. DOI: 10.1006/anbe.2003.2106

Altmann, J. (1974). Observational study of behavior: sampling methods. Behaviour, 49, 227-267. DOI: 10.1163/156853974X00534

Altmann, S. A. (1979). Baboon progressions: Order or chaos? A study of one-dimensional group geometry. Animal Behaviour, 27, 46-80. DOI: 10.1016/0003-3472(79)90128-3

Amornbunchornvej, C., \& Berger-Wolf, T. (2018). Framework for inferring leadership dynamics of complex movement from time series. SIAM International Conference on Data Mining (SDM18). DOI: 10.1137/1.9781611975321.62

Anandam, M. V., Bennett, E. L., Davenport, T. R. B., Davies, N. J., Detwiler, K. M., Engelhardt, A., Eudey, A. A., Gadsby, E. L., Groves, C. P., Healy, A., Karanth, K. P., Molur, S., Nadler, T., Richardson, M. C., Riley, E. P., Roos, C., Rylands, A. B., Sheeran, L. K., Ting, N., Wallis, J., Waters, S. S., Whittaker, D. J., \& Zinner, D. (2013). Species accounts of Cercopithecidae. In: Mittermeier, R. A., Rylands, A. B., \& Wilson, D. E. (Eds.). Handbook of the mammals of the world (Primates, Vol. 3). Lynx Edicions, Barcelona, Spain. pp. 628-753.

Baayen, R. H. (2008). Analyzing linguistic data: a practical introduction to statistics using R. Cambridge University Press, Cambridge, U.K. pp 1-353.

Ballerini, M., Cabibbo, N., Candelier, R., Cavagna, A., Cisbani, E., Giardina, I., Orlandi, A., Parisi, G., Procaccini, A., Viale, M., \& Zdravkovic, V. (2008). Empirical investigation of starling flocks: a benchmark study in collective animal behaviour. Animal Behaviour, 76(1), 201215. DOI: 10.1016/j.anbehav.2008.02.004

Barelli, C., Boesch, C., Heistermann, M., \& Reichard, U. H. (2008). Female white-handed gibbons (Hylobates lar) lead group movements and have priority of access to food resources. Behaviour, 145(7), 965-981. DOI: 10.1163/156853908784089243

Barr, D. J., Levy, R., Scheepers, C., \& Tily, H. J. (2013). Random effects structure for cofirmatory hypothesis testing: Keep it maximal. Journal of Memory and Language, 68(3), 255-278. DOI: 10.1016/j.jml.2012.11.001 
Barrett, L., \& Henzi, S. P. (2008). Baboons. Current Biology, 18(10), 404-406. DOI: 10.1016/j.cub.2008.02.074

Bates, B., Maechler, M., Bolker, B., \& Walker S. (2015). Fitting linear mixed-effects models using Ime4. Journal of Statistical Software, 67, 1-48. DOI: 10.18637/jss.v067.i01

Bazazi, S., Buhl, J., Hale, J. J., Anstey, M. L., Sword, G. A., Simpson, S. J., \& Couzin, I. D. (2008). Collective motion and cannibalism in locust migratory bands. Current Biology, 18(10), 735-739. DOI: 10.1016/j.cub.2008.04.035

Bentley-Condit, V. K., \& Smith, E. O. (1999). Female dominance and female social relationships in yellow baboons (Papio hamadryas cynocephalus). American Journal of Primatology, 47, 321-334.

Berdahl, A., Torney, C. J., Ioannou, C. C., Faria, J. J., \& Couzin, I. D. (2013). Emergent sensing of complex environments by mobile animal groups. Science, 339(6119), 574-6. DOI: 10.1126/science. 1225883

Berry, P. S. M., \& Bercovitch, F. B. (2014). Leadership of herd progressions in the Thornicroft's giraffe of Zambia. African Journal of Ecology, 53, 175-182. DOI: 10.1111/aje.12173

Bode, N. W. F., Franks, D. W., \& Wood, A. J. (2012). Leading from the front? Social networks in navigating groups. Behavioral Ecology and Sociobiology, 66(6), 835-843. DOI: 10.1007/s00265-012-1331-6

Bolker, B. M., Brooks, M. E., Clark C. J., Geange S. W., Poulsen, J. R., Stevens, M. H. H., \& White J.-S. S. (2008). Generalized Linear Mixed Models: a practical guide for ecology and evolution. Trends in Ecology and Evolution, 24, 127-135. DOI: 10.1016/j.tree.2008.10.008

Boinski, S. (1991). The coordination of spatial position: a field study of the vocal behaviour of adult female squirrel monkeys. Animal Behaviour, 41, 89-102. DOI: 10.1016/S00033472(05)80505-6

Bonnell, T. R., Clarke, P. M., Henzi, S. P., \& Barrett, L. (2017). Individual-level movement bias leads to the formation of higher-order social structure in a mobile group of baboons. Royal Society Open Science, 4(7), 170148. DOI: 10.1098/rsos.170148

Bonnell, T. R., Henzi, S. P., \& Barrett, L. (2019). Functional social structure in baboons: Modeling interactions between social and environmental structure in group-level foraging. Journal of Human Evolution, 126, 14-23. DOI: 10.1016/j.jhevol.2018.10.011

Boos, M., Kolbe, M., \& Strack, M. (2011). An Inclusive Model of Group Coordination. In Boos, M., Kolbe, M., Kappeler, P. M., \& Ellwart, T. (Eds.). Coordination in human and primate groups. Springer, Heidelberg, Germany. pp. 11-35. 
Bourjade, M., Thierry, B., Maumy, M., \& Petit, O. (2009). Decision-making in Przewalski horses (Equus ferus przewalskii) is driven by the ecological contexts of collective movements. Ethology, 115, 321-330. DOI: 10.1111/j.1439-0310.2009.01614.x

Bourjade, M., \& Sueur, C. (2010). Shared or unshared consensus for collective movement? Towards methodological concerns. Behavioural Processes, 84, 648-652. DOI: 10.1016/j.beproc.2010.02.027

Bousquet, C. A. H., Sumpter, D. J. T., Manser, M. B. (2011). Moving calls: a vocal mechanism underlying quorum decisions in cohesive groups. Proceedings of the Royal Society $B$, 278(1711), 1482-1488. DOI: 10.1098/rspb.2010.1739

Brent, L. J. N., Franks, D. W., Cant, M. A., \& Croft, D. P. (2015). Ecological knowledge, leadership, and the evolution of menopause in killer whales. Current Biology, 25(6), 746-750. DOI: 10.1016/j.cub.2015.01.037

Briard, L., Dorn, C., \& Petit, O. (2015). Personality and affinities play a key role in the organisation of collective movements in a group of domestic horses. Ethology, 121(9), 888-902. DOI: 10.1111/eth.12402

Bumann, D., Rubenstein, D., \& Krause, J. (1997). Mortality risk of spatial positions in animal groups: the danger of being in the front. Behaviour, 134(13), 1063-1076. DOI: 10.1163/156853997X00403

Busse, C. (1980). Leopard and lion predation upon chacma baboons living in the Moremi Wildlife Reserve. Botswana Notes and Records, 12, 15-21.

Busse, C., \& Hamilton, W. J. (1981). Infant carrying by male chacma baboons. Science, 212(4500), 1281-1283. DOI: 10.1126/science.212.4500.1281

Byrne, R. W., Noser, R., Bates, L. A., \& Jupp, P. E. (2009). How did they get here from there? Detecting changes of direction in terrestrial ranging. Animal Behaviour, 77(3), 619-631. DOI: 10.1016/j.anbehav.2008.11.014

Byrne, R. W., Whiten, A., \& Henzi, S. P. (1990). Social relationships of mountain baboons: Leadership and affiliation in a non-female-bonded monkey. American Journal of Primatology, 20, 313-329. DOI: 10.1002/ajp.1350180303

Cheney, D. L., \& Seyfarth, R. M. (1996). The function and mechanisms underlying baboon 'contact' barks. Animal Behaviour, 52, 507-518. DOI: org/10.1006/anbe.1996.0193

Cheney, D. L., \& Seyfarth, R. M. (2007). Baboon metaphysics. University of Chicago Press, Chicago, Illinois, U.S.A. 
Cheney, D. L., \& Seyfarth, R. M. (2018). Flexible usage and social function in primate vocalizations. Proceedings of the National Academy of Sciences, 115(9), 1974-1979. DOI: 10.1073/pnas.1717572115

Collins, D. A. (1984). Spatial pattern in a troop of yellow baboons (Papio cynocephalus) in Tanzania. Animal Behaviour, 32(2), 536-553. DOI: 10.1016/S0003-3472(84)80292-4

Conradt, L. (2011). When it pays to share decisions. Nature, 471(7336), 40-41. DOI: 10.1038/471040a

Conradt, L., \& Roper, T. J. (2003). Group decision-making in animals. Nature, 421, 155-158. DOI: $10.1038 /$ nature01294

Conradt, L., \& Roper, T. J. (2005). Consensus decision making in animals. Trends in Ecology \& Evolution, 20(8), 449-456. DOI: 10.1016/j.tree.2005.05.008

Conradt, L., \& Roper, T. J. (2009). Conflicts of interest and the evolution of decision sharing. Philosophical Transactions of the Royal Society B, 364(1518), 807-819. DOI: 10.1098/rstb.2008.0257

Cords, M. (2012). The Behavior, Ecology, and Social Evolution of Cercopithecine Monkeys. In: Mitani, J. C., Call, J., Kappeler, P. M., Palombit, R. A., \& Silk, J. B. (Eds.). The evolution of primate societies. University of Chicago Press, Chicago, Illinois, U.S.A. pp. 91-112.

Couzin, I. D., \& Krause, J. (2003). Self-organization and collective behavior in vertebrates. Advances in the Study of Behavior, 32, 1-75. DOI: 10.1016/S0065-3454(03)01001-5

Couzin, I. D., Krause, J., James, R., Ruxton, G. D., \& Franks, N. R. (2002). Collective memory and spatial sorting in animal groups. Journal of Theoretical Biology, 218(1), 1-11. DOI: 10.1006/yjtbi.3065

Cowlishaw, G. (1994). Vulnerability to predation in baboon populations. Behaviour, 131, 293304. DOI: $10.1163 / 156853994 X 00488$

Czaczkes, T. J., Czaczkes, B., \& Iglhaut, C. (2015). Composite collective decision-making. Proceedings of the Royal Society B, 282, 1-8. DOI: 10.1098/rspb.2014.2723

Czirók, A., Stanley, H. E., \& Vicsek, T. (1997). Spontaneously ordered motion of self-propelled particles. Journal of Physics A: Mathematical and General, 30(5), 1375-1385. DOI: 10.1088/0305-4470/30/5/009

Dal Pesco, F., Trede, F., Zinner, D., \& Fischer, J. (in prep.). Fitness benefits of male-male sociality in wild Guinea baboons (Papio papio). 
Danish, L. M., \& Palombit, R. A. (2014). "Following," an alternative mating strategy used by male olive baboons (Papio hamadyras anubis): quantitative behavioral and functional description. International Journal of Primatology, 35(2), 394-410. DOI: 10.1007/s10764013-9743-3

DeVore, I., \& Washburn,. S. L. (1963). Baboon ecology and human evolution. In: Bourlière, F., \& Howell, C. F. (Eds.). African Ecology and Human Evolution. Aldine, Chicago, Illinois, U.S.A. pp. 335-367.

De Waal, F. B. M., \& Tyack, P. L. (2003) Life history and brain evolution. In: De Waal, F. B. M., \& Tyack, P. L. (Eds.). Animal social complexity: intelligence, culture, and individualized societies. Harvard University Press, Cambridge, Massachusetts, U.S.A. pp. 1-4.

Di Silvestre, I., Novell, O., \& Bogliani, G. (2000). Feeding habits of the spotted hyaena in the Niokolo Koba National Park, Senegal. African Journal of Ecology, 38(2), 102-107. DOI: 10.1046/j.1365-2028.2000.00220.x

Dobson, A. J. (2002). An Introduction to Generalized Linear Models. Chapman and Hall/CRC, Boca Raton.

Dostie, M. J., Lusseau, D., Bonnell, T., Clarke, P. M. R., Chaplin, G., Kienzle, S., Barrett, L., \& Henzi, S. P. (2016). Proof of principle: the adaptive geometry of social foragers. Animal Behaviour, 119, 173-178. DOI: 10.1016/j.anbehav.2016.07.011

Dubuc, C., \& Chapais, B. (2007). Feeding competition in Macaca fascicularis: An assessment of the early arrival tactic. International Journal of Primatology, 28(2), 357-367. DOI: $10.1007 /$ s10764-007-9118-8

Dunbar, R. I. M. (1983). Structure of gelada baboon reproductive units: IV. Integration at group level. Zeitschrift für Tierpsychologie, 63(4), 265-282. DOI: 10.1111/j.14390310.1983.tb00743.x

Erhart, E. M., \& Overdorff, D. J. (1999). Female coordination of group travel in wild Propithecus and Eulemur. International Journal of Primatology, 20(6), 927-940. DOI: 10.1023/a:1020830703012

Ey, E., Hammerschmidt, K., Seyfarth, R. M., \& Fischer, J. (2007). Age- and sex-related variations in clear calls of Papio ursinus. International Journal of Primatology, 28(4), 947-960. DOI: 10.1007/s10764-007-9139-3

Ey, E., Rahn, C., Hammerschmidt, K., \& Fischer, J. (2009). Wild female olive baboons adapt their grunt vocalisations to environmental conditions. Ethology, 115, 493-503. DOI: 10.1111/j.1439-0310.2009.01638.x 
Fahrmeir, L., Kneib, T., Lang, S., \& Marx, B. (2013). Regression - Models, Methods and Applications. Springer, Heidelberg, Germany.

Farine, D. R., Strandburg-Peshkin, A., Berger-Wolf, T., Ziebart, B., Brugere, I., Li, J., \& Crofoot, M. C. (2016). Both nearest neighbours and long-term affiliates predict individual locations during collective movement in wild baboons. Scientific Reports, 6, 27704. DOI: 10.1038/srep27704

Farine, D. R., Strandburg-Peshkin, A., Couzin, I. D., Berger-Wolf, T. Y., \& Crofoot, M. C. (2017). Individual variation in local interaction rules can explain emergent patterns of spatial organization in wild baboons. Proceedings of the Royal Society B: Biological Sciences, 284(1853), 20162243. DOI: 10.1098/rspb.2016.2243

Fichtel, C., Pyritz, L., \& Kappeler, P. M. (2011). Coordination of group movements in non-human primates. In Boos, M., Kolbe, M., Kappeler, P. M., \& Ellwart, T. (Eds.). Coordination in human and primate groups. Springer, Heidelberg, Germany. pp. 37-56.

Fischer, J., Hammerschmidt, K., Cheney, D. L., \& Seyfarth, R. M. (2002). Acoustic features of male baboon loud calls: Influences of context, age, and individuality. The Journal of the Acoustical Society of America, 111(3), 1465-1474. DOI: 10.1121/1.1433807

Fischer, J., Kopp, G. H., Dal Pesco, F., Goffe, A., Hammerschmidt, K., Kalbitzer, U., Klapproth, M., Maciej, P., Ndao, I., Patzelt, A., Zinner, D. (2017). Charting the neglected West: The social system of Guinea baboons. American Journal of Physical Anthropology, 162, 15-31. DOI: 10.1002/ajpa.23144

Fischer, J., \& Zinner, D. (2011). Communication and cognition in primate group movement. International Journal of Primatology, 32(6), 1279-1295. DOI: 10.1007/s10764-011-9542-7

Fischhoff, I. R., Sundaresan, S. R., Cordingley, J., Larkin, H. M., Sellier, M. J., \& Rubenstein, D. I. (2007). Social relationships and reproductive state influence leadership roles in movements of plains zebra, Equus burchellii. Animal Behaviour, 73(5), 825-831. DOI: 10.1016/j.anbehav.2006.10.012

Forstmeier, W., \& Schielzeth, H. (2011). Cryptic multiple hypotheses testing in linear models: overestimated effect sizes and the winner's course. Behavioural Ecology and Sociobiology, 65, 47-55. DOI: 10.1007/s00265-010-1038-5

Franks, N. R., Dornhaus, A., Fitzsimmons, J. P., \& Stevens, M. (2003). Speed versus accuracy in collective decision making. Proceedings of the Royal Society B: Biological Sciences, 270(1532), 2457-2463. DOI: 10.1098/rspb.2003.2527

Garland, J., Berdahl, A. M., Sun, J., \& Bollt, E. (2018). The anatomy of leadership in collective behaviour. arXiv preprint, 1-16. arXiv:1802.01194v2 
Gerald, M. S. (2002). The finding of an inverse relationship between social dominance and feeding priority among pairs of unfamiliar adult male vervet monkeys (Cercopithecus aethiops sabaeus). Primates, 43(2), 127-132. DOI: 10.1007/BF02629672

Giardina, I. (2008). Collective behavior in animal groups: Theoretical models and empirical studies. HFSP Journal, 2(4), 205-219. DOI: 10.2976/1.2961038

Glowacki, L., \& von Rueden, C. (2015). Leadership solves collective action problems in smallscale societies. Philosophical Transactions Royal Society B, 370(20150010), 1-13. DOI: $10.1098 /$ rstb.2015.0010

Goffe, A. S., \& Fischer, J. (2016). Meat sharing between male and female Guinea baboons (Papio papio), Primate Biology, 3, 1-8. DOI: 10.5194/pb-3-1-2016

Goffe, A. S., Zinner, D., \& Fischer, J. (2016). Sex and friendship in a multilevel society: behavioural patterns and associations between female and male Guinea baboons. Behavioural Ecology and Sociobiology, 70, 323. DOI: 10.1007/s00265-015-2050-6

Gray, M., Roy, J., Vigilant, L., Fawcett, K., Basabose, A., Cranfield, M., Uwingeli, P., Mburanumwe, I., Kagoda, E., Robbins, M. M. (2013). Genetic census reveals increased but uneven growth of a critically endangered mountain gorilla population. Biological Conservation, 158, 230-238. DOI: 10.1016/j.biocon.2012.09.018

Hadfield, J. D. (2010) MCMC methods for multi-response Generalized Linear Mixed Models: the MCMCglmm $R$ Package. Journal of Statistical Software, 33, 1-22. DOI:10.18637/jss.v033.i02

Hartig, F. (2017) DHARMa: residual diagnostics for hierarchical (multi-level/mixed) regression models. R package. http://florianhartig.github.io/DHARMa

Henzi, S. P., \& Barrett, L. (2005). The historical socioecology of savanna baboons (Papio hamadryas). Journal of Zoology, 265(3), 215-226. DOI: 10.1017/S0952836904006399

Herbert-Read, J. E. (2016). Understanding how animal groups achieve coordinated movement. Journal of Experimental Biology, 219, 2971-2983. DOI: 10.1242/jeb.129411

Heymann, E. (2011). Coordination in Primate Mixed-Species Groups. In Boos, M., Kolbe, M., Kappeler, P. M., \& Ellwart, T. (Eds.). Coordination in human and primate groups. Springer, Heidelberg, Germany. pp. 263-281.

Hockings, K. J., Anderson, J. R., \& Matsuzawa, T. (2006). Road crossing in chimpanzees: A risky business. Current Biology, 16(17), 668-670. DOI: 10.1016/j.cub.2006.08.019 
Jacobs, A., Maumy, M., \& Petit, O. (2008). The influence of social organisation on leadership in brown lemurs (Eulemur fulvus fulvus) in a controlled environment. Behavioural Processes, 79(2), 111-113. DOI: org/10.1016/j.beproc.2008.05.004

Jacobs, A., Sueur, C., Deneubourg, J. L., \& Petit, O. (2011a). Social network influences decision making during collective movements in brown lemurs (Eulemur fulvus fulvus). International Journal of Primatology, 32, 721-736. DOI: 10.1007/s10764-011-9497-8

Jacobs, A., Watanabe, K., \& Petit, O. (2011b). Social structure affects initiations of group movements but not recruitment success in Japanese macaques (Macaca fuscata). International Journal of Primatology, 32(6), 1311-1324. DOI: 10.1007/s10764-011-9554-3

Janson, C. H. (1990). Ecological consequences of individual spatial choice in foraging groups of brown capuchin monkeys, Cebus apella. Animal Behaviour, 40(5), 922-934. DOI: 10.1016/S0003-3472(05)80994-7

Jolles, J. W., Boogert, N. J., Sridhar, V. H., Couzin, I. D., \& Manica, A. (2017). Consistent individual differences drive collective behavior and group functioning of schooling fish. Current Biology, 27(18), 2862-2868.e7. DOI: 10.1016/j.cub.2017.08.004

Jolly, C. J. (2013). Genus Papio. Baboons. In: Butynski, T. M., Kingdon, J., \& Kalina, J. (Eds.). Mammals of Africa (Primates, Vol.2). Bloomsbury, London, U.K. pp. 217-218.

Jolly, CJ (subm.) Philopatry at the Frontier: a demographically-driven scenario for the evolution of multi-level societies in baboons (Papio).

Joly, M., Micheletta, J., De Marco, A., Langermans, J. A., Sterck, E. H. M., \& Waller, B. M. (2017). Comparing physical and social cognitive skills in macaque species with different degrees of social tolerance. Proceedings of the Royal Society B: Biological Sciences, 284(1862), 20162738. DOI: 10.1098/rspb.2016.2738

Kalbitzer, U., Heistermann, M., Cheney, D., Seyfarth, R., \& Fischer, J. (2015). Social behavior and patterns of testosterone and glucocorticoid levels differ between male chacma and Guinea baboons. Hormones and Behavior, 75, 100-110. DOI: 10.1016/j.yhbeh.2015.08.013

Kane, M. D. (2014) Estimating population size, density, and occupancy of lions (Panthera leo), leopards ( $P$. pardus) and servals (Leptailurus serval) using camera traps in the Niokolo Koba National Park in Senegal, West Africa. MSc Thesis. Virginia Polytechnic Institute and State University, Blacksburg, Virginia, U.S.A.

Kappeler, P. M. (2019). A framework for studying social complexity. Behavioral Ecology and Sociobiology 73:13, 1-14. DOI: 10.1007/s00265-018-2601-8 
Kappeler, P. M., \& van Schaik, C. P. (2002). Evolution of primate social systems. International Journal of Primatology, 23(4), 707-740. DOI: 10.1023/A:1015520830318

Kappeler, P. M., \& van Schaik, C. P. (2006). Cooperation in primates and humans: Mechanisms and evolution. Springer, Heidelberg, Germany.

King, A. J., \& Cowlishaw, G. (2009a). Leaders, followers, and group decision-making. Communicative \& Integrative Biology, 2(2), 147-150. DOI: 10.4161/cib.7562

King, A. J., \& Cowlishaw, G. (2009b). All together now: behavioural synchrony in baboons. Animal Behaviour, 78(6), 1381-1387. DOI: 10.1016/j.anbehav.2009.09.009

King, A. J., Douglas, C. M. S., Huchard, E., Isaac, N. J. B., \& Cowlishaw, G. (2008). Dominance and affiliation mediate despotism in a social primate. Current Biology, 18(23), 1833-1838. DOI: 10.1016/j.cub.2008.10.048

King, A. J., Fehlmann, G., Biro, D., Ward, A. J., \& Fürtbauer, I. (2018). Re-wilding collective behaviour: an Ecological Perspective. Trends in Ecology \& Evolution, $x x, 1-11$. DOI: 10.1016/j.tree.2018.03.004

King, A. J., Isaac, N. J. B., \& Cowlishaw, G. (2009a). Ecological, social, and reproductive factors shape producer-scrounger dynamics in baboons. Behavioral Ecology, 20(5), 1039-1049. DOI: 10.1093/beheco/arp095

King, A. J., Johnson, D. D. P., \& Van Vugt, M. (2009b). The Origins and Evolution of Leadership. Current Biology, 19(19), R911-R916. DOI: 10.1016/j.cub.2009.07.027

King, A. J., \& Sueur, C. (2011). Where next? Group coordination and collective decision making by primates. International Journal of Primatology, 32(6), 1245-1267. DOI: 10.1007/s10764-011-9526-7

King, A. J., Sueur, C., Huchard, E., \& Cowlishaw, G. (2011). A rule-of-thumb based on social affiliation explains collective movements in desert baboons. Animal Behaviour, 82(6), 1337-1345. DOI: 10.1016/j.anbehav.2011.09.017

Klapproth M., Fischer J., Sennhenn-Reulen H., Zinner D. (in prep.). Range use, travel patterns and movement strategies of Guinea baboons (Papio papio) in the Niokolo-Koba National Park, Senegal

Krause, J. \& Ruxton, G. D. (2002). Living in groups. Oxford University Press, Oxford, U.K.

Kummer, H. (1968a). Social organization of hamadryas baboons: a field study. University of Chicago Press, Chicago, Illinois, U.S.A. 
Kummer, H. (1968b). Two variations in the social organization of baboons. In: Jay, P. C. (Eds.). Primates: studies in adaptation and variability. Holt, Rinehart \& Winston, New York, New York, U.S.A. pp. 293-312.

Kummer, H. (1995). In quest of the sacred baboon: a scientist's journey. Princeton University Press, Princeton, New Jersey, U.S.A.

Leca, J., Gunst, N., Thierry, B., \& Petit, O. (2003). Distributed leadership in semifree-ranging white-faced capuchin monkeys. Animal Behaviour, 66(6), 1045-1052. DOI: 10.1006/anbe.2003.2276

Lee, P. C. (1999). Comparative methods. In: Lee, P. C. (Eds.). Comparative Primate Socioecology. Cambridge University Press, Cambridge, U.K. pp 1-3.

Lorenz, K. (1931). Beiträge zur Ethologie sozialer Corviden. Journal für Ornithologie, 79(1), 67120. In: Tinbergen, N. (1953). Social behaviour in animals, with special reference to vertebrates. Butler and Tanner, London, U.K. pp. 54-55.

Lukas, D., \& Clutton-Brock, T. (2018). Social complexity and kinship in animal societies. Ecology Letters, 21(8), 1129-1134. DOI: 10.1111/ele.13079

Maciej, P. (2013). Vocal communication in a tolerant multi-level society: insights from signallers and receivers in Guinea baboons. Doctoral dissertation. Göttingen University, Göttingen, Germany.

Madsen, J. E., Dione, D., Traore, A., \& Sambou, B. (1996). Flora and vegetation of Niokolo-Koba National Park, Senegal. In L. van der Maesen, X. M. van der Burgt, and J. M. van Medenbach de Rooy (Eds.). The Biodiversity of African Plants: Proceedings XIVth AETFAT Congress. 22-27 August 1994, Wageningen, The Netherlands. Springer, Dordrecht, The Netherlands. pp. 214-219.

Mann, R. P. (2018). Collective decision making by rational individuals. Proceedings of the National Academy of Sciences, 115(44), E10387-E10396. DOI: 10.1073/pnas.1811964115

Mehlman, P. T. (1996). Branch shaking and related displays in wild Barbary macaques. In: Fa, J. E., \& Lindburg, D. G. (Eds.). Evolution and ecology of macaque societies. Cambridge University Press, Cambridge, U.K. pp. 503-526.

MATLAB and Statistics Toolbox Release 2018a (2018) The MathWorks, Inc., Natick, Massachusetts, U.S.A. http://www.mathworks.com/

Mbow, C., Goïta, K., \& Bénié, G. B. (2004) Spectral indices and fire behavior simulation for fire risk assessment in savanna ecosystems. Remote Sensing of Environment, 91, 1-13 DOI: 10.1016/j.rse.2003.10.019 
Mittermeier, R. A. (2013). Introduction. In: Mittermeier, R. A., Rylands, A. B., \& Wilson, D. E. (Eds.). Handbook of the mammals of the world (Primates, Vol. 3). Lynx Edicions, Barcelona, Spain. pp. 13-26.

Morrell, L. J., \& Romey, W. L. (2008). Optimal individual positions within animal groups. Behavioral Ecology, 19(4), 909-919. DOI: 10.1093/beheco/arn050

Nagy, M., Couzin, I. D., Fiedler, W., Wikelski, M., \& Flack, A. (2018). Synchronization, coordination and collective sensing during thermalling flight of freely migrating white storks. Philosophical Transactions of the Royal Society B, 373(20170011), 1-9. DOI: 10.1098/rstb.2017.0011

Ndao, I., \& Henschel, P. (2011). Rapport de l'étude sur la population des lions au Parc National Niokolo Koba. Tambacounda, Senegal: DPN

Norton, G.W. (1986). Leadership: decision processes of group movement in yellow baboons. In J. G. Else \& P. C. Lee (Eds.). Primate ecology and conservation. Cambridge University Press, Cambridge, U.K. pp. 145-156.

Noser, R., \& Byrne, R. W. (2007). Mental maps in chacma baboons (Papio ursinus): using intergroup encounters as a natural experiment. Animal Cognition, 10, 331-340. DOI: $10.1007 / \mathrm{s} 10071-006-0068-x$

Overdorff, D. J., Erhart, E. M., \& Mutschler, T. (2005). Does female dominance facilitate feeding priority in black-and-white ruffed lemurs (Varecia variegata) in southeastern Madagascar? American Journal of Primatology, 66(1), 7-22. DOI: 10.1002/ajp.20125

Pannozzo, P. L., Phillips, K. A., Haas, M. E., \& Mintz, E. M. (2007). Social monitoring reflects dominance relationships in a small captive group of brown capuchin monkeys (Cebus apella). Ethology, 113(9), 881-888. DOI: 10.1111/j.1439-0310.2007.01392.x

Patzelt, A., Kopp, G. H., Ndao, I., Kalbitzer, U., Zinner, D., \& Fischer, J. (2014). Male tolerance and male-male bonds in a multilevel primate society. Proceedings of the National Academy of Sciences, 111(41), 14740-14745. DOI: 10.1073/pnas.1405811111

Petit, O., \& Bon, R. (2010). Decision-making processes: The case of collective movements. Behavioural Processes, 84(3), 635-647. DOI: 10.1016/j.beproc.2010.04.009

Pines, M., Saunders, J., \& Swedell, L. (2011). Alternative routes to the leader male role in a multi-level society: Follower vs. solitary male strategies and outcomes in hamadryas baboons. American Journal of Primatology, 73(7), 679-691. DOI: 10.1002/ajp.20951

Pines, M., \& Swedell, L. (2011). Not without a fair fight: Failed abductions of females in wild hamadryas baboons. Primates, 52(3), 249-252. DOI: 10.1007/s10329-011-0242-x 
Pitcher, T. J., Magurran, A. E., \& Edwards, J. I. (1985). Schooling mackerel and herring choose neighbours of similar size. Marine Biology, 86, 319-322. DOI: 10.1007/BF00397518

Planas-Sitjà, I., Nicolis, S. C., Sempo, G., \& Deneubourg, J. L. (2018). The interplay between personalities and social interactions affects the cohesion of the group and the speed of aggregation. PloS ONE, 13(8), e0201053. DOI: 10.1371/journal.pone.0201053

Polo, P., \& Colmenares, F. (2012). Behavioural processes in social context: female abductions, male herding and female grooming in hamadryas baboons. Behavioural Processes, 90(2), 238-245. DOI: 10.1016/j.beproc.2012.02.004

Pyritz, L., Fichtel, C., \& Kappeler, P. (2010). Conceptual and methodological issues in the comparative study of collective group movements. Behavioural Processes, 84(3), 681684. DOI: 10.1016/j.beproc.2010.02.025

Pyritz, L. W., Kappeler, P. M., \& Fichtel, C. (2011a). Coordination of group movements in wild red-fronted lemurs (Eulemur rufifrons): Processes and influence of ecological and reproductive seasonality. International Journal of Primatology, 32, 1325-1347. DOI: 10.1007/s10764-011-9549-0

Pyritz, L. W., King, A. J., Sueur, C., \& Fichtel, C. (2011b). Reaching a consensus: Terminology and concepts used in coordination and decision-making research. International Journal of Primatology, 32(6), 1268-1278. DOI: 10.1007/s10764-011-9524-9

R Core Team (2018) R: A language and environment for statistical computing. R Foundation for Statistical Computing, Vienna, Austria. https://www.R-project.org/

Ramos, A., Manizan, L., Rodriguez, E., Kemp, Y. J. M., \& Sueur, C. (2018). How can leadership processes in European bison be used to improve the management of free-roaming herds. European Journal of Wildlife Research, 64 (18). DOI: 10.1007/s10344-018-1175-0

Ransom, T.W. (1981). Beach troop of the Gombe. Bucknell University Press, Lewisburg, Pennsylvania, U.S.A.

Rendall, D., Seyfarth, R. M., Cheney, D. L., \& Owren, M. J. (1999). The meaning and function of grunt variants in baboons. Animal Behaviour 57, 583-592. DOI: 10.1006/anbe.1998.1031

Rhine, R. J. (1975). The order of movement of yellow baboons (Papio cynocephalus). Folia Primatologica, 23, 72-104. DOI: 10.1159/000155662

Rhine, R. J., Bioland, P., \& Lodwick, L. (1985). Progressions of adult male chacma baboons (Papio ursinus) in the Moremi Wildlife Reserve. International Journal of Primatology, 6(2), 115122. DOI: $10.1007 / \mathrm{BF} 02693649$ 
Rhine, R. J., Forthman, D. L., Stillwell-Barnes, R., Westlund, B. J., \& Westlund, H. D. (1981). Movement patterns of yellow baboons (Papio cynocephalus): Sex differences in juvenile development toward adult patterns. American Journal of Physical Anthropology, 55(4), 473-484. DOI: 10.1002/ajpa.1330550408

Rhine, R. J., \& Tilson, R. (1987). Reactions to fear as a proximate factor in the sociospatial organization of baboon progressions. American Journal of Primatology, 13, 119-128. DOI: 10.1002/ajp.1350130203

Rhine, R. J., \& Westlund, B. J. (1981). Adult male positioning in baboon progressions: order and chaos revisited. Folia Primatologica, 35(2-3), 77-116. DOI: 10.1159/000155968

Ron, T., Henzi, S. P., \& Motro, U. (1996). Do Female Chacma Baboons Compete for a Safe Spatial Position in a Southern Woodland Habitat? Behaviour, 133(5-6), 475-490. DOI: $10.1163 / 156853996 \times 00549$

RStudio Team (2016) RStudio: Integrated Development for R. RStudio, Inc., Boston, MA http://www.rstudio.com/

Schreier, A. L., \& Swedell, L. (2009). The fourth level of social structure in a multi-level society: ecological and social functions of clans in hamadryas baboons. American Journal of Primatology, 71(11), 948-955. DOI: 10.1002/ajp.20736

Scott-Phillips, T. C. (2008). Defining biological communication. Journal of Evolutionary Biology, 21(2), 387-395. DOI: 10.1111/j.1420-9101.2007.01497.x

Sellers, W. I., Hill, R. A., \& Logan, B. S. (2007) An agent-based model of group decision making in baboons. Philosophical Transaction of the Royal Society B, 362, 1699-1710. DOI: 10.1098/rstb.2007.2064

Seltmann, A., Majolo, B., Schülke, O., \& Ostner, J. (2013). The organization of collective group movements in wild Barbary macaques (Macaca sylvanus): Social structure drives processes of group coordination in macaques. PloS ONE, 8(6), e67285. DOI: 10.1371/journal.pone.0067285

Seltmann, A., Franz, M., Majolo, B., Qarro, M., \& Ostner, J. (2016). Recruitment and monitoring behaviors by leaders predict following in wild Barbary macaques (Macaca sylvanus). Primate Biology, 3, 23-31. DOI: 10.5194/pb-3-23-2016

Schülke, O., \& Ostner, J. (2012). Ecological and social influences on sociality. In: Mitani, J. C., Call, J., Kappeler, P. M., Palombit, R. A., \& Silk, J. B. (Eds.). The evolution of primate societies. University of Chicago Press, Chicago, Illinois, U.S.A. pp. 195-219. 
Sigg, H., \& Stolba, A. (1981). Home range and daily march in a hamadryas baboon troop. Folia Primatologica, 36, 40-75. DOI: 10.1159/000156008

Silk, J. B. (2007). Social Components of Fitness in Primate Groups. Science, 317(5843), 13471351. DOI: 10.1126/science.1140734

Silk, J. B., Beehner, J. C., Bergman, T. J., Crockford, C., Engh, A. L., Moscovice, L. R., Wittig, R. M., Seyfarth, R. M., \& Cheney, D. L. (2009). The benefits of social capital: close social bonds among female baboons enhance offspring survival. Proceedings of the Royal Society $B$, 276, 3099-3104. DOI: 10.1098/rspb.2009.0681

Silk, J. B., Beehner, J. C., Bergman, T. J., Crockford, C., Engh, A. L., Moscovice, L. R., Wittig, R. M., Seyfarth, R. M., \& Cheney, D. L. (2010). Strong and consistent social bonds enhance the longevity of female baboons. Current Biology, 20, 1359-1361. DOI: 10.1016/j.cub.2010.05.067

Smith, A. C., Buchanan-Smith, H. M., Surridge, A. K., \& Mundy, N. I. (2003). Leaders of progressions in wild mixed-species troops of saddleback (Saguinus fuscicollis) and mustached tamarins (S. mystax), with emphasis on color vision and sex. American Journal of Primatology, 61(4), 145-157. DOI: org/10.1002/ajp.10117

Smith, J. E., Gavrilets, S., Mulder, M. B., Hooper, P. L., Mouden, C. El, Nettle, D., Hauert, C., Hill, K., Perry, S., Pusey, A. E., van Vugt, M., \& Smith, E. A. (2016). Leadership in mammalian societies: emergence, distribution, power, and payoff. Trends in Ecology \& Evolution, 31(1), 54-66. DOI: 10.1016/j.tree.2015.09.013

Stensland, E., Angerbjorn, A., \& Berggren, P. (2003). Mixed species groups in mammals. Mammal Review, 33(3-4), 205-223. DOI: 10.1046/j.1365-2907.2003.00022.x

Stewart, K. J., \& Harcourt, A. H. (1994). Gorillas' vocalizations during rest periods: signals of impending departure. Behaviour, 130, 1-2.

Strandburg-Peshkin, A., Farine, D. R., Couzin, I. D., \& Crofoot, M. C. (2015a). Shared decisionmaking drives collective movement in wild baboons. Science, 348(6241), 1358-1361. DOI: 10.1126/science.aaa5099

Strandburg-Peshkin, A., Twomey, C. R., Bode, N. W. F., Kao, A. B., Katz, Y., Ioannou, C. C., Rosenthal, S. B., Torney, C. J., Wu, H. S., Levin, S. A., \& Couzin, I. D. (2015b). Visual sensory networks and effective information transfer in animal groups. Current Biology, 23(17), R709-R711. DOI: 10.1016/j.cub.2013.07.059

Strandburg-Peshkin, A. (2016). From fish schools to primate societies: the dynamics of collective movement in animal groups. Doctoral dissertation. Princeton University, Princeton, New Jersey, U.S.A. 
Strandburg-Peshkin, A., Farine, D. R., Crofoot, M. C., \& Couzin, I. D. (2017). Habitat and social factors shape individual decisions and emergent group structure during baboon collective movement. eLife, 6. DOI: 10.7554/eLife.19505

Strandburg-Peshkin, A., Papageorgiou, D., Crofoot, M. C., \& Farine, D. R. (2018). Inferring influence and leadership in moving animal groups. Philosophical Transactions of the Royal Society B, 1-22. DOI: 10.1098/rstb.2017.0006

Strum, S. C. (2012). Darwin's monkey: Why baboons can't become human. Yearbook of Physical Anthropology, 149, 3-23. DOI: 10.1002/ajpa.22158

Stueckle, S., \& Zinner, D. (2008). To follow or not to follow: decision making and leadership during the morning departure in chacma baboons. Animal Behaviour, 75(6), 1995-2004. DOI: 10.1016/j.anbehav.2007.12.012

Sueur, C., King, A. J., Conradt, L., Kerth, G., Lusseau, D., Mettke-Hofmann, C., Schaffner, C. M., Williams, L., Zinner, D., \& Aureli, F. (2011). Collective decision-making and fission-fusion dynamics: a conceptual framework. Oikos, 120(11), 1608-1617. DOI: 10.1111/j.16000706.2011.19685.x

Sueur, C., Kuntz, C., Debergue, E., Keller, B., Robic, F., Siegwalt-Baudin, F., Richer, C., Ramos, A., \& Pelé, M. (2017). Leadership linked to group composition in Highland cattle (Bos taurus): Implications for livestock management. Applied Animal Behaviour Science, 198(suppl. C), 9-18. DOI: 10.1016/j.applanim.2017.09.014

Sueur, C., \& Petit, O. (2008a). Shared or unshared consensus decision in macaques? Behavioural Processes, 78(1), 84-92. DOI: 10.1016/j.beproc.2008.01.004

Sueur, C., \& Petit, O. (2008b). Organization of group members at departure is driven by social structure in Macaca. International Journal of Primatology, 29(4), 1085-1098. DOI: 10.1007/s10764-008-9262-9

Sueur, C., Petit, O., \& Deneubourg, J. L. (2009). Selective mimetism at departure in collective movements of Macaca tonkeana: an experimental and theoretical approach. Animal Behaviour, 78, 1087-1095. DOI: 10.1016/j.anbehav.2009.07.029

Sumpter, D. J. T., Krause, J., James, R., Couzin, I. D., \& Ward, A. J. W. (2008). Consensus decision making by fish. Current Biology, 18(22), 1773-1777. DOI: 10.1016/j.cub.2008.09.064

Swedell, L. (2011). African Papionins: diversity of social organization and ecological flexibility. In: Campbell, J. C., Fuentes, A., MacKinnon, K. C., Panger, M., \& Bearder, S. K. (Eds). Primates in perspective. Oxford University Press, Oxford, U.K. pp. 241-277. 
Swedell, L., Saunders, J., Pines, M., Schreier, A., \& Davis, B. (2008). Alternative reproductive strategies in male hamadryas baboons: leaders, followers, and solitary males. American Journal of Physical Anthropology, 46, 203.

Swedell, L., \& Schreier, A. (2009). Male aggression towards females in hamadryas baboons: conditioning, coercion, and control. In: Muller, M. N., \& Wrangham, R. W. (Eds.). Sexual coercion in primates and humans: an evolutionary perspective on male aggression against females. Harvard University Press, Cambridge, Massachusetts, U.S.A. pp. 244-268.

Teichroeb, J. A., White, M. M. J., \& Chapman, C. A. (2015). Vervet (Chlorocebus pygerythrus) Intragroup spatial positioning: dominants trade-off predation risk for increased food acquisition. International Journal of Primatology, 36(1), 154-176. DOI: 10.1007/s10764015-9818-4

Thierry, B. (2007). Unity in diversity: Lessons from macaque societies. Evolutionary Anthropology, 16(6), 224-238. DOI: 10.1002/evan.20147

Tofts, C., \& Franks, N. R. (1992). Doing the right thing: ants, honeybees and naked mole-rats. Trends in Ecology and Evolution, 7(10), pp. 346-349. DOI: 10.1016/0169-5347(92)90128-X

Tokuyama, N., \& Furuichi, T. (2017). Leadership of old females in collective departures in wild bonobos (Pan paniscus) at Wamba. Behavioral Ecology and Sociobiology, 71(3). DOI: 10.1007/s00265-017-2277-5

Toulet, S., Gautrais, J., Bon, R., \& Peruani, F. (2015). Imitation combined with a characteristic stimulus duration results in robust collective decision-making. PloS ONE, 10(10), e0140188. DOI: 10.1371/journal.pone.0140188

Trillmich, J., Kappeler, P., \& Fichtel, C. (2004). Coordination of group movements in wild verreaux's sifakas (Propithecus verreauxi). Behaviour, 141(9), 1103-1120. DOI: $10.1163 / 1568539042664579$

Tinbergen, N. (1953). Social behaviour in animals, with special reference to vertebrates. Butler and Tanner, London, U.K. pp. 1-150.

van Belle, S., Estrada, A., \& Garber, P. A. (2013). Collective group movement and leadership in wild black howler monkeys (Alouatta pigra), 67, 31-41. DOI: 10.1007/s00265-012-1421-5

van Roosmalen, M. G. M. (1985). Habitat preferences, diet, feeding strategy and social organisation of the black spider monkey (Ateles panisius paniscus L.) in Surinam. Acta Amazonica, 15, 1-238. DOI: 10.1590/1809-43921985155238 
van Schaik, C. P., \& Kappeler, P. M. (2006). Cooperation in primates and humans: closing the gap. In: Kappeler, P. M., \& van Schaik, C. P. (Eds.). Cooperation in primates and humans: Mechanisms and evolution. Springer, Heidelberg, Germany. pp. 3-21.

van Schaik, C. P., \& van Hooff, J. a. R. a. M. (1983). On the ultimate causes of primate social systems. Behaviour, 85(1/2), 91-117. DOI: 10.1163/156853983X00057

Walker, R. H., King, A. J., Mcnutt, J. W., Jordan, N. R., \& Walker, R. H. (2017). Sneeze to leave: African wild dogs (Lycaon pictus) use variable quorum thresholds facilitated by sneezes in collective decisions. Proceedings of the Royal Society B, 284: 20170347. DOI: 10.1098/rspb.2017.0347

Walz, J. T. (2016). Competition, coercion, and choice: The sex lives of female olive baboons (Papio anubis). Doctoral dissertation. The Ohio State University, Columbus, Ohio, U.S.A.

Wang, X. I., Sun, L., Sheeran, L. K., Sun, B., Zhang, Q., \& Zhang, D. A. O. (2016). Social rank versus affiliation: which is more closely related to leadership of group movements in Tibetan macaques (Macaca thibetana)? American Journal of Primatology, 1-9. DOI: 10.1002/ajp.22546

Waser, P. M. (1985). Spatial structure in mangabey groups. International Journal of Primatology, 6(6), 569-580. DOI: 10.1007/BF02692289

Watts, D. (2000). Mountain gorilla habitat use strategies and group movements. In: Boinski, S., \& Garber, P. A. (Eds.). On the move: How and why animals travel in groups. University of Chicago Press, Chicago, Illinois, U.S.A. pp. 351-374.

Weyher, A. H., Phillips-Conroy, J. E., Fourrier, M. S., \& Jolly, C. J. (2014). Male-driven grooming bouts in mixed-sex dyads of Kinda baboons (Papio kindae). Folia Primatologica, 85(3), 178-191. DOI: 10.1159/000362544

Wright, P. C. (1990). Patterns of Paternal Care in Primates. International Journal of Primatology, 11(2), 89-102. DOI: 10.1007/BF02192783

Zinner, D., Fickenscher, G., \& Roos, C. (2013a). Family Cercopithecidae (Old World Monkeys). In: Mittermeier, R. A., Rylands, A. B., \& Wilson, D. E. (Eds). Handbook of the mammals of the world (Primates, Vol. 3). Lynx Edicions, Barcelona, Spain. pp. 550-627.

Zinner, D., Wertheimer, J., Liedigk, R., Groeneveld, L. F., \& Roos, C. (2013b). Baboon phylogeny as inferred from complete mitochondrial genomes. American Journal of Physical Anthropology, 150(1), 133-140. DOI: 10.1002/ajpa.22185 


\section{Acknowledgements}

This project and this whole experience would not have been possible without the initiative, guidance and support of Julia Fischer and Dietmar Zinner. I am sincerely grateful that I have been given the chance of developing this work. I would like to thank Julia for guiding my work with constructive critics and discussions and for being so considerate not only about scientific progress but also about emotional well-being. I thank Dietmar for his office door always open, for all his answers, for his friendly and constructive spirit and for building a collaborative environment outside working hours. He gave me infinite chances of learning interesting things, especially about birds. I am also grateful to Julia Ostner and Stefan Schulz-Hardt for their support and comments during the committee meetings. I would like to thank Julien Humbackers

and Roger Mundry for their crucial statistical consulting. Many thanks go to Rebecca, for her availability and help in all bureaucratic procedures that I had to face during this project; to Mechthild, because of her help and her smile, which really makes the working days lighter; and to Ludwig, for his engagement in supporting the project and resolving functional issues. In general, I am very grateful to all the people of the Cognitive Ethology Lab that hosted me for the duration of this project.

I would like to express my appreciation to the Diréction des Parcs Nationaux and the Ministère de l'Environnement et de la Protéction de la Nature de la République du Sénégal that allowed my fieldwork in the Parc Nationale de Niokolo Koba. I also extend my gratitude to the Senegalese agents and cooks that collaborated with the CRP Simenti, especially, Nyafouna, Danshoko, Sonko and Biaye, for all the days spent together surrounded by baboons. The months spent in Senegal are full of nice moments. Some of them are absolutely unforgettable memories. I am very grateful to Lauriane, Harry, Franziska, Josie, Muriel and Antonin for sharing with me that time and building an atmosphere that I will always remember with a smile.

I deeply thank all the friends that I have made in Göttingen: Alessio, Domingo, Filipa, Ivan, Marta, Amelie, Natalia, Dima, Barbara, Alexandra, Sarah, Steffi, Philip, Pascal and many others. Someone more than others but truly everyone helped me throughout a path that sometimes was fun and exciting but sometimes just needed a word of comfort or a beer together. These people always addressed such needs and never let me feeling lonely. Most 
importantly, they often conceived some great time together when not necessarily needed. I will always treasure the time we spent together.

As baboons can benefit of their long-term bonds to succeed, so did I, profoundly. Countless thanks go to Giulio, Antonio, Alessia, Sara, Valerio, Matteo and all the other friends in Mantova and outside. They have always believed in me, reassured me, boosted my confidence and created fun moments, making me feeling special with their perseverance in our relationships. My immense gratitude goes to my family for their total and unconditional love and support. They managed to make me feel safe and protected even though following my dreams meant spending years in separate nations and remote areas. If I threw myself into the adventures that made me the person that I am today, it was mainly because I always had and always will have a home waiting to take care of me, whenever I feel the need, and because I knew that a phone call would have brought them where I was, whenever needed. That safety feeling has always been the tool to face my obstacles. On the whole, I find hard to use few words to explain why my family and friends are so essential in my life. I have shared so much life with them and our relationships are so rooted in time that their sticking by my side is what makes me proud of myself. If I achieved something in my life, it is thanks to them.

The most special thanks go to Sonia, who crossed the path of this research project and turned it in an absolute life-changing experience. She enriched a very challenging interval of my existence with many of the most intense moments of my life. More or less physically, she also managed to stay by my side to feed my self-esteem, to restore my calm, to joke... up to rising as crucial in many phases of this doctorate. However, again, what she has been for me goes well beyond what I can express with words.

This work was generously supported by Research Training Group 2070, founded by the German Science Foundation DFG. Several learning opportunities have been also financed by the Leibniz ScienceCampus "Primate Cognition", founded by Leibniz Association. 


\section{Curriculum vitae}

\section{Personal information}

Name

Date of birth

Nationality

Languages

E-mail
Davide Montanari

$21^{\text {th }}$ April, 1987

Italian

Italian (mother tongue), English (fluent), Spanish (fluent), French (basic) dmontanari.mn@gmail.com

\section{Education}

Present - Ph.D. student in the Behavior and Cognition programme University of Göttingen (Germany)

Research: Group coordination during collective movements in Guinea baboons (Papio papio).

Aug, 2014 - M.Sc. in Environmental Biology - track Behavioural Ecology (level 7 - ISCED 2011). University of Utrecht (The Netherlands)

Research: Ranging patterns of Seringbara chimpanzees: methodological insights.

Extra enrichment and its effects on a (potential) judgement bias test for mice.

Clearing the ways of space use.

Sep, 2010 - B.Sc. in Ecological Biology (level 6 - ISCED 2011).

University of Parma (Italy)

Research: Brain lateralization in aggressive behaviours of the common lizard Podarcis muralis.

Test of monitoring systems for the populations of four endangered species of saproxylic insects (Lucanus cervus, Morimus asper, Osmoderma eremita and Cerambyx cerdo).

\section{Research experiences}

Mar, 2015 / Aug, 2015 - Inkawu Vervet Research Project, Kwazulu-Natal, South Africa Supervisor: Dr. Erica van de Waal

Oct, 2012 / Jul, 2013 - Kyoto University Primate Research Institute, Bossou, Guinea Supervisors: Dr. Kathelijne Koops, Prof. Dr. Liesbeth Sterck

Feb, 2012 / Aug, 2012 - Faculty of Veterinary Science, Uni. of Utrecht, Utrecht, The Netherlands Supervisors: Dr. Saskia S. Arndts, Prof. Berry M. Spruijt

Jul, 2010 / Aug, 2010 - Bosco Fontana Natural Reserve, Mantua, Italy

Supervisor: Dr. Alessandro Campanaro,

Apr, 2009 / Apr, 2010 - Museum of Natural History, Parma, Italy

Supervisor: Prof. Davide Csermely 
